Modelagem matemática-computacional da conectividade cerebral em ressonância magnética funcional para o estudo do estado de repouso

\author{
Gilson Vieira \\ DisSERTAÇÃo APRESENTADA \\ $\mathrm{AO}$ \\ Programa Interunidades em Bioinformática \\ DA \\ Universidade De SÃo Paulo \\ PARA \\ OBTENÇÃO DO TÍTULO \\ $\mathrm{DE}$ \\ Mestre EM CiÊnCIAS \\ Área de Concentração: Bioinformática \\ Orientador: Prof. Dr. Luiz Antonio Baccalá
}

Durante o desenvolvimento deste trabalho o autor recebeu auxílio financeiro da CAPES

São Paulo, abril de 2011 


\title{
Modelagem matemática-computacional da conectividade cerebral em ressonância magnética funcional para o estudo do estado de repouso
}

\author{
Este exemplar corresponde à redação \\ final da dissertação devidamente corrigida \\ e defendida por Gilson Vieira \\ e aprovada pela Comissão Julgadora.
}

Banca Examinadora:

- Prof. Dr. Edson Amaro Júnior - FM-USP.

- Prof. Dr. Luciano - IFSC-USP.

- Prof. Dr. João Sato - UFABC. 


\section{Agradecimentos}

Gostaria de agradecer à todos que diretamente ou indiretamente me ajudaram nesta jornada.

À Lucilene, por todo carinho que me deu nos útimos cinco anos, por compreender e respeitar meus estudos mesmo sendo necessário sacrificar muitos finais de semana.

À minha família, principalmente minha irmã Marília que se orgulha de ter um irmão cientista.

Aos meus amigos de São Paulo e Varginha e aqueles que estão espalhados pelo mundo.

Gostaria de agredecer, em especial, três pessoas que me deram conselhos para o resto da vida e me orientaram nos momentos de desespero.

O meu orientador Prof. Dr. Luiz Antonio Baccalá, exemplo de educador, por sempre me acolher em sua sala para discutir sobre o trabalho, por ser paciente e confiar em minha pesquisa.

O Prof. Dr. João Sato, pesquisador prático e objetivo, por me passar artigos interessantes e por ajudar a construir o método, apoiando e contrapondo minhas idéias.

O Prof. Dr. Edson Amaro, por me motivar a desenvolver ferramentas úteis para a ciência e por passar boas perpectivas sobre a neurociência do Brasil.

Ao Programa Interunidades de Pós-Graduação em Bioinformática da Universidade de São Paulo, por oferecer a estrutura necessária para o desenvolvimento da dissertação.

À CAPES, por ter fomentado minha pesquisa. 


\section{Resumo}

Esta dissertação desenvolve e aplica métodos para caracterizar regiões cerebrais durante o estado de repouso. Utilizam-se grafos para representar a inter-dependência temporal de sinais de ressonância magnética funcional provenientes de regiões cerebrais distintas. Vértices representam regiões cerebrais e arestas representam a conectividade funcional. Buscando superar os problemas de visualização e interpretação desta forma de representação, elaboram-se métodos quantitativos para caracterizar padrões de conectividade entre regiões cerebrais. Para cada sujeito analisado: 1) Faz-se a redução da dimensionalidade espacial das imagens de ressonância magnética funcional respeitando os limites anatômicos das regiões cerebrais. 2) Estima-se a rede de conectividade funcional pela coerência direcionada entre pares de regiões distintas. 3) Constrói-se um grafo direcionado e pesado pela medida de conectividade. 4) Quantificam-se os vértices por índices e faz-se o registro destes valores no espaço comum MNI. 5) Avalia-se a consistência de cada índice pelo teste não paramétrico de Friedman seguido de análises de múltiplas comparações. A análise de 198 imagens de sujeitos sadios produziu resultados consistentes e biologicamente plausíveis. Em sua maioria, revelou regiões associadas a conceitos anatômicos de conectividade e integração cerebral. Embora de implementação simples, o método proporciona informações de natureza dinâmica sobre as relações entre diferentes regiões cerebrais e pode ser utilizado futuramente para estudar e entender desordens psiquiátricas/neurológicas.

Palavras-chave: Conectividade Funcional, Ressonância Magnética Funcional, Grafos, Estado de Repouso. 


\section{Abstract}

This dissertation develops and applies methods to characterize brain regions during resting state. Graphs are used to represent functional MRI connectivity from different brain regions. Vertices represent brain regions and edges represent connectivity. To overcome the visualization and interpretation problems of this form of representation, we developed quantitative methods to characterize its patterns. Methods: For each subject: 1) The reduction of spatial dimensionality of functional magnetic resonance imaging is carried out taking into account the anatomic limits of the brain regions. 2) The network is estimated by directed coherence between pairs of separate regions. 3) A directed graph with weights on its edges is constructed using the later connectivity measure. 4) The vertices are quantified by indexes that are registered in the MNI common space. 5) The consistency of each index is evaluated by the nonparametric Friedman followed by Post-Hoc analysis. Results: The analysis of 198 images of healthy subjects produced consistent and biologically plausible results. They revealed anatomical regions involved in brain integration. Conclusion: The method provides information about the dynamic nature of the relationships between different brain regions and can be used in future clinical studies to understand psychiatric and neurological disorders.

Keywords: Brain Connectivity, Functional Magnetic Resonance Image, Graphs, Resting State. 


\section{Sumário}

Lista de Abreviaturas

Lista de Símbolos $\quad$ xiii

Lista de Figuras $\quad$ Xv

Lista de Tabelas $\quad$ xix

1 Introdução $\quad 1$

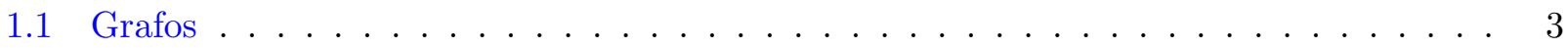

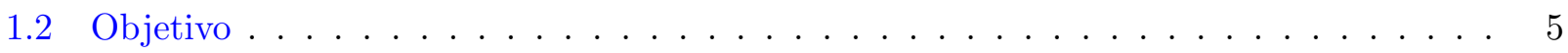

2 Princípios de Teoria dos Grafos $\quad 9$

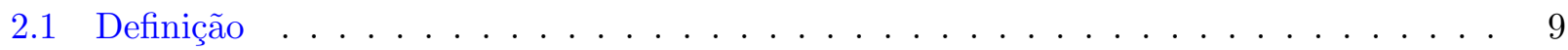

2.2 Índices para conectividade . . . . . . . . . . . . . . . . . . . . 11

2.2 .1 Índices de centralidade . . . . . . . . . . . . . . . . . . 11

2.2.2 Índices não baseados em centralidade . . . . . . . . . . . . . . . . . . . . 14

3 Material e métodos $\quad 19$

3.1 Sujeitos e parâmetros de aquisição ～. . . . . . . . . . . . . . . . . . . . 19

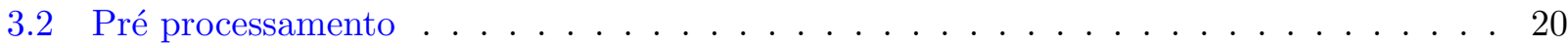

vii 
3.3 Segmentação anatômica . . . . . . . . . . . . . . . . . . 20

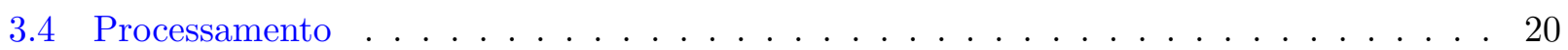

3.4 .1 Redução da dimensionalidade . . . . . . . . . . . . . . . . . . 20

3.4.2 Análise da conectividade (coerência direcionada e parâmetros topológicos) . . . 21

3.5 Consistência - Estatística . . . . . . . . . . . . . . . . . 21

4 Resultados $\quad 23$

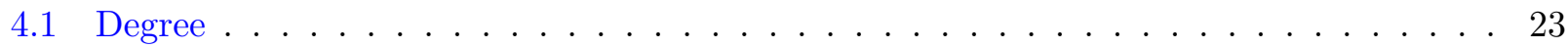

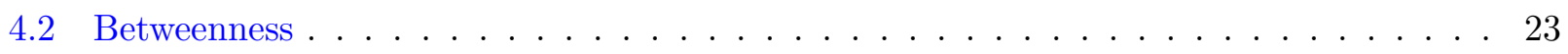

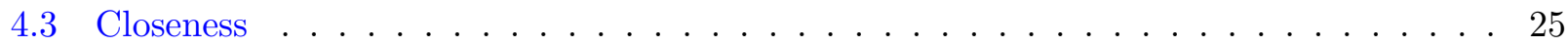

4.4 Hub e Authority . . . . . . . . . . . . . . . . . . 25

5 Discussão $\quad 29$

5.1 Introdução . . . . . . . . . . . . . . . . . . . . . . . 29

5.1 Sobre a segmentação cerebral . . . . . . . . . . . . . . . . . . . 29

5.1 .2 Sobre a medida de conectividade . . . . . . . . . . . . . . 30

5.1 .3 Sobre a construção das redes . . . . . . . . . . . . . . . 30

5.1 .4 Sobre os índices . . . . . . . . . . . . . . . . . . . . . 31

5.2 Redes do estado de repouso . . . . . . . . . . . . . . . . . 34

5.3 Programa e custo computacionais . . . . . . . . . . . . . . . . 34

6 Conclusão $\quad 35$

$\begin{array}{ll}\text { A Ressonância Magnética Funcional } & 37\end{array}$

A.1 Bases físicas da RMf . . . . . . . . . . . . . . . . 37

A.1.1 Os estados energéticos e excitação . . . . . . . . . . . . . . 37 
A.1.2 O vetor de magnetização total . . . . . . . . . . . . . . . 40

A.1.3 As equações de Bloch . . . . . . . . . . . . . . . . . . . . . 42

A.2 Recepção do Sinal . . . . . . . . . . . . . . . . . . . . . . . . 43

A.3 Bases biológicas da RMf . . . . . . . . . . . . . . . . . . . . . . 44

A.3.1 A resposta hemodinâmica do efeito BOLD . . . . . . . . . . . . . . . 47

A.4 Processamento de imagens em RM . . . . . . . . . . . . . . . . . 47

A.4.1 Correção de movimento . . . . . . . . . . . . . . . . . . . . 47

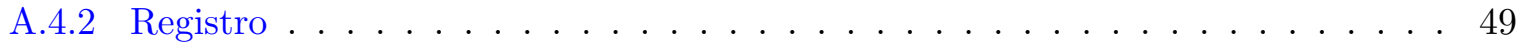

A.5 Estado de repouso e RMf . . . . . . . . . . . . . . . . . . . . . . . 49

A.6 Divisões anatômicas do Sistema Nervoso Central . . . . . . . . . . . . . . . . . . 50

A.7 Segmentação cerebral . . . . . . . . . . . . . . . . . . 53

B Conectividade Funcional Cerebral $\quad 55$

B.1 Introdução . . . . . . . . . . . . . . . . . . . . . . . . . . 55

B.2 Algumas medidas de conectividade . . . . . . . . . . . . . . . 56

B.2.1 Correlação e correlação parcial . . . . . . . . . . . . . . . . 56

B.2.2 Função de auto-correlação e função de auto-correlação parcial . . . . . . . . . . . 56

B.2.3 Coerência, coerência parcial e coerência parcial direcionada . . . . . . . . . 56

B.2.4 Informação mútua e informação mútua parcial . . . . . . . . . . . . . . . . 57

B.2.5 Análise de componentes principais . . . . . . . . . . . . . . 57

B.2.6 Modelo de equações estruturadas . . . . . . . . . . . . . . . . . 57

B.2.7 Dynamic Causal Models . . . . . . . . . . . . . . . . . . . . 58

B.3 O cérebro como o um sistema dinâmico . . . . . . . . . . . . . 58

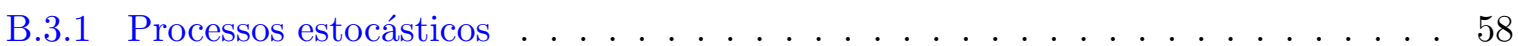

B.3.2 Processos estocásticos estacionários . . . . . . . . . . . . . . . . . 60 
B.3.3 O estimador de mínimos quadrados . . . . . . . . . . . . . . 62

B.3.4 Causalidade de Granger . . . . . . . . . . . . . . . . . . . . . 63

B.3.5 Coerência parcial direcionada . . . . . . . . . . . . . . . . 64

$\begin{array}{ll}\text { Referências Bibliográficas } & 67\end{array}$

$\begin{array}{ll}\text { Índice Remissivo } & 74\end{array}$ 


\title{
Lista de Abreviaturas
}

\author{
ATP Trifosfato de Adenosina (adenosine triphophate). \\ BOLD Blood Oxigenation Level Dependence. \\ CBV Volume Sanguíneo Cerebral (Cerebral Blood Volume). \\ CBF Fluxo Sanguíneo Cerebral (Cerebral Blood Flow). \\ CD Coerência Direcionada \\ $\mathrm{CMRO}_{2}$ Taxa Metabólica Cerebral de Oxigênio (Cerebral Metabolic Rate of Oxygen). \\ CN Core Network \\ DMN Default Mode Network \\ EEG Eletroencefalograma. \\ FAIR flow-sensitive alternating inversion recovery \\ FID Free Induction Decay. \\ HRF Função de Resposta Hemodinâmica (Hemodynamic Reponse Function) \\ MNI Montreal Neurological Institute \\ MEG Magnetoencefalograma. \\ $\operatorname{MAR}(p) \quad$ Modelo Autoregressivo Multivariado de ordem $p$ \\ PET Tomografia por Emissão de Pósitros (Positron Emission Tomography) \\ RM Ressonância Magnética. \\ RMN Ressonância Magnética Nuclear. \\ RMf Ressonância Magnética funcional. \\ RSN Rede do Estado de Repouso (Resting State Network). \\ SNC Sistema Nervoso Central \\ TR Tempo de Repetição
}




\section{Lista de Símbolos}

$\tilde{\mathbf{Y}}_{z} \quad$ Transformada de $\mathrm{Z}$ de $\mathbf{Y}_{t}$.

$\widehat{\mathbf{B}} \stackrel{p}{\rightarrow} \mathbf{B} \quad \widehat{\mathbf{B}}$ converge em probabilidade para $\mathbf{B}$ 


\section{Lista de Figuras}

1.1 Áreas estatisticamente ativas durante uma tarefa de decisão semântica com sujeitos

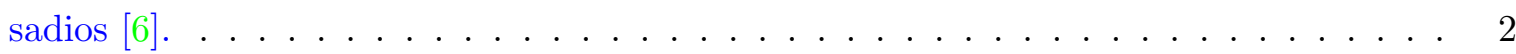

1.2 Um exemplo do uso da teoria dos grafos na caracterização das redes de conectividade cerebral em sujeitos com epilepsia do lobo temporal pode ser encontrado em [8]. Neste artigo, a conectividade cerebral foi estimada pela coerência parcial direcionada dos canais de EEG durante crises epiléticas. O grafo do lado esquerdo representa toda a rede de conectividade de um sujeito em particular. O grafo do lado direito é um subconjunto fortemente conexo do grafo ao lado. O mesmo artigo mostrou que subconjuntos fortemente conexos estão associados aos vértices de regiões determinadas pela análise clínica como focos epileptogênicos. . . . . . . . . . . . . . . . . 4

1.3 O pré-processamento corrige o movimento natural da cabeça durante o experimento, diminui o ruído de baixa freqüência causado pela variação do campo magnético e estima a matriz de registro do espaço funcional para o espaço comum MNI para cada sujeito analisado. Os sinais são normalizados de forma que cada série temporal tenha média zero e variância um. A dimensão da imagem de RMf é reduzida na andrazão de 1:3 em cada dimensão espacial. Interpolam-se os valores pela média respeitando as características anatômicas das regiões cerebrais. Constroem-se grafos direcionados e pesados a partir da conectividade funcional estimada pela coerência direcionada entre pares de regiões distintas. Quantificam-se seus vértices por índices e faz-se o registro dos valores no espaço comum MNI. Avalia-se a consistência de cada índice pelo teste não paramétrico de Friedman seguido de análises de múltiplas comparações. . . . . . 
2.1 Grafo exemplo utilizado neste capítulo para estudar parâmetros topológicos de redes de conectividade. As arestas possuem coloração em escala de cinza proporcional ao seu peso. O fim da aresta é representado por um retângulo azul e indica a direção da aresta. . . . . . . . . . . . . . . . . . . . . . 10

2.2 Grafo exemplo com vértices coloridos com base no seu índice Degree. Os valores estão em escala de cinza. . . . . . . . . . . . . . . . . . . . . . . . 12

2.3 Grafo exemplo com vértices coloridos com base no seu índice Closeness. Os valores estão em escala de cinza. . . . . . . . . . . . . . . . . . . . . . . . . . 13

2.4 Grafo exemplo com vértices coloridos com base no seu índice Betweenness. Os valores estão em escala de cinza. . . . . . . . . . . . . . . . . . . . . . . 15

2.5 Grafo exemplo com vértices coloridos com base no seu índice Authority. Os valores estão em escala de cinza. . . . . . . . . . . . . . . . . . . . . . . 17

2.6 Grafo exemplo com vértices coloridos com base no seu índice Hub. Os valores estão em escala de cinza. . . . . . . . . . . . . . . . . . . . . . 18

4.1 Vista axial dos mapas estatísticos. De cima para baixo tem-se os índices Degree, Betweenness, Closeness, Hub e Authority. As regiões destacadas são os voxels cujo posto é estatisticamente maior que o valor esperado sobre a hipótese nula (p-valor $<0,01$, com correção de bonferroni) . . . . . . . . . . . . 25

4.2 Visão lateral em três dimensões dos mapas estatísticos. Da esquerda para a direita tem-se os índices Degree, Betweenness, Closeness, Hub e Authority. . . . . . . . . . . 26

4.3 Visão posterior em três dimensões dos mapas estatísticos. Da esquerda para a direita tem-se os índices Degree, Betweenness, Closeness, Hub e Authority. . . . . . . . . . . 26

A.1 Representação esquemática da cascata de eventos responsáveis pela geração do sinal

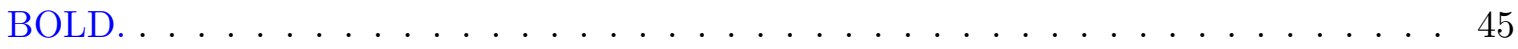

A.2 O neurônio e suas sub componentes. Imagem removida de http://pt.wikipedia.org/wiki/Neurório 46 A.3 Resposta hemodinâmica canônica gerada a partir da soma de duas funções gammas. . 48 
A.4 O cérebro pode ser divido quanto aos padrões de sulcos e giros exibidos pela maioria

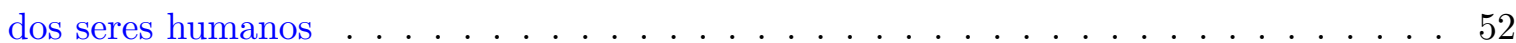




\section{Lista de Tabelas}

4.1 Estruturas cerebrais que contém voxels cujo posto é estatisticamente maior que o valor esperado sobre a hipótese nula para um dado índice. As estruturas foram nomeadas com base no atlas de estruturas corticais e subcorticais Harvard-Oxford (p-valor < 0,01 , com correção de bonferroni) . . . . . . . . . . . . . . . . 24

5.1 Tipo funcional, nome, área de Brodman das principais regiões corticais identificadas pela análise da rede de conectividade. . . . . . . . . . . . . . . . . 32

A.1 Constantes encontradas em núcleos com propriedades de ressonância magnética . . . . 38 


\section{Capítulo 1}

\section{Introdução}

Hoje em dia sabe-se que o córtex cerebral é responsável pela capacidade humana de compreensão da realidade e que algumas funções cognitivas estão associadas às regiões corticais necessárias para sua execução. Estudos de sujeitos que sofreram lesão traumática no córtex mostram que a ausência ou o comprometimento de determinadas regiões corticais causa perda cognitiva [56]. Por exemplo, lesões no giro temporal superior esquerdo podem provocar a afasia de Wernicke, distúrbio caracterizado por grandes perturbações na compreensão e expressão da linguagem [31]. Por outro lado, o cérebro é uma máquina de processamento paralelo e muitas funções cognitivas estão distribuídas entre diferentes regiões corticais. Embora a cor e a forma de uma figura sejam codificadas por diferentes conjuntos de neurônios do sistema visual [72], o cérebro percebe um quadrado vermelho como um único objeto e não como duas características separadas (forma e cor).

Nos últimos anos, muito esforço de pesquisa tem sido empregado para entender o funcionamento cerebral. O cérebro é constituído de pequenas unidades celulares interconectadas [59], em sua maioria os neurônios e as células da glia. Geralmente, as células neurais formam estruturas especializadas no processamento de uma determinada função [10]. Os agrupamentos formam sistemas que vão desde o simples arco-reflexo [39] até múltiplas regiões corticais envolvidas simultaneamente no processamento da linguagem (Figura 1.1). Mesmo modulares, os sistemas não são independentes e suas interconexões podem atingir distâncias de grande escala anatômica [42,69]. O objetivo do estudo da conectividade cerebral é descrever os mecanismos de comunicação entre diferentes regiões cerebrais.

Conectividade possui vários significados em neurociência e os conceitos de conectividade anatômica e funcional são fundamentais para seu entendimento. A conectividade anatômica é o conjunto de ligações sinápticas e processos biofísicos de transmissão de sinal (axônios, neurotransmissores e etc.) 


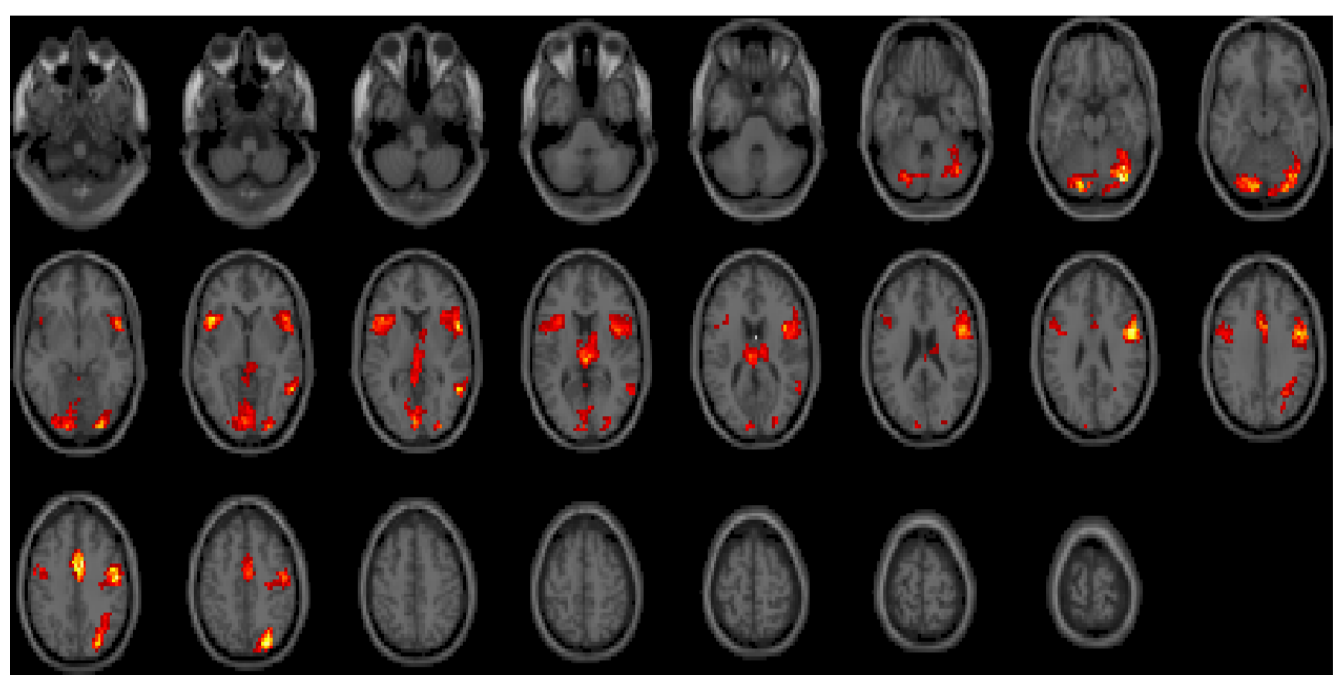

Figura 1.1: Áreas estatisticamente ativas durante uma tarefa de decisão semântica com sujeitos sadios [6].

presentes na estrutura cerebral. A conectividade funcional mede características dinâmicas/estocásticas (correlação, coerência, causalidade) entre sinais de diferentes regiões durante o processamento da informação cerebral.

Existem dois princípios que regem a lógica do estudo da conectividade cerebral: os conceitos de (a) segregação (especialização) e (b) integração. A segregação fundamenta que funções cerebrais podem ser mapeadas em regiões específicas que respondem à estímulos da mesma natureza [69]. Entretanto, para produzir os mais diversos estados cerebrais é necessário uma integração funcional de diferentes regiões, ou seja, uma ativação coordenada de diversos grupos neuronais dentro encéfalo humano. De acordo com Bullmore e Sporns [18]:

A atividade simultânea de diversos módulos corticais, juntamente com um padrão bem definido de comunicação, é a principal base neurofisiológica do processamento da informação e representação mental nos seres humanos.

Por questões éticas e a menos de casos patológicos, o estudo da conectividade funcional com humanos exige técnicas não invasivas de monitoramenteo da atividade cerebral como o eletroencefalograma (EEG) e a ressonância magnética funcional (RMf). A atividade cerebral produz sinais neurofisiológicos que podem ser monitorados e modelados estatisticamente. O EEG mede variações do potencial elétrico próximo à superfície cortical que representam diretamente a atividade neu- 
ronal [62]. A RMf mede variações do nível de oxigenação sanguínea nas proximidades das células neuronais que representam indiretamente a atividade neuronal [51].

O estudo da conectividade cerebral pela técnica de RMf é um tema novo e bastante discutido na neurociência. Além de representar uma medida indireta da atividade neuronal, os sinal de RMf possui outras limitações básicas. 1) Baixa resolução temporal: A taxa de amostragem na RMf varia entre 0,3 e $2 \mathrm{~Hz}$ enquanto que processos neuronais possuem características na ordem de milissegundos. 2) Alta dimensionalidade: As imagens de RMf possuem três dimensões espaciais e uma dimensão temporal. Cada volume amostrado é formado por matrizes quadradas paralelamente alinhadas da base ao topo da cabeça. Para cobrir todo o encéfalo com resolução espacial de $3 \times 3 \times 3 \mathrm{~mm}^{3}$ são necessárias 47 matrizes de $72 \times 72$ pontos, totalizando aproximadamente 240 mil cubos conhecidos como voxels. 3) Sinais auto-correlacionados: O sinal de RMf é dependente do nível de oxigenação sanguínea das regiões cerebrais ( $B O L D$, do inglês Blood Oxigenation Level Dependence), portanto, a distribuição dos vasos e artérias cerebrais produz uma dependência natural em sinais de voxels espacialmente muito próximos.

Mesmo assim, a técnica de RMf é capaz de discriminar regiões cerebrais ativas durante diferentes condições experimentais e doenças neurológicas [44]. Porém, grande parte dos resultados já publicados depende da aplicação e interpretação de modelos estatísticos para caracterizar o efeito que diferentes condições experimentais produzem na resposta hemodinâmica cerebral [37].

\subsection{Grafos}

Este trabalho estuda padrões de conectividade funcional por técnicas da teoria dos grafos. Um grafo é constituído de vértices (nós) e arestas (setas). No estudo da conectividade cada vértice representa uma região cerebral e cada aresta representa a conectividade entre duas regiões, i.e. grafos cujas arestas são compostas por setas associadas a pesos que podem representar forças relativas da interação ou mesmo magnitudes de fluxo de informação [78] entre os vértices. As medidas de conectividade comumente utilizadas se baseiam nos conceitos de correlação no domínio do tempo ou coerência no domínio da freqüência. Essa representação, embora intuitiva, freqüentemente é de difícil análise, sobretudo quando há muitas regiões sob análise simultânea, e nem sempre elucida facilmente os padrões de ligação e como estes se modificam ao longo da evolução de estados cerebrais. Uma idéia da complexidade típica de grafos obtidos por este tipo de análise pode ser apreciada na Figura 1.2 e suporta a necessidade de se buscar quantificadores estruturais. 

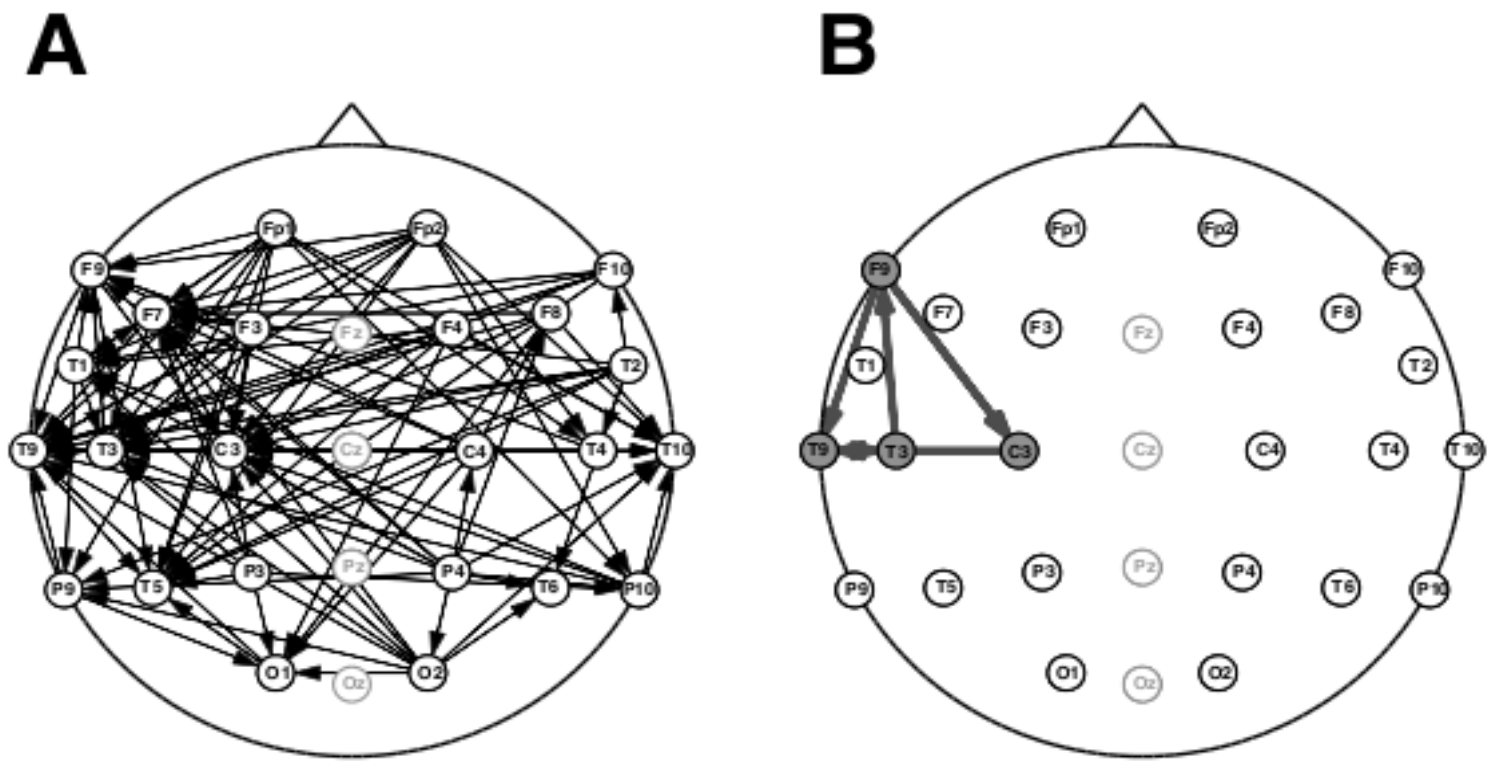

Figura 1.2: Um exemplo do uso da teoria dos grafos na caracterização das redes de conectividade cerebral em sujeitos com epilepsia do lobo temporal pode ser encontrado em [8]. Neste artigo, a conectividade cerebral foi estimada pela coerência parcial direcionada dos canais de EEG durante crises epiléticas. O grafo do lado esquerdo representa toda a rede de conectividade de um sujeito em particular. O grafo do lado direito é um subconjunto fortemente conexo do grafo ao lado. O mesmo artigo mostrou que subconjuntos fortemente conexos estão associados aos vértices de regiões determinadas pela análise clínica como focos epileptogênicos.

A representação da conectividade cerebral por grafos tem se tornado uma ferramenta bastante popular na caracterização de redes cerebrais [9,34,50,73,74]. Em geral, as análises buscam caracterizar a dinâmica cerebral através de parâmetros topológicos como grau de conectividade, coeficiente de agrupamento, comprimento do caminho e eficiência global ${ }^{1}[4,68,76]$. Tais parâmetros têm origem na teoria das redes complexas que se encaixa no conceito moderno de funcionamento cerebral.

Aspectos topológicos da rede de conectividade têm sido utilizados para entender as oscilações co-

${ }^{1} \mathrm{O}$ grau de conectividade de um vértice é número de arestas chegam ou saem do vértice. O grau de conectividade global é a média do grau de conectividade dos seus vértices. O coeficiente de agrupamento de um vértice $v$ é a razão entre o número de arestas na vizinhança de $v$ e o número máximo de arestas que a vizinhança poderia ter. A vizinhança de $v$ são todos os vértices que estão ligados a $v$. O coeficiente de agrupamento de um grafo é a média do coeficiente de agrupamento de seus vértices. O comprimento do caminho é a média do tamanho de todos os caminhos existentes na rede. A eficiência do caminho é o inverso de seu tamanho. A eficiência entre dois vértices é a eficiência do menor caminho que existe entre eles. A eficiência global do grafo é a média das eficiências entre todos os vértices. 
erentes de diferentes regiões cerebrais no seu estado normal e durante as crises epiléticas [53,55]. [29] mostrou em modelo computacional do giro denteado dos ratos que o grau de conectividade global possui pouca variação mesmo se o número de células hilares for reduzido drasticamente. Características de redes do tipo mundo pequeno tem sido observadas em redes neurais reais cultivadas in vitro [12]. Redes do tipo mundo pequeno possuem coeficiente de agrupamento alto e comprimento do caminho curto. Tais características estão entre redes puramente aleatórias (coeficiente de agrupamento baixo e comprimento do caminho curto) e redes regulares (coeficiente de agrupamento alto e comprimento do caminho longo). Devido a estas características, redes do tipo mundo pequeno estão associadas a conceitos de eficiência na transmissão da informação e resistência contra danos aleatórios.

Padrões de conectividade estrutural têm sido analisados em redes neurais reais e também em redes estimadas por imagens por tensor de difusão (DTI, do inglês Diffusion tensor imaging) e imagens por espectro de difusão ( $D S I$, do inglês Diffusion spectrum imaging). Watts e Strogatz foram os primeiros a demonstrar que o sistema nervoso da C. elegans tem coeficiente de agrupamento alto e tamanho do caminho curto, sugerindo uma arquitetura do tipo mundo pequeno [77]. Estudos envolvendo o sistema nervoso de primatas e subestruturas do encéfalo humano tiveram resultados semelhantes [42]. Eguiluz et al utilizou a correlação entre sinais de RMf durante uma tarefa de finger-tap para construir grafos não direcionados e não pesados [30]. Esta análise aplicada em sete sujeitos sadios revelou grafos com coeficiente de agrupamento alto, tamanho do caminho curto e distribuição do grau de conectividade livre de escala, ou seja, seguindo uma lei de potência. O mesmo resultado foi obtido em estado de repouso [61], porém com uso da correlação parcial entre noventa regiões cerebrais. Utilizando o conjunto de dados do trabalho anterior, [2] mostrou que a rede estimada possuía um agrupamento gigante (do inglês, giant cluster) em sua maioria de áreas corticais associativas.

\subsection{Objetivo}

Várias abordagens teóricas e algorítmicas foram propostas nos últimos anos para estudar a conectividade [43, 47, 60, 75]. Embora intuitivos, os conceitos de redes do tipo mundo pequeno e livre de escala não são suficientes para descrever o papel de cada região na dinâmica cerebral e os resultados raramente concordam com as idéias clássicas sobre a fisiologia e anatomia encefálica. Neste trabalho, a teoria dos grafos foi utilizada como mecanismo de mineração de dados, pois se quantificam regiões cerebrais por índices que refletem os papéis destas regiões na rede de conectividade cerebral. A análise completa consiste em (Figura 1.3): 

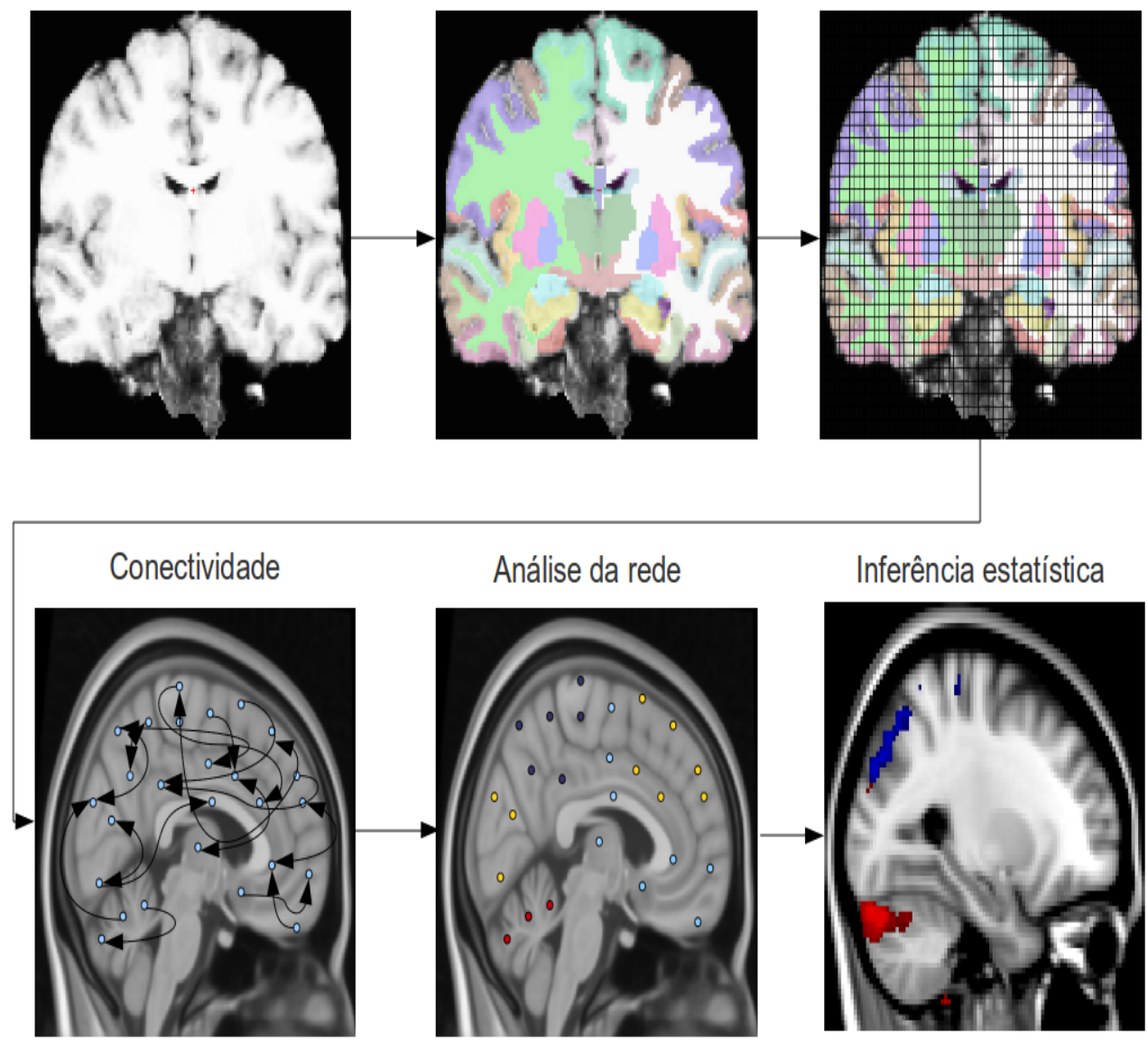

Figura 1.3: O pré-processamento corrige o movimento natural da cabeça durante o experimento, diminui o ruído de baixa freqüência causado pela variação do campo magnético e estima a matriz de registro do espaço funcional para o espaço comum MNI para cada sujeito analisado. Os sinais são normalizados de forma que cada série temporal tenha média zero e variância um. A dimensão da imagem de RMf é reduzida na andrazão de 1:3 em cada dimensão espacial. Interpolam-se os valores pela média respeitando as características anatômicas das regiões cerebrais. Constroem-se grafos direcionados e pesados a partir da conectividade funcional estimada pela coerência direcionada entre pares de regiões distintas. Quantificam-se seus vértices por índices e faz-se o registro dos valores no espaço comum MNI. Avalia-se a consistência de cada índice pelo teste não paramétrico de Friedman seguido de análises de múltiplas comparações. 
1. Pré-processamento das imagens: Para as imagens de RMf de cada sujeito, faz se a correção de movimento, filtragem do ruído de alta freqüência e o registro para o espaço padrão $\mathbf{M N I}^{2}$. Para as imagens RM de alta resolução, faz se a segmentação cerebral levando em conta a intensidade de cada voxel e características regionais anatômicas.

2. Redução da dimensionalidade espacial: Parte da substância branca das imagens de RMf é removida utilizando a imagem de segmentação anatômica. Em seguida reduz-se a resolução da imagem de RMf na razão 1:3. Na interpolação, calcula-se a média do sinal nas subparcelas da imagem original.

3. Conectividade funcional: Calcula-se a média quadrática entre $[0,01-0,1] \mathrm{Hz}$ da coerência direcionada dois a dois sobre todas as parcelas.

4. Análise dos grafos: Estudam-se características topológicas da rede de conectividade cerebral pela da indexação dos vértices.

5. Registra-se os índices no espaço padrão MNI utilizando a matriz estimada em 1.

6. Analisa-se estatisticamente cada índice identificando vértices cujo posto é maior que o valor esperado sobre a hipótese de homogeneidade.

Esta dissertação está organizada da seguinte maneira. O capítulo 2 apresenta alguns conceitos da teoria dos grafos utilizados para entender características topológicas de redes de conectividade cerebral. O capítulo 3 exibe os detalhes teóricos necessários para desenvolver este tipo de análise. Os resultados da análise de 198 sujeitos sadios durante o estado de repouso são apresentados no capítulo 4. O capítulo 5 discute dentro do contexto neurofisiológico os principais resultados. Neste capítulo, levanta-se questões sobre a metodologia e aplicações futuras da técnica. O apêndice A apresenta a natureza do efeito BOLD e técnicas de processamento de imagens de RMf. O fenômeno estado de repouso é brevemente discutido no fim do apêndice A. O apêndice B discute alguns modelos propostos pela literatura para estimar a conectividade cerebral e a ligação da coerência direcionada com os conceitos de causalidade de Granger.

\footnotetext{
${ }^{2}$ O template MNI (Montreal Neurological Institute) é um mapa estereotáxico construído a partir de 152 imagens de ressonância magnética (RM) de sujeitos sadios.
} 


\section{Capítulo 2}

\section{Princípios de Teoria dos Grafos}

\subsection{Definição}

Matematicamente, um conjunto de nós e setas direcionadas pode ser representado através de um grafo direcionado $G(V, E)$, em que $V$ é o conjunto de vértices e $E$ é o conjunto de arestas. $e_{k}=\left(v_{i}, v_{j}\right) \in E$ representa uma aresta que conecta o vértice origem $v_{i} \in V$ ao vértice destino $v_{j} \in V$. Em um grafo direcionado $\left(v_{i}, v_{j}\right)$ é diferente de $\left(v_{j}, v_{i}\right)$. A força, ou grau de conectividade, de uma aresta é representada por uma função $w: E \mapsto \Re^{+}$, conhecida como função peso e definida pela medida de conectividade. Na ausência de peso, por definição $w(e)=1$ para todo $e \in E$.

Um grafo $G(V, E)$ também pode ser definido através de sua matriz de adjacências $\mathbf{A}$

- $\mathbf{A} \in M(\# V, \# V)^{12}$

- $\mathbf{A}_{i, j}=w(e)$ se $e=\left(v_{i}, v_{j}\right) \in E$

- $\mathbf{A}_{i, j}=0$ se $\left(v_{i}, v_{j}\right) \notin E$

Para exemplificar os índices definidos na próxima seção, utiliza-se um grafo direcionado, com

${ }^{1} \# V$ é o número de elementos pertencentes ao conjunto $V$

${ }^{2} M(N, N)$ é o conjunto de todas as matrizes $N \times N$ 
arestas pesadas pela seguinte matriz de adjacências ${ }^{3}$

$$
\mathbf{A}=\left[\begin{array}{cccccccc}
0 & 0 & 0,20 & 0,45 & 0 & 0 & 0 & 0 \\
0 & 0 & 0 & 0,60 & 0 & 0 & 0 & 0 \\
0 & 0 & 0 & 0 & 0 & 0 & 0 & 0 \\
0 & 0 & 0,45 & 0 & 0 & 0 & 0,50 & 0 \\
0 & 0,30 & 0 & 0 & 0 & 0 & 0,30 & 0 \\
0 & 0 & 0,10 & 0,40 & 0 & 0 & 0 & 0 \\
0 & 0 & 0 & 0 & 0 & 0 & 0 & 0 \\
0 & 0 & 0 & 0 & 0 & 0 & 0,20 & 0
\end{array}\right]
$$

A Figura 2.1 exibe o gráfico deste grafo que será chamado de grafo exemplo.

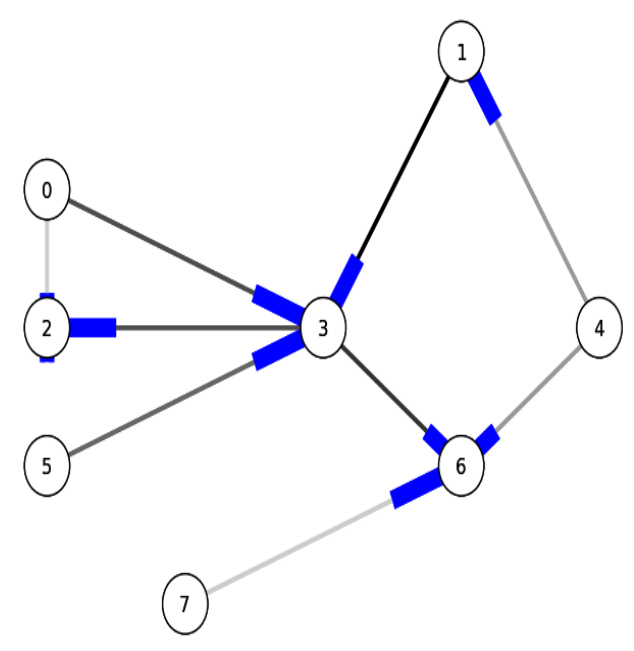

Figura 2.1: Grafo exemplo utilizado neste capítulo para estudar parâmetros topológicos de redes de conectividade. As arestas possuem coloração em escala de cinza proporcional ao seu peso. O fim da aresta é representado por um retângulo azul e indica a direção da aresta.

\footnotetext{
${ }^{3}$ Nesta notação o vértice origem aparece na linha enquanto que o vértice destino aparece na coluna.
} 


\section{2 Índices para conectividade}

Naturalmente, a conectividade cerebral pode ser representada por um grafo. A depender da medida de conectividade adotada, as arestas do grafo podem ser pesadas e direcionadas. Assim, o problema da análise estrutural da conectividade cerebral se reduz a análise estrutural de grafos. Uma das técnicas mais utilizadas na literatura para quantificar padrões de conectividade em grafos é o método de indexação [17,82].

Formalmente, um indice $I$ é um mapeamento de $M(\# V, \# V)$ para $\Re^{\# V}$. Seja $\mathbf{A} \in M(\# V, \# V)$ a matrix de adjacência de um grafo $G, I(\mathbf{A})$ é um vetor que associa um valor real para cada vértice de $G$. Um índice também pode ser considerado um parâmetro topológico que reflete as posições dos vértices relativas ao restante da rede.

As próximas sessões ilustram as principais características de cada índice utilizado neste trabalho para estudar a conectividade cerebral. As análises se passam em um contexto relativamente simples, com poucos vértices, mas são importantes para interpretar os índices quando aplicados a dados de RMf (milhares de vértices). Primeiramente, definem-se índices baseados no conceito de centralidade: Degree, Closeness, Betweenness. Logo após, definem-se dois índices baseados nos conceitos de compartilhamento de informação, conhecidos como Hub e Authority.

\subsection{1 Índices de centralidade}

Centralidade é um dos conceitos mais básicos no estudo de redes. Um índice de centralidade busca descobrir quais vértices são mais importantes dentro da rede [82]. Diferentes critérios de importância definem diferentes índices de centralidade. Geralmente índices de centralidade se baseiam na posição de cada vértice na rede e na força de suas conexões. A posição do vértice na rede define seu padrão de conectividade que depende do processamento cognitivo no momento da aquisição dos dados.

\section{Degree}

O índice Degree de um vértice é simplesmente o número de vértices que estão conectados a ele. Em um grafo direcionado, o índice Degree é a soma do número de arestas que entram mais o número de arestas que saem do vértice. A Figura 2.2 mostra o grafo exemplo com os vértices coloridos com base no seu índice Degree. 


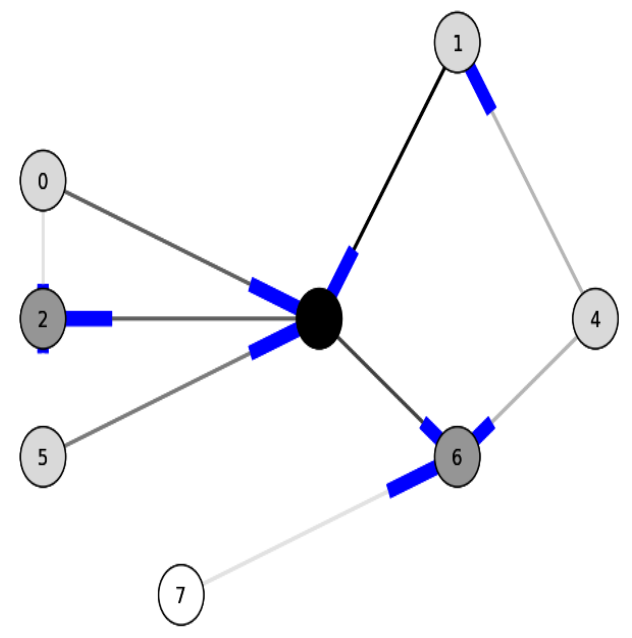

Figura 2.2: Grafo exemplo com vértices coloridos com base no seu índice Degree. Os valores estão em escala de cinza.

\section{Closeness}

O índice Closeness mede o grau de proximidade do vértice em relação aos demais vértices da rede. Vértices com altos índices de Closeness são vértices que podem rapidamente interagir com (influenciar) a rede [82]. Na conectividade cerebral, vértices com altos índices de Closeness podem representam regiões que geraram informação no cérebro. O índice Closeness de um vértice $v_{i}$ é o inverso da distância média de $v_{i}$ para todos outros vértices, ou seja:

$$
\operatorname{Clo}\left(v_{i}\right)=1 / \mu_{i}
$$

O índice é normalizado tal que o maior valor do índice dentro de cada componente do grafo é igual a $\left(n_{j}-1\right) /(\# V-1)$, em que $n_{j}$ é o número de vértices pertencentes à componente $\mathrm{j}$ do grafo.

A Figura 2.3 mostra o grafo exemplo com coloração definida pelo índice closeness em cada vértice. Os vértices que somente recebem arestas (vértices dois e seis) possuem índice Closeness igual a zero. Isto reflete a incapacidade dos vértices dois e seis de se comunicarem com o restante da rede. Vértices 
deste tipo, que somente recebem informação, são conhecidos como vértices sorvedouros. Embora o vértice três na Figura 2.3 receba arestas de praticamente toda a rede (os vértices três e seis possuem os maiores valores de incidência na rede) e envie arestas na mesma proporção que os vértices zero, quatro e cinco (totalizando duas arestas), seu valor de Closeness é menor que os valores de Closeness dos vértices zero, quatro e cinco, pois os vértices que recebem informação do vértice três (vértices dois e seis) não enviam informação para outros vértices na rede, ou seja, a mensagem termina no segundo nível de processamento. Por outro lado, mensagens que tem origem nos vértices zero, quatro ou cinco, podem ser repassadas através do vértice três para outras camadas da rede. Isto torna estes vértices mais capazes de interagir ou influenciar o restante da rede.

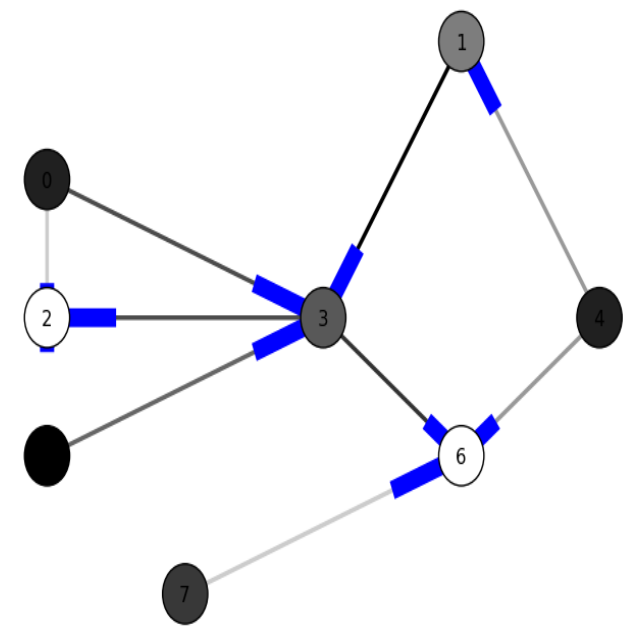

Figura 2.3: Grafo exemplo com vértices coloridos com base no seu índice Closeness. Os valores estão em escala de cinza.

\section{Betweenness}

Interações entre duas regiões cerebrais, A e B, podem depender de outra região C localizada no caminho da comunicação entre A e B. Regiões intermediárias podem modular a atividade entre regiões adjacentes, portanto são úteis para entender a dinâmica cerebral. O índice Betweenness caracteriza vértices com tal característica. O índice Betweenness é proporcional a quantidade de 
vezes que o vértice participa de um menor caminho entre outros dois vértices.

Sejam $s, t$ e $v$ vértices de um grafo direcionado. Um caminho com início no vértice $s$ e fim no vértice $t$ é uma seqüência de vértices e arestas $s,\left(s, v_{1}\right), v_{1},\left(v_{1}, v_{2}\right), \ldots, v_{k},\left(v_{k}, t\right), t$ tal que os vértices antes e depois de cada aresta são respectivamente o vértice origem e o vértice destino desta aresta. O tamanho do caminho é o inverso da soma dos pesos de suas arestas. O menor caminho entre $s$ e $t$ é o caminho com menor tamanho dentre todos os caminhos entre $s$ e $t$. Sejam $\sigma_{s t}$ e $\sigma_{s t}(v)$ respectivamente o número de menores caminhos entre $v_{s}$ e $v_{t}$ e o número de menores caminhos entre $s$ e $t$ que contém o contém o vértice $v$. A probabilidade de $v$ ser vértice intermediário entre $s$ e $t$ é dada por

$$
\delta_{s t}\left(v_{i}\right)=\sigma_{s t}\left(v_{i}\right) / \sigma_{s t}
$$

O índice Betweenness de $v$ é a proporção de todos os menores caminhos que passam por $v$, ou seja,

$$
\operatorname{Bet}\left(v_{i}\right)=\sum_{s \neq v_{i}} \sum_{t \neq v_{i}} \delta_{s t}\left(v_{i}\right)
$$

Supondo que a comunicação entre $s$ e $t$ é eficiente se for transmitida pelo menor caminho entre $s$ e $t$, o índice Betweenness reflete o poder de controle e/ou modulação do vértice sobre a informação da rede. O algoritmo utilizado neste trabalho para calcular o índice Betweenness é baseado no algoritmo de Ulrik Brandes [80].

A Figura 2.4 mostra o grafo exemplo 2.1 com coloração definida pelo índice Betweenness em cada vértice. No índice Betweenness, diferentemente do índice Closeness, o vértice três é o vértice mais central, ou seja, o vértice três é o vértice presente na maioria dos menores caminhos existentes na rede. Embora o vértice três não influencie a rede de modo instantâneo, porque possui baixo índice Closenness, ele tem papel modulador na rede. Para ser compartilhada na rede, a informação entre dois vértices precisa, na maioria das vezes, passar pelo vértice três, portanto o vértice três tem capacidade de decidir como a informação é repassada.

\subsection{2 Índices não baseados em centralidade}

\section{Authority e Hub}

Os índices Authority e Hub têm origem no estudo da informação compartilhada por documentos conectados pela internet. Documentos na internet (páginas, arquivos de texto, etc.) podem ser 


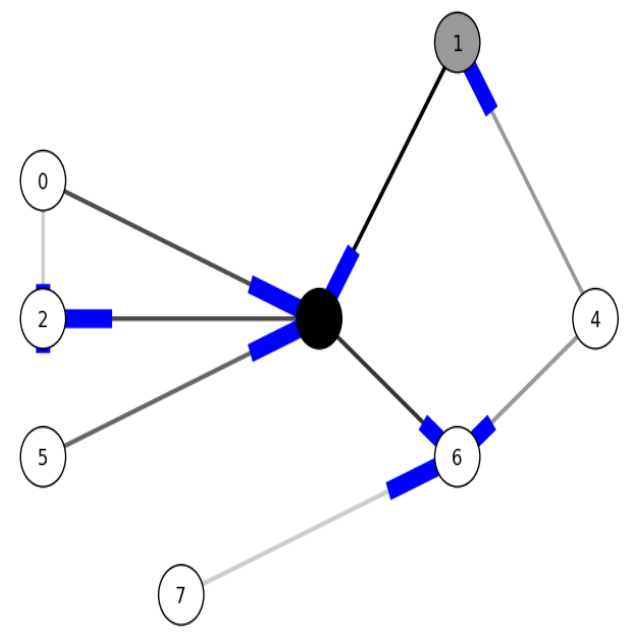

Figura 2.4: Grafo exemplo com vértices coloridos com base no seu índice Betweenness. Os valores estão em escala de cinza.

representados por vértices e referências entre documentos, conhecidas no jargão da informática de hiperlinks, podem ser represetandas por arestas direcionadas

$\mathrm{O}$ vértice é bom $H u b$ se envia informações para vértices que são bons Authorities e o vértice é bom Authority se recebe informações de vértices que são bons Hubs. Sejam a $=\left[a_{1}, \ldots, a_{\# V}\right]$ e $\mathbf{h}=\left[h_{1}, \ldots, h_{\# V}\right]$ respectivamente os valores dos índices Authority e Hub nos vértices do grafo definido pela matriz de adjacências A. A relação recíproca entre os índices Authority e Hub pode ser expressa pelo seguinte conjunto de equações:

$$
\begin{gathered}
\mathbf{a}=\mathbf{A}^{T} \mathbf{h} \\
\mathbf{h}=\mathbf{A} \mathbf{a}
\end{gathered}
$$


ou equivalentemente

$$
\begin{aligned}
& \mathbf{a}=\mathbf{A}^{T} \mathbf{A} \mathbf{a} \\
& \mathbf{h}=\mathbf{A} \mathbf{A}^{T} \mathbf{h}
\end{aligned}
$$

Sejam $\mathbf{a}^{0}=\mathbf{e}$ e $\mathbf{h}^{0}=\mathbf{e}^{4}$ valores iniciais dos vetores $\mathbf{a}$ e $\mathbf{h}$, o algoritmo para obter os valores dos índices Authority e Hub é expresso pelas recursões: [49]

$$
\begin{aligned}
\mathbf{a}^{k} & =\mathbf{A}^{T} \mathbf{A} \mathbf{a}^{k-1} \\
\mathbf{h}^{k} & =\mathbf{A} \mathbf{A}^{T} \mathbf{h}^{k-1}
\end{aligned}
$$

até a convergência dos valores de $\mathbf{a}^{k}$ e $\mathbf{b}^{k}$. Os valores de $\mathbf{a}^{k}$ e $\mathbf{b}^{k}$ obtidos na recursão 2.3 são os autovetores associados aos maiores autovalores respectivamente das matrizes $\mathbf{A}^{T} \mathbf{A}$ e $\mathbf{A} \mathbf{A}^{T}$. Mais detalhes sobre a implementação e convergência da recursão 2.3 podem ser encontrados em [49].

As Figuras 2.5 e 2.6 apresentam o grafo exemplo com os vértices coloridos a partir dos valores respectivamente do índice Authority e do índice Hub. Como esperado, o índice Authority caracteriza vértices que recem informação da rede enquanto que o índice $H u b$ caracteriza vértices que enviam informação para a rede.

\footnotetext{
${ }^{4} \mathbf{e}=[1, \ldots, 1, \ldots, 1]$ é o vetor de uns de tamanho $\# V$
} 


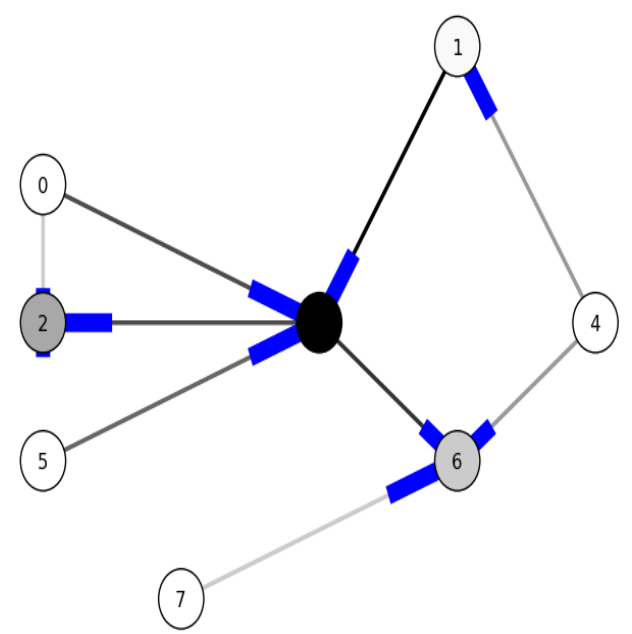

Figura 2.5: Grafo exemplo com vértices coloridos com base no seu índice Authority. Os valores estão em escala de cinza. 


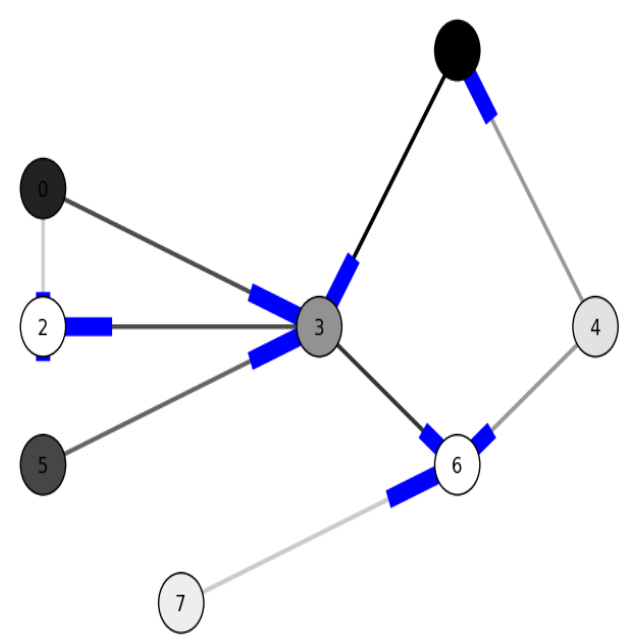

Figura 2.6: Grafo exemplo com vértices coloridos com base no seu índice Hub. Os valores estão em escala de cinza. 


\section{Capítulo 3}

\section{Material e métodos}

\subsection{Sujeitos e parâmetros de aquisição}

Os dados utilizados neste trabalho são de domínio público, foram obtidos do projeto 1000 Functional Connectomes Project e coletados sob a supervisão do pesquisador Randy L. Buckner (randy_buckner@harvard.edu) ${ }^{1}$. Cento e noventa e oito voluntários sadios (idade mínima,máxima e média: 18, 30, e 21, 03 anos; 123 mulheres e 75 homens; 27 canhotos e 171 destros) participaram do estudo. Os participantes realizaram uma tarefa de estado de repouso [35]: durante a aquisição os sujeitos foram orientados a entrar dentro máquina de ressonância magnética, relaxados, de olhos abertos, sem cair no sono e tentando não pensar em nada específico.

Os experimentos foram realizados em um equipamento SIEMENS 3 T Trio (Erlangen, Alemanha), localizada em Cambridge, MA, EUA. Imagens funcionais foram adquiridas utilizando uma seqüência single-shot, gradient-recalled echo planar imaging sequence (EPI). Quarenta e sete fatias transversais alinhadas ao longo da Comissura Anterior e Comissura-Posterior (AC-PC) foram adquiridas (FOV $=24 \mathrm{~cm}$, no plano da matriz $=72 \times 72$, espessura de corte $=3 \mathrm{~mm}$, sem espaço). Um total de 124 volumes foram adquiridos para cada sujeito sendo que os cinco primeiros volumes foram descartados para garantir o estado de equilíbrio do vetor de magnetização longitudinal. Para o registro e localização das áreas cerebrais de cada sujeito, imagens estruturais de alta resolução (contraste T1) foram adquiridas na orientação axial utilizando uma seqüência 3D spoiled gradient-recalled sequence (SPGR) $(T R=2300 \mathrm{~ms}, T E=2,98 \mathrm{~ms}$, ângulo de rotação $=9$ graus, tamanho da matriz $=192 \times 192 \times 144$ e tamanho do voxel $=1,2 \times 1,197 \times 1,197 \mathrm{~mm} 3)$.

\footnotetext{
${ }^{1}$ Dados disponíveis para download no site www.nitrc.org/projects/fcon_1000
} 


\subsection{Pré processamento}

O pré-processamento dos dados de RMf foi executado pelo programa FEAT (FMRI Expert Analysis Tool) Versão 5.98, parte do pacote FSL (FMRIB's Software Library, www.fmrib.ox.ac.uk/fsl). As imagens de RMf foram registradas para corrigir o movimento da cabeça utilizando o programa MCFLIRT [45]. O tecido não cerebral foi removido pelo programa BET [67]. Foi utilizado um filtro passa alta $^{2}$ para remover tendências lineares nos dados. Estimou-se a matriz de registro da imagem funcional dos sujeitos para o espaço da sua respectiva imagem estrutural de alta resolução e para o espaço padrão MNI utilizando o programa FLIRT [45].

\subsection{Segmentação anatômica}

As imagens estruturais foram segmentadas em regiões anatômicas utilizando o pacote de análise Freesurfer v4.5.0 (Athinoula A. Martinos Center at the Massachusetts General Hospital, Harvard Medical School; http://www.surfer.nmr.mgh.harvard.edu/). O método de segmentação e reconstrução cortical utilizado pelo FreeSurfer está detalhadamente descrito em [23,33]. Basicamente, os voxels de cada hemisfério cerebral são classificados como WM (substância branca) e non-WM (substância cinzenta) baseado na intensidade local de cada voxel. A informação da curvatura e localização espacial da superfície pial é utilizada para parcelar o córtex em regiões de interesse pré-determinadas. As regiões subcorticais são identificadas atribuindo-se rótulos de um atlas probabilístico aos voxels com base na sua intensidade e localização espacial. Correções subseqüentes são realizadas comparando o rótulo de cada voxel com os rótulos de voxels vizinhos.

Para cada sujeito, a imagem de segmentação gerada pelo FreeSurfer (aparc.a2009s+aseg) foi reamostrada no espaço da respectiva imagem funcional pré-processada no FSL (filtered_func_data). Para tal, utilizou-se as rotinas reg-feat2anat e aseg2feat do FreeSurfer.

\subsection{Processamento}

\subsubsection{Redução da dimensionalidade}

As séries temporais das estruturas corticais e subcorticais do cérebro de cada sujeito foram extraídas da imagem funcional utilizando a imagem de segmentação. Cada série temporal foi normalizada para ter média zero e variância um. A dimensão da imagem de RMf foi reduzida na razão

\footnotetext{
${ }^{2}$ Gaussian-Weighted Least-Squares, com parâmetro sigma=30.0s [84].
} 
de 1:3 em cada dimensão espacial. Interpolam-se os valores pela média somente entre voxels da mesma estrutura anatômica. No caso de estruturas adjacentes, a estrutura anatômica considerada foi aquela com maior representatividade local, ou seja, com maior número de voxels. Isso permitiu que as características anatômicas das regiões cerebrais fossem respeitadas, pois cada voxel manteve a informação de uma única estrutura anatômica. Os voxels relativos à substância branca cortical e o cerebelo foram desconsiderados.

\subsubsection{Análise da conectividade (coerência direcionada e parâmetros topológicos)}

Após a redução da dimensionalidade espacial das imagens de RMf, a conectividade funcional foi mensurada pela coerência direcionada (CD) em todos os pares de séries temporais. A CD é um caso particular da coerência parcial direcionada (veja a seção B.3.5 ou [7]) tomada dois a dois sobre um conjunto de séries temporais. A CD foi estimada através de modelos auto-regressivos bivariados e a ordem de cada modelo foi determinada pelo critério de Akaike [3] sendo permitindo no máximo doze atrasos temporais. A CD foi definida como nula quando a ordem sugerida foi igual a zero. Os quadrados dos valores absolutos da CD entre 0,01 e $0,1 \mathrm{~Hz}$ foram somados e serviram para a construção da matriz de conectividade de cada sujeito.

Para a análise das redes construídas a partir da matriz de conectividade, foram calculados os parâmetros topológicos descritos em detalhe no capítulo 2: Degree, Closeness, Betweenness, Hub e Authority. Para cada sujeito, os valores dos índices foram reamostrados para a resolução da imagem de RMf e posteriormente registrados no espaço MNI utilizando o programa FLIRT.

\subsection{Consistência - Estatística}

As análises estatísticas foram realizadas através do teste não paramétrico de Friedman seguido de análises de comparações múltiplas [65] descritas a seguir.

Para cada índice, considere $R_{i j}$ o posto do índice no vértice $v_{j}$ em relação aos índices nos demais vértices do grafo $G_{i}$. Seja $R_{j}=\sum_{i} R_{i j}$ a soma dos postos no vértice $v_{j}$ sobre o total de grafos em análise. A estatística do teste de Friedman é:

$$
R=\frac{12}{N k(k+1)} \sum_{j} R_{j}^{2-3 N(k+1)}
$$


em que $k$ é o número de vértices e $N$ o número grafos ${ }^{3}$.

No limite, a estatística $R$ possui distribuição chi-quadrado com $k-1$ graus de liberdade, $R \sim \mathcal{X}_{k-1}^{2}$, podendo ser utilizada para testar se existem evidências contra a hipótese nula. A hipótese nula assume homogeneidade dos postos em todos os vértices, ou seja, diferenças no posto entre vértices do mesmo grafo são em média iguais a zero.

Quando a hipótese nula é rejeitada, o posto médio de cada vértice pode ser submetido a análise de comparações múltiplas. Seja $r=\frac{N k}{2}$ o valor esperado de $R_{j}$ sobre a hipótese nula, [25] sugere que

$$
z=\frac{\left|R_{j}-r\right|}{\sqrt{\frac{N k(k+1)}{6}}} \sim \mathcal{N}(0,1)
$$

Utilizando a correção de Bonferroni, a estatística $z$ de cada vértice foi convertida em $\mathrm{p}$-valores baseados em uma distribuição normal padrão com nível de significância $\alpha=\frac{0,01}{k(k-1)}$. Assim, foram geradas cinco imagens de p-valores, uma para cada índice analisado.

\footnotetext{
${ }^{3}$ Observe que cada grafo representa um sujeito do conjunto de dados analisados
} 


\section{Capítulo 4}

\section{Resultados}

A análise dos parâmetros de conectividade funcional na rede dos 198 sujeitos revelou características importantes de regiões cerebrais envolvidas no processamento da informação durante o estado de repouso. A Figura 4 mostra no plano sagital os mapas estatísticos referentes à análise de múltiplas comparações dos índices. As Figuras 4.2 e 4.3 mostram os mesmos mapas, porém, em três dimensões. A Tabela 4 mostra o número total de voxels (volume) de cada estrutura anatômica cerebral identificada em cada índice e o número de voxels significativos (p-valor $<0,01$, com correção de bonferroni).

\subsection{Degree}

As regiões identificadas pelo índice Degree são: Bilateral: Acumbens, Núcleo Caudado, Giro do Cíngulo - divisão posterior, Córtex Orbitofrontal, Pólo Frontal, Hipocampo, Giro Temporal Inferior - parte tempo-occipital, Córtex Occipital Lateral - divisão superior, Giro Temporal Médio - parte tempo-occipital, Globo Pálido, Giro Parahipocampal - divisão anterior, Córtex Pré-Cúneo, Putame, Córtex Sub-Caloso, Giro Frontal Superior, Tálamo, Tronco Encefálico; Lado Direito: Giro Angular, Giro Supramarginal - divisão anterior, Giro Supramarginal - divisão posterior; Lado Esquerdo: Córtex Frontal Medial.

\subsection{Betweenness}

As seguintes regiões foram identificadas pelo índice Betweenness: Bilateral: Giro do Cíngulo divisão posterior; Lado Direito: Córtex Occipital Lateral - divisão superior, Córtex Pré-Cúneo, Giro Angular. 
Tabela 4.1: Estruturas cerebrais que contém voxels cujo posto é estatisticamente maior que o valor esperado sobre a hipótese nula para um dado índice. As estruturas foram nomeadas com base no atlas de estruturas corticais e subcorticais Harvard-Oxford (p-valor < 0,01, com correção de bonferroni).

\begin{tabular}{|c|c|c|c|c|c|c|c|}
\hline Side & Area & Volume & Degree & Betweenness & Closeness & Authority & Hub \\
\hline & Tronco Encefálico & 8078 & 26 & - & 2324 & 1164 & - \\
\hline Lado Esquerdo & Acumbens & 111 & 62 & - & 62 & 66 & 20 \\
\hline Lado Direito & Acumbens & 86 & 41 & - & 40 & 44 & - \\
\hline Lado Esquerdo & Amígdala & 390 & 6 & - & 82 & 28 & - \\
\hline Lado Direito & Amígdala & 399 & 9 & - & 86 & 39 & - \\
\hline Lado Direito & Giro Angular & 2189 & 70 & 8 & - & - & 42 \\
\hline Lado Esquerdo & Núcleo Caudado & 572 & 131 & - & 153 & 166 & 37 \\
\hline Lado Direito & Núcleo Caudado & 515 & 106 & - & 126 & 134 & - \\
\hline Lado Esquerdo & Giro do Cíngulo - divisão anterior & 2075 & 8 & - & 6 & 21 & 38 \\
\hline Lado Direito & Giro do Cíngulo - divisão anterior & 2064 & - & - & - & - & 50 \\
\hline Lado Esquerdo & Giro do Cíngulo - divisão posterior & 2255 & 288 & 9 & 63 & 139 & 226 \\
\hline Lado Direito & Giro do Cíngulo - divisão posterior & 2193 & 215 & 36 & 21 & 91 & 163 \\
\hline Lado Esquerdo & Córtex Frontal Medial & 707 & 31 & - & - & 6 & 7 \\
\hline Lado Esquerdo & Córtex Orbitofrontal & 2659 & 85 & - & 100 & 83 & 48 \\
\hline Lado Direito & Córtex Orbitofrontal & 2386 & 106 & - & 146 & 124 & 43 \\
\hline Lado Esquerdo & Pólo Frontal & 10909 & 100 & - & - & - & 28 \\
\hline Lado Direito & Pólo Frontal & 14043 & 51 & - & - & - & 17 \\
\hline Lado Esquerdo & Hipocampo & 921 & 82 & - & 272 & 184 & - \\
\hline Lado Direito & Hipocampo & 772 & 63 & - & 231 & 164 & - \\
\hline Lado Esquerdo & Giro Temporal Inferior - parte tempo-occipital & 1113 & 17 & - & - & 102 & - \\
\hline Lado Direito & Giro Temporal Inferior - parte tempo-occipital & 1439 & 61 & - & - & 172 & 11 \\
\hline Lado Esquerdo & Ínsula & 1823 & - & - & 108 & 65 & - \\
\hline Lado Direito & Ínsula & 1781 & - & - & 89 & 93 & - \\
\hline Lado Esquerdo & Córtex Occipital Lateral - divisão inferior & 3319 & 7 & - & - & 55 & - \\
\hline Lado Direito & Córtex Occipital Lateral - divisão inferior & 3976 & - & - & - & 157 & 10 \\
\hline Lado Esquerdo & Córtex Occipital Lateral - divisão superior & 6958 & 23 & - & - & - & 24 \\
\hline Lado Direito & Córtex Occipital Lateral - divisão superior & 7174 & 48 & 21 & - & - & - \\
\hline Lado Esquerdo & Lingual Gyrus & 2385 & - & - & - & - & 10 \\
\hline Lado Direito & Middle Temporal Gyrus - posterior division & 2116 & 9 & - & - & - & - \\
\hline Lado Esquerdo & Giro Temporal Médio - parte tempo-occipital & 1391 & 50 & - & - & 23 & - \\
\hline Lado Direito & Giro Temporal Médio - parte tempo-occipital & 1781 & 42 & - & - & 16 & - \\
\hline Lado Esquerdo & Globo Pálido & 312 & 8 & - & 109 & - & - \\
\hline Lado Direito & Globo Pálido & 266 & 12 & - & 74 & 9 & - \\
\hline Lado Esquerdo & Paracingulate Gyrus & 2087 & 91 & - & 20 & - & 27 \\
\hline Lado Direito & Paracingulate Gyrus & 2008 & 17 & - & - & - & 11 \\
\hline Lado Esquerdo & Giro Parahipocampal - divisão anterior & 984 & 26 & - & 220 & 53 & - \\
\hline Lado Direito & Giro Parahipocampal - divisão anterior & 1170 & 15 & - & 255 & 76 & - \\
\hline Lado Esquerdo & Giro Parahipocampal - divisão posterior & 676 & - & - & 39 & 6 & - \\
\hline Lado Direito & Giro Parahipocampal - divisão posterior & 529 & - & - & 55 & 16 & - \\
\hline Lado Esquerdo & Planum Polare & 591 & - & - & - & 10 & - \\
\hline Lado Direito & Planum Polare & 619 & - & - & - & 25 & - \\
\hline Lado Direito & Giro Pré-Central & 6934 & - & - & - & - & 18 \\
\hline Lado Esquerdo & Córtex Pré-Cúneo & 3790 & 159 & - & 11 & 36 & 151 \\
\hline Lado Direito & Córtex Pré-Cúneo & 3950 & 132 & 18 & - & 7 & 124 \\
\hline Lado Esquerdo & Putame & 923 & 276 & - & 424 & 224 & 125 \\
\hline Lado Direito & Putame & 800 & 245 & - & 376 & 179 & 47 \\
\hline Lado Esquerdo & Córtex Sub-Caloso & 935 & 49 & - & 73 & 50 & 12 \\
\hline Lado Direito & Córtex Sub-Caloso & 1042 & 63 & - & 99 & 60 & - \\
\hline Lado Esquerdo & Giro Frontal Superior & 4652 & 25 & - & - & - & 13 \\
\hline Lado Direito & Giro Frontal Superior & 4209 & 11 & - & - & - & 8 \\
\hline Lado Direito & Giro Temporal Superior - divisão posterior & 1486 & - & - & - & - & 9 \\
\hline Lado Direito & Giro Supramarginal - divisão anterior & 1282 & 7 & - & - & - & 14 \\
\hline Lado Direito & Giro Supramarginal - divisão posterior & 2172 & 44 & - & - & - & 48 \\
\hline Lado Direito & Temporal Fusiform Cortex - anterior division & 618 & - & - & 7 & - & - \\
\hline Lado Direito & Temporal Fusiform Cortex - posterior division & 1382 & - & - & 11 & - & - \\
\hline Lado Direito & Temporal Occipital Fusiform Cortex & 1347 & - & - & - & 26 & - \\
\hline Lado Esquerdo & Pólo Temporal & 3820 & - & - & 8 & - & - \\
\hline Lado Direito & Pólo Temporal & 4007 & - & - & 7 & - & - \\
\hline Lado Esquerdo & Tálamo & 1591 & 451 & - & 805 & 787 & 261 \\
\hline Lado Direito & Tálamo & 1398 & 427 & - & 746 & 766 & 258 \\
\hline
\end{tabular}




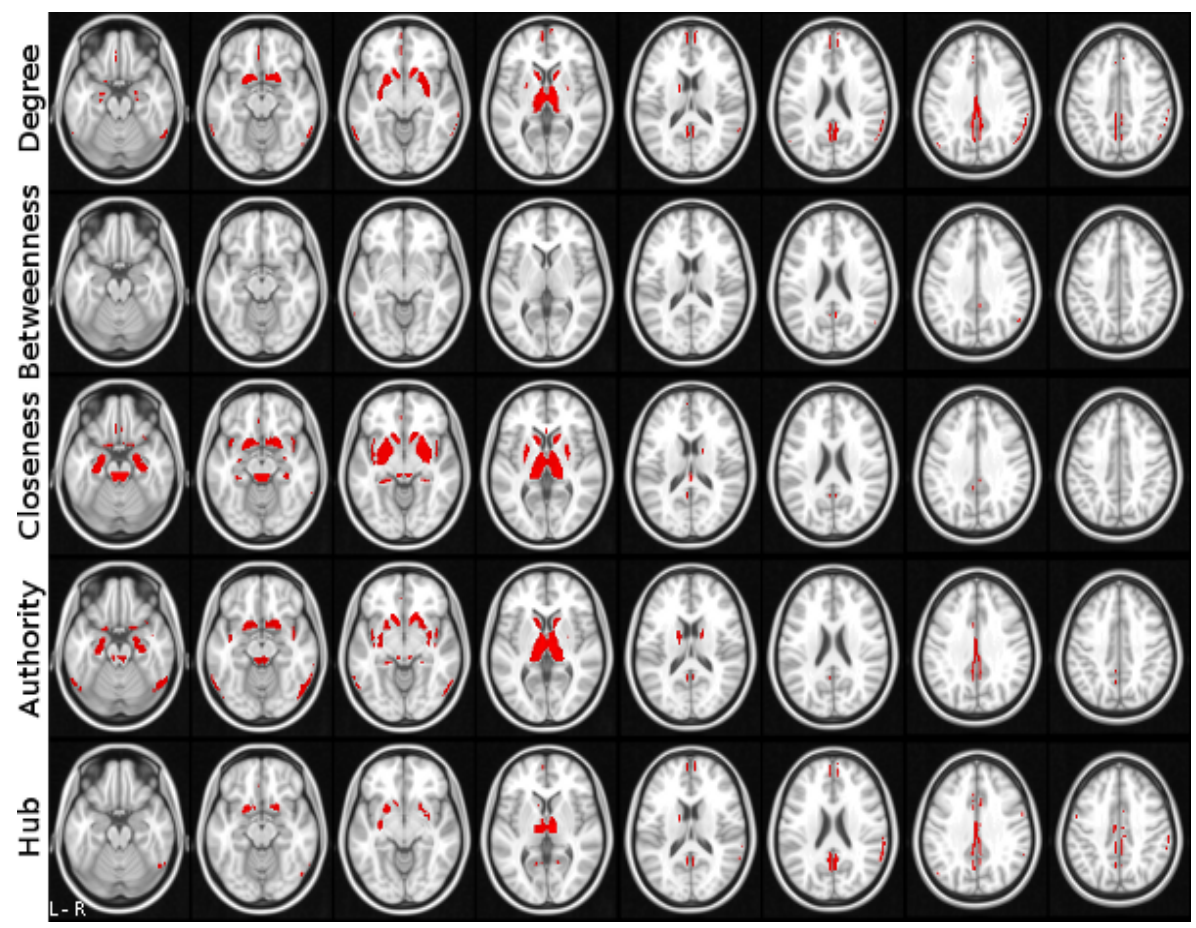

Figura 4.1: Vista axial dos mapas estatísticos. De cima para baixo tem-se os índices Degree, Betweenness, Closeness, Hub e Authority. As regiões destacadas são os voxels cujo posto é estatisticamente maior que o valor esperado sobre a hipótese nula (p-valor $<0,01$, com correção de bonferroni).

\subsection{Closeness}

O indice Closeness destacou as seguintes regiões: Bilateral: Acumbens, Amígdala, Núcleo Caudado, Giro do Cíngulo - divisão posterior, Córtex Orbitofrontal, Hipocampo, Ínsula, Globo Pálido, Giro Parahipocampal - divisão anterior, Giro Parahipocampal - divisão posterior, Putame, Córtex Sub-Caloso, Pólo Temporal, Tálamo, Tronco Encefálico; Lado Direito: Temporal Fusiform Cortex - anterior division, Temporal Fusiform Cortex - posterior division; Lado Esquerdo: Giro Frontal Superior.

\subsection{Hub e Authority}

Em relação ao índice $H u b$ destaca-se as seguintes regiões, bilateral: Giro do Cíngulo - divisão anterior, Giro do Cíngulo - divisão posterior, Córtex Orbitofrontal, Pólo Frontal, Lingual Gyrus, Giro Pré-Central, Córtex Pré-Cúneo, Putame, Giro Frontal Superior, Tálamo; Lado Direito: Giro Angular, 


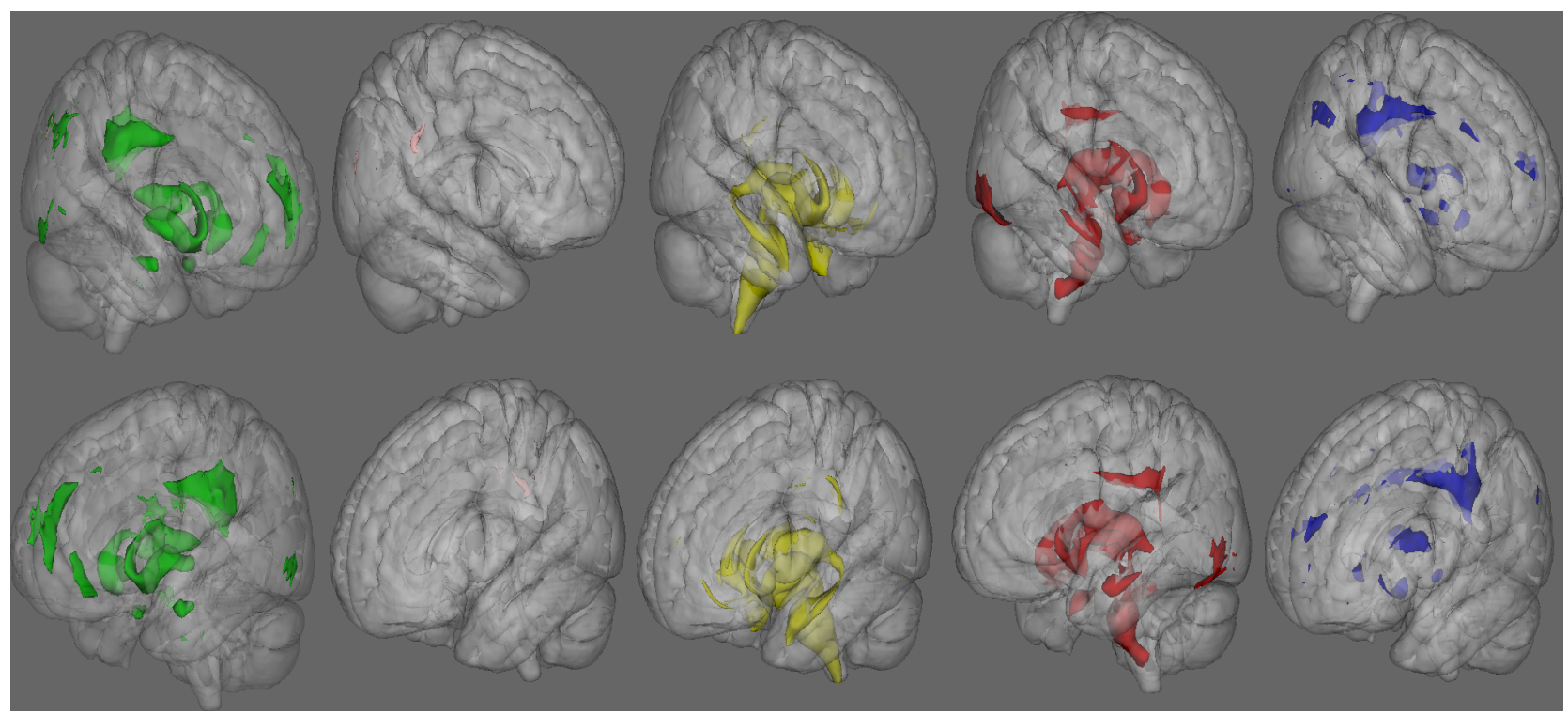

Figura 4.2: Visão lateral em três dimensões dos mapas estatísticos. Da esquerda para a direita tem-se os índices Degree, Betweenness, Closeness, Hub e Authority.

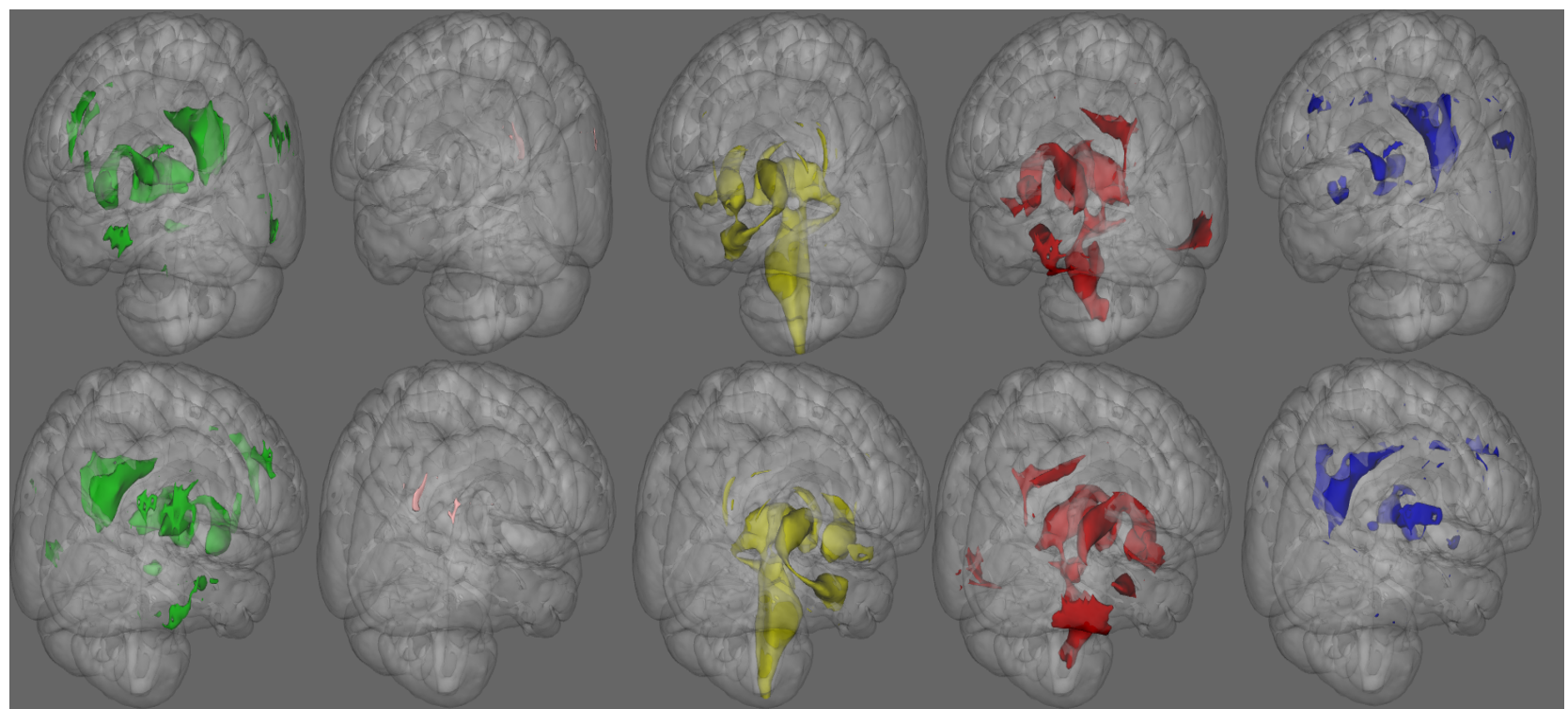

Figura 4.3: Visão posterior em três dimensões dos mapas estatísticos. Da esquerda para a direita tem-se os índices Degree, Betweenness, Closeness, Hub e Authority. 
Giro Temporal Inferior - parte tempo-occipital, Córtex Occipital Lateral - divisão inferior, Giro Temporal Superior - divisão posterior, Giro Supramarginal - divisão anterior, Giro Supramarginal divisão posterior; Lado Esquerdo: Acumbens, Núcleo Caudado, Córtex Occipital Lateral - divisão superior.

Por fim, o índice Authority identificou as seguintes regiões: Bilateral: Acumbens, Amígdala, Núcleo Caudado, Giro do Cíngulo - divisão posterior, Córtex Orbitofrontal, Hipocampo, Giro Temporal Inferior - parte tempo-occipital, Ínsula, Córtex Occipital Lateral - divisão inferior, Giro Temporal Médio - parte tempo-occipital, Giro Parahipocampal - divisão anterior, Giro Parahipocampal divisão posterior, Córtex Pré-Cúneo, Putame, Córtex Sub-Caloso, Tálamo, Tronco Encefálico; Lado Direito: Temporal Occipital Fusiform Cortex; Lado Esquerdo: Giro do Cíngulo - divisão anterior. 


\section{Capítulo 5}

\section{Discussão}

\subsection{Introdução}

Este trabalho desenvolveu e aplicou métodos para estudar papéis de regiões cerebrais em redes de conectividade funcional. Cinco padrões de conectividade foram quantificados pelos índices Degree, Closeness, Betweenness, Hub e Authority. A análise dos 198 sujeitos durante o estado de repouso revelou regiões associadas a conceitos anatômicos de conectividade e integração cerebral sob diferentes aspectos da rede. A idéia de caracterizar redes de conectividade através de parâmetros topológicos já foi explorada por outros grupos de pesquisa [2,30,61], entretanto, a metodologia utilizada neste trabalho possui algumas diferenças importantes discutidas a seguir.

\subsubsection{Sobre a segmentação cerebral}

Uma vantagem em segmentar o cérebro durante o pré-processamento é remover parte da substância branca que contém pouca informação neuronal e manter a substância cinzenta composta em sua maioria de corpos neuronais. Além disso, a segmentação permite identificar regiões anatomicamente distintas. [61] [2] e [50] segmentaram o cérebro em 90 estruturas anatômicas e utilizaram a média dos sinais de cada estrutura para reduzir a dimensionalidade espacial dos dados. Desta forma, aumentase a relação sinal ruído [37] enquanto preservam-se informações anatômicas. Entretanto, a média dos sinais em estruturas cerebrais representadas por milhares de voxels, como o Giro Frontal Superior, podem perder características locais do sinal BOLD e comprometer a qualidade dos resultados. Por isso, este trabalho considera ideal parcelar as estruturas após a segmentação cerebral.

[34] estudando parâmetros topológicos em redes de conectividade funcional obtidas com difer- 
entes tipos de parcelamentos concluiu que aumentar a resolução espacial (aumentar o número de parcelas) aumenta o coeficiente de agrupamento e diminui o tamanho do caminho. Portanto, reduzir a dimensionalidade espacial diminui a complexidade local da rede. O efeito da resolução espacial nos valores de parâmetros topológicos provavelmente é conseqüência da autocorrelação natural observada em sinais de regiões cerebrais muito próximas. alguma

\subsubsection{Sobre a medida de conectividade}

Pouco se sabe sobre os efeitos do uso de diferentes medidas de conectividade no estudo dos parâmetros topológicos de redes de conectividade cerebral. Em [15] os autores utilizam três tipos de métodos de análise para estimar redes de conectividade funcional no estado de repouso com diferentes tipos de equipamentos, parâmetros de aquisição de imagem e centros de pesquisa espalhados pelo mundo. Os autores concluíram que existem evidências de uma arquitetura funcional intrínseca e universal no cérebro humano, ou seja, regiões cerebrais com flutuações espontâneas de sinal BOLD autocorrelacionadas independentemente do método de análise.

Medidas de conectividade bidirecionais e multivariadas no contexto de RMf, ou seja, envolvendo mais variáveis que observações, em geral restringem o número de regiões analisadas simultaneamente [36] ou o número máximo de conexões admissíveis na estrutura de conectividade [50,81]. Buscando estudar relações causais sem fazer uso de tais hipóteses, este trabalho adotou a coerência direcionada por ser uma medida de conectividade no domínio da freqüência, direcionada e estimada por modelos bivariados.

A banda de freqüência foi escolhida com base em estudos recentes sobre flutuações espontâneas do sinal BOLD. Embora a taxa de amostragem das imagens analisadas neste trabalho seja baixa (0, 3 $\mathrm{Hz}$ ) e possa provocar aliasing dos sinais cardíacos e respiratórios de alta freqüência para as baixas freqüências, [22] mostrou que correlações entre regiões cerebrais durante o estado de repouso possuem mais influência de sinais de baixa freqüência entre 0,01 e $0,1 \mathrm{~Hz}$ que do ruído fisiológico.

\subsubsection{Sobre a construção das redes}

Neste trabalho grafos direcionados e pesados foram utilizados para representar a interdependência temporal de sinais de ressonância magnética funcional entre regiões cerebrais distintas. Grafos pesados permitem quantificar padrões de conectividade de maneira consistente mesmo com possibilidade de relações (arestas) espúrias. Relações entre regiões com forte conectividade são mais valorizadas 
pelos índices enquanto que relações espúrias tendem a ser mais fracas e portanto menos valorizadas (ainda que esta afirmação não seja comprovada formalmente).

Grafos direcionados permitem avaliar características temporais da conectividade que estão relacionadas aos conceitos de causalidade no sentido de Granger [50]. Entretanto, a causalidade de Granger se baseia no conceito de precedência temporal, ou seja, uma série temporal Granger-causa outra série se o passado da primeira conter informações que reduz o erro de predição da segunda. Sabese que características temporais do sinal de RMf dependem da velocidade da resposta hemodinâmica que pode variar de região para região. Portanto, em alguns casos, a causalidade de Granger pode refletir a defasagem na resposta hemodinâmica entre duas regiões cerebrais em vez de interações entre populações de neurônios.

\subsubsection{Sobre os índices}

Os índices Degree, Closeness, Betweenness, Hub e Authority estabelecem conexão entre estrutura e função, ou seja, revelam papéis associados a regiões cerebrais durante o processamento cognitivo. Estes termos são mais intuitivos que os conceitos de rede mundo pequeno, eficiência, distribuição do grau de conectividade dos vértices e capacidade de sincronia.

Quando a teoria dos grafos foi aplicada da maneira proposta neste trabalho aos dados do projeto conectome ${ }^{1}$ os resultados foram coerentes com os modelos clássicos da literatura a respeito da neuroanatomia e neurofisiologia encefálica $[39,54]$. A seguir estes resultados são discutidos dentro do contexto neurofisiológico.

\section{Degree}

As regiões identificadas pelo índice Degree possuem elevado número de conexões funcionais independentemente da direção, pois o Degree de uma região é a soma do número de arestas que saem com o número de arestas que entram na região. As regiões do tálamo, núcleo caudado e putame foram completamente identificadas pelo índice Degree. Estas regiões, anatomicamente, fazem parte da mais extensa e organizada estrutura de conectividade envolvendo praticamente todo o encéfalo [71]. Como esperado, o tálamo é o relé cerebral e o principal elo entre estímulos sensíveis e o córtex cerebral. A maioria das conexões anatômicas envolvendo tálamo-córtex é recíproca, ou seja, regiões corticais recebem axônios de regiões do tálamo que recebem seus axiônios. O núcleo caudado e o putâmen, comu-

\footnotetext{
${ }^{1}$ Veja o capítulo 3
} 
Tabela 5.1: Tipo funcional, nome, área de Brodman das principais regiões corticais identificadas pela análise da rede de conectividade.

\begin{tabular}{|l|l|c|c|c|c|c|c|}
\hline Sistema & Brodman & Degree & Betweenness & Closeness & Authority & Hub \\
\hline Multimodal & Córtex Frontal Medial & 32 & $\mathrm{X}$ & & & & \\
Multimodal & Giro Frontal Superior & 9 & $\mathrm{X}$ & & & & $\mathrm{X}$ \\
Multimodal & Pólo Frontal & 10 & $\mathrm{X}$ & & & & $\mathrm{X}$ \\
Multimodal & Parietal Inferior & Córtex Pré-Cúneo & 79,40 & $\mathrm{X}$ & $\mathrm{X}$ & & \\
Paralímbico & Córtex Orbitofrontal & 12 & $\mathrm{X}$ & & & $\mathrm{X}$ & $\mathrm{X}$ \\
Paralímbico & Cíngulo Anterior & 23,24 & & & $\mathrm{X}$ & $\mathrm{X}$ & $\mathrm{X}$ \\
Paralímbico & Cíngulo Posterior & 23,31 & $\mathrm{X}$ & $\mathrm{X}$ & $\mathrm{X}$ & $\mathrm{X}$ & $\mathrm{X}$ \\
Paralímbico & Córtex Parahipocampal & 28 & $\mathrm{X}$ & & $\mathrm{X}$ & $\mathrm{X}$ & \\
Paralímbico & Córtex Insular & 13 & & & $\mathrm{X}$ & $\mathrm{X}$ & \\
Límbico & Hipocampo & 28 & $\mathrm{X}$ & & $\mathrm{X}$ & $\mathrm{X}$ & \\
Unimodal & Giro Temporal Inferior & 37 & $\mathrm{X}$ & & & $\mathrm{X}$ & \\
Unimodal & Giro Temporal Médio & 21 & $\mathrm{X}$ & & & $\mathrm{X}$ & \\
Unimodal & Córtex Occipital Lateral & 19 & & & & $\mathrm{X}$ & \\
\hline
\end{tabular}

mente referidos como estriado, está altamente conectado com o cérebro, recebe projeções excitatórias de praticamente todo o córtex cerebral e dos núcleos intralaminar e ventrolateral do tálamo [71]. Funcionalmente, o estriado está envolvido no controle e modulação do movimento e provavelmente no processamento cognitivo de funções executivas [39]. Como o estriado e os núcleos subtalâmicos são portões de entrada para toda informação que chega até os núcleos da base, é esperado que estas regiões possuam altos índices de conectividade funcional.

As regiões corticais identificadas pelo índice Degree estão resumidas na Tabela 5.1.4 e em sua maioria fazem parte de sistemas multimodais de integração. Este resultado concorda com outros resultados da literatura. [70] e [2] observaram que o comprimento médio dos menores caminhos ligando áreas associativas multimodais a outras regiões cerebrais geralmente são menores que o comprimento médio dos menores caminhos de redes de conectividade anatômica e funcional.

Para [39], o conceito de sistemas de integração integrativos é de extrema importância para entender o funcionamento cerebral. Estudos com macacos e seus respectivos mapeamentos em humanos (através de lesões e ressonância magnética funcional) buscam explicar a função cognitiva de tais regiões cerebrais indicando resumidamente que [54]:

1. Os córtices Frontal Medial (B12) e Orbitofrontal (B32) estão envolvidos no controle de funções executivas e do comportamento.

2. O Giro Frontal Superior (B12) e o Pólo Frontal (B32) são áreas de integração multimodais e possuem diversas funções complexas. Basicamente, estes giros fazem parte de sistemas envolvi- 
dos no controle de funções executivas, atenção e gerenciamento da memória de trabalho.

3. Os giros Temporal Inferior (B37) e Temporal Médio (B21) são áreas associativas unimodais relacionadas ao processamento da informação visual especificamente no reconhecimento de faces e identificação de objetos.

4. O Giro do Cíngulo (B23,B24), córtex Parahipocampal e o hipocampo (B28) formam regiões cujo a função está associada ao processamento da informação de caráter emocional no aprendizado e na formação da memória.

5. As regiões do Córtex Parietal Inferior (B39,B40), Cíngulo Posterior (B31) e Pré-Cúneo (B7b) são áreas de integração somatosensoriais. O córtex Pré-Cúneo, em relação a demais regiões cerebrais, possui as maiores taxas de consumo metabólico de glucose durante o estado de repouso e abrangente estrutura de conectividade anatômica envolvendo muitas estruturas corticais e subcorticais.

\section{Betweenness}

O índice Betweenness valoriza regiões presentes na maioria dos menores caminhos existentes na rede. Tais regiões são consideradas pontos preferenciais (com maior probabilidade) para a passagem da informação. Embora integradas, acredita-se que regiões cerebrais aproximadamente do tamanho de um voxel de RMf responda somente a estímulos da mesma natureza [69]. Este conceito é conhecido como especialização. Portanto, é esperado que poucas ou até mesmo nenhuma região cerebral, tenha altos índices de Betweenness. Na Tabela 5.1.4 o índice Betweenness apresenta somente regiões cerebrais que formam zonas de convergência somatosensorial (B39,B40,B31 e B7b) e consideradas regiões centrais na integração da informação exterior com a informação gerada internamente no cérebro [21].

\section{Closeness}

O índice Closeness procura identificar regiões cerebrais relativamente mais próximas do restante da rede. Curiosamente, a Figura 4.3 mostra que o índice Closeness identificou regiões anatomicamente centrais dentro do encéfalo dando destaque principalmente para o tronco encefálico. É no tronco encefálico que se encontra a formação reticular ascendente da qual saem axônios nas direções do tálamo, medula espinhal e córtex cerebral. A formação reticular ascendente regula funções complexas do sistema nervoso mantendo os níveis basais de atenção e comportamento humano [39]. 


\section{Hub e Authority}

A relação entre os índices Hub e Authority permite decompor a rede de conectividade em regiões que enviam e regiões que recebem grande número de conexões. A Tabela 5.1.4 mostra que áreas associativas multimodais responsáveis por funções cognitivas mais complexas (B9, B10, B38, B40) tem altos índices de $H u b$ enquanto que regiões responsáveis pelo processamento visual (B19, B21, B37) e o complexo hipocampal (B28) tem altos índices de Authority. Os índices tem em comum as regiões Giro do Cíngulo (B23,B24), Pré-Cúneo (B7b) e Orbitofrontal (B32) regiões responsáveis pelo comportamento e estados emocionais.

Certamente este é um dos resultados mais importantes deste trabalho. Com base nele pode se sugerir que as flutuações espontâneas no sinal de RMf entre diferentes regiões cerebrais durante o estado de repouso refletem padrões de conectividade funcional onde as regiões assumem diferentes papéis funcionais fortemente associados a conceitos neurofisiólogicos.

\subsection{Redes do estado de repouso}

Observa-se grande associação dos resultados apresentados na Tabela 5.1.4 com regiões da Default Mode Network (Pré-Cúneo, Córtex Frontal Medial, Parietal Inferior e Giro Temporal) e da Core Network (Cíngulo Anterior e bilateralmente Córtex Insular e Lobos Temporais). Estas redes são frequëntemente encontradas em estudos de estado de repouso (veja a seção A.5 para mais detalhes). Acredita-se que a Default Mode Network e a Core Network estejam envolvidas no processamento da consciência humana [35, 41, 58] e outras funções características do homem [28].

\subsection{Programa e custo computacionais}

O método possui alto custo computacional, é possível processar 3 indivíduos simultaneamente utilizando um computador com $4 \mathrm{G}$ de memória e 4 processadores de $2 \mathrm{GHz}$ em 48 horas. Todo o ferramental desenvolvido e utilizado neste trabalho (modelos estatísticos e rotinas computacionais) estão implementados na linguagem de programação Python e podem ser encontrados para download no site http://www.lcs.poli.usp.br/ gvieira. 


\section{Capítulo 6}

\section{Conclusão}

O desenvolvimento recente da análise quantitativa de redes complexas tem mostrado que o cérebro, tanto estruturalmente quanto funcionalmente, possui características de redes complexas [18]. Por construção, parâmetros topológicos estão relacionados a padrões de conectividade funcional e conseqüentemente a mecanismos neurais de processamento cognitivo.

A análise dos 198 sujeitos sugere que o estudo cerebral através da parametrização da rede de conectividade funcional é consistente e apresenta resultados interessantes e biologicamente plausíveis. É provável que os padrões de conectividade funcional em RMf observados no estado de repouso são frutos das interações entre regiões anatomicamente bem conectadas entre si.

Uma possibilidade de desenvolvimento futuro a partir do nosso trabalho é aplicar a técnica desenvolvida em grupos de pacientes psiquiátricos. Algumas desordens psiquiátricas são consideradas síndromes de desconectividade cerebral [18,27], por exemplo a esquizofrenia, a doença de Parkinson e o mal de Alzheimer. Identificar papéis em regiões cerebrais de pacientes com síndromes pode ser fundamental para entender os principais distúrbios destas doenças. Stam [73] comparou mudanças na redes de conectividade funcional medidas por MEG durante o estado de repouso em pacientes com a doença de Alzheimer com controles sadios. Sujeitos com a doença de Alzheimer apresentaram diminuição nos valores dos parâmetros coeficiente de agrupamento e tamanho do caminho. Isto sugere um padrão de conectividade mais aleatório em sujeitos com a doença de Alzheimer comparados a controles sadios.

Futuramente, outros conceitos da teoria dos grafos poderão ser incorporados na análise da conectividade cerebral. Os conceitos de grau restrição do sujeito (vértice) na sociedade [19] e de comunidade [57] são bastante utilizados em estudos de redes sociais. Um vértice é restrito na rede quando 
os vértices de sua vizinhança se interagem pouco com vértices fora da vizinhança. Uma comunidade é um subconjunto de vértices agrupados que se relacionam (se conectam) mais com os próprios elementos (vértices) da comunidade que com os elementos fora da comunidade. Estes conceitos podem ser utilizados para dividir o cérebro utilizando conceitos de conectividade.

O estudo detalhado dos sistemas neurais depende da evolução de técnicas de segmentação cerebral, redução de dimensionalidade, estimação da conectividade cerebral. O aperfeiçoamento de tais técnicas permitirá construir redes de conectividade devidamente delineadas, mais robustas e com menos relações espúrias de conectividade. 


\section{Apêndice A}

\section{Ressonância Magnética Funcional}

Intervenções cerebrais, acidentais (lesões) ou não acidentais (estimulação neuronal) produzem medidas diretamente relacionadas com o funcionamento cerebral e com o comportamento em geral [44]. Nos últimos anos, tem-se feito muito uso de imagens por RMf para construir mapas indiretamente relacionados ao nível de atividade neuronal durante um experimento. Produzir mapas através de dados de RMf adquiridos de voluntários sadios ou pacientes requer conhecimento multidisciplinar [63] envolvendo ciências cognitivas, física, engenharia e estatística.

A RMf possui uma grande vantagem: adquire dados sem perturbar o sistema (cérebro). A RMf é uma técnica não evasiva e "teoricamente" o cérebro dento do aparelho de RMf se comporta como se estivesse fora dele. "Teoricamente", pois algumas mudanças de fato acontecem. Para produzir imagens de RMf é necessário que o sujeito entre em um equipamento cilíndrico de aproximadamente $60 \mathrm{~cm}$ de largura e $120 \mathrm{~cm}$ de comprimento. Durante a aquisição das imagens o equipamento produz um ruído acústico que pode chegar a $120 \mathrm{~dB}$ [5]. Ademais, o sujeito precisa se manter imóvel durante o experimento (ou tentar não se mexer) para evitar artefatos de movimento que podem comprometer a qualidade dos dados. Outra vantagem do sinal de RMf é sua alta resolução espacial (1 - $10 \mathrm{~mm})$. É possível observar quase simultaneamente todas estruturas cerebrais em apenas uma aquisição.

\section{A.1 Bases físicas da RMf}

\section{A.1.1 Os estados energéticos e excitação}

A ressonância magnética nuclear $(\mathrm{RMN})$ é uma técnica que utiliza as propriedades presentes em isótopos que possuem número ímpar de prótons e/ou nêutrons Devido a energia térmica, as partículas 
Tabela A.1: Constantes encontradas em núcleos com propriedades de ressonância magnética

\begin{tabular}{|c|c|c|c|c|c|}
\hline elemento & spin & $\gamma\left(s^{-1} T^{-1}\right)$ & na natureza (\%) & no corpo humano & $\nu_{0}$ em 1 Tesla $(\mathrm{MHz})$ \\
\hline${ }^{1} \mathrm{H}$ & $1 / 2$ & $2,675 \times 10^{8}$ & 99,98 & $88 M$ & 42,573 \\
${ }^{13} \mathrm{C}$ & $1 / 2$ & $6,726 \times 10^{7}$ & 1,11 & - & 10,705 \\
${ }^{19} \mathrm{~F}$ & $1 / 2$ & $2,517 \times 10^{8}$ & 100 & $4 \mu M$ & 40,052 \\
\hline
\end{tabular}

nucleares dos átomos apresentam movimento giratório denominado spin. Durante o spin, a massa do isótopo gera momento angular $\boldsymbol{J}$ (força rotacional) enquanto que a carga elétrica positiva do próton gera momento magnético $\boldsymbol{\mu}$ (tendência de alinhamento com o campo magnético) e ambos possuem a mesma direção, portanto:

$$
\boldsymbol{\mu}=\gamma \boldsymbol{J}=\gamma \hbar \boldsymbol{I}
$$

A constante $\gamma$ conhecida como razão giromagnética é específica de cada núcleo, $\hbar$ é a constante de Planck reduzida, ou seja, $\hbar=h / 2 \pi$ e $h$ é a constante de Planck. O vetor $\boldsymbol{I}$ corresponde ao spin do núcleo. De acordo com a física quântica, o spin de um núcleo possui finitos estados diferentes. Portanto, a componente $z$ de $\boldsymbol{J}$ pode ser escrita como:

$$
J_{z}=m \hbar
$$

em que $\{S, m\} \subset \mathbb{N}$ e $-S<=m<=S$. Alguns exemplos de constantes encontradas em núcleos com propriedades de ressonância magnética podem ser encontrados na Tabela A.1.1.

Basicamente, o fenômeno de ressonância magnética ocorre quando um sistema composto de um núcleo com spin não nulo e um campo magnético $\boldsymbol{B}_{\mathbf{0}}$ recebe energia devido à outro campo magnético ocilante $\boldsymbol{B}_{\mathbf{1}}$ [48]. Para que o spin mude de estado, ele deve receber ou emitir energia na forma de um pulso eletromagnético [44]. A energia recebida pelo núcleo é devolvida para o ambiente e pode ser medida por outro sistema de bobinas que transformam energia eletromagnética em energia elétrica.

A energia de um fóton absorvido é $E=h \nu_{0}$, em que $\nu_{0}$ é a sua radiofreqüência de ressonância e $h$ a constante de Planck. Para que haja ganho de energia a freqüência de ocilação $\omega$ de $\boldsymbol{B}_{\mathbf{1}}$, necessariamente deve obedecer a seguinte equação:

$$
h \nu_{0}=\hbar \omega=\left|E_{i}-E_{i^{\prime}}\right|=|\Delta E|
$$


$E_{i}$ e $E_{i^{\prime}}$ correspondem às energias de Zeeman de interação entre o momento magnético $\boldsymbol{\mu}$ e o campo magnético $\boldsymbol{B}_{\mathbf{0}}$.

Para exemplificar, considere uma barra presa pela ponta a outra barra formando um ângulo de 90 graus. Considere também que primeira barra possa rodar em torno da segunda que está fixa perpendicular ao campo gravitacional. Os pontos de equilíbrio da primeira barra em relação ao campo gravitacional são para baixo ou para cima. A energia necessária para mudar o estado de um spin é análoga a energia necessária para mudar o estado de baixa energia da barra paralela ao campo gravitacional (para baixo) para um estado de maior energia antiparalelo ao campo gravitacional. Ambos estados são estáveis, portanto tendem a permanecer nesta posição à menos que sejam perturbados.

Quando um spin está em equilíbrio térmico, sua energia está uniformemente distribuída entre os diferentes estados, porém, em um campo magnético $\boldsymbol{B}_{\mathbf{0}}$, sua energia potencial é dada pela seguinte equação [48]:

$$
E=-\boldsymbol{\mu} \boldsymbol{B}_{0}
$$

Como $\boldsymbol{B}_{0}$ geralmente está orientado no eixo $z$, a equação A.4 se resume em

$$
E=-\mu_{z} B_{0}=-\gamma J_{z} B_{0}=-\gamma m \hbar B_{0}
$$

Em um campo magnético uniforme a interação entre o momento magnético nuclear e o campo magnético $\boldsymbol{B}_{\mathbf{0}}$ faz que a distribuição de energia seja não uniforme entre cada um dos $m$ estados.

Em isótopos de ${ }^{1} H$ são admitidos somente dois estados quânticos, um estado de baixa energia, paralelos ao campo magnético $\left(m=\frac{1}{2}\right)$ e um estado de alta energia, anti-paralelos ao campo magnético $\left(m=-\frac{1}{2}\right)$. Portanto, a diferença $\Delta E$ de energia entre os dois estados no spin de um núcleo de hidrogênio é:

$$
\Delta E=\gamma \hbar B_{0}
$$

Da mesma forma, a diferença de energia entre os dois estados pode ser calculada integrando-se o torque $\tau$ exercido na partícula devido a iteração do campo magnético com seu momento magnético entre 0 e 180 graus [44].

$$
\Delta E=-\int_{0}^{\pi} \tau \mathrm{d} \theta=-\int_{0}^{\pi} \mu B_{0} \sin \theta \mathrm{d} \theta=2 \mu B_{0}
$$


juntando as duas equações anteriores obtém a freqüência de ressonância necessária em A.3 para que haja mudança de estado no spin de um núcleo de hidrogênio:

$$
\omega=\frac{\Delta E}{\hbar}=\frac{2 \mu B_{0}}{\hbar}=\frac{2 \gamma J_{z} B_{0}}{\hbar}=\frac{\gamma \hbar B_{0}}{\hbar}=\gamma B_{0}
$$

Portanto, para o sistema ganhar energia $\omega$ deve ser igual a razão giromagnética (freqüência de precessão de Larmor de um núcleo em um campo magnético constante) multiplicado pela intensidade do campo magnético.

\section{A.1.2 O vetor de magnetização total}

No tecido biológico, existe grande quantidade de prótons, cada um com seu momento magnético. O vetor de magnetização total $\boldsymbol{M}$ de um volume é a soma de todos os momentos de seus prótons individuais. O átomo de hidrogênio é o mais abundante no corpo humano. Todo o restante desta sessão foca especificamente nas propriedades do vetor de magnetização total de prótons de hidrogênio. Na ausência de campo magnético a magnetização total é nula, pois não existe direção preferida para cada momento. Sob a ação de campo magnético uniforme, os momentos magnéticos dos prótons se alinham com o campo. $P_{p}$ por cento permanecem no estado paralelo e $P_{a}$ por cento permanecem no estado antiparalelo ao campo. O vetor de magnetização total é dado pela seguinte equação [44]:

$$
\boldsymbol{M}=\left(P_{p}-P_{a}\right) n \mu_{z} \overrightarrow{\boldsymbol{k}}=\frac{\Delta E}{2 k_{B} T} n \mu_{z} \overrightarrow{\boldsymbol{k}}=\frac{\gamma h n \mu_{z} B_{0}}{4 k_{B} T} \overrightarrow{\boldsymbol{k}}
$$

$n$ número de prótons por unidade de volume

$\mu_{z}$ momento magnético ao longo da componente $z$

$\overrightarrow{\boldsymbol{k}}$ vetor unitário na direção do eixo $z$

$k_{B}$ constante de Boltzmann

$T$ temperatura

Portanto, sobre temperatura constante $\boldsymbol{M}$ é constante e proporcional a $B_{0}$. O estado paralelo ao campo magnético possui menor energia, portanto a probabilidade de existirem momentos magnéticos no estado paralelo à $\boldsymbol{B}_{\mathbf{0}}$ é maior que a probabilidade de existirem momentos magnéticos no estado 
antiparalelo à $\boldsymbol{B}_{\mathbf{0}}$. Logo, a magnetização total na condição de equilíbrio possui um valor positivo somente na direção de $\boldsymbol{B}_{\mathbf{0}}$ e valores nulos nas outras direções.

A equação A.9 sugere que propriedades quânticas de um sistema composto de momentos magnéticos podem ser analisadas utilizando modelos de mecânica clássica. Embora somente a mecânica quântica possa explicar completamente o fenômeno de ressonância magnética [48], o movimento e consequentemente o sinal gerado por $\boldsymbol{M}$ pode ser explicado por teorias clássicas de eletromagnetismo. Por exemplo, caso $\boldsymbol{M}$ seja perturbado da posição de equilíbrio, $\boldsymbol{M}$ irá precessar (movimento giroscópio exibido pelo eixo de rotação do núcleo sobre a ação de um campo magnético), com movimento determinado pela seguinte equação

$$
\frac{\mathrm{d} \boldsymbol{M}}{\mathrm{d} t}=\gamma \boldsymbol{M} \times \boldsymbol{B}_{\mathbf{0}}
$$

cuja solução mostra a evolução do vetor de magnetização total a partir de uma posição inicial $\left(M_{x}(0), M_{y}(0), M_{z}(0)\right)$, isto é:

$$
\boldsymbol{M}(t)=\left(M_{x}(0) \cos \omega t+M_{y}(0) \sin \omega t\right) \overrightarrow{\boldsymbol{i}}+\left(M_{y}(0) \cos \omega t-M_{x}(0) \sin \omega t\right) \overrightarrow{\boldsymbol{j}}+M_{z}(0) \overrightarrow{\boldsymbol{k}}
$$

em que $\omega=\gamma B_{0}$, ou seja, $\omega$ é igual a freqüência de Larmor do núcleo sob um campo magnético $\boldsymbol{B}_{\mathbf{0}}$.

Na presença de um campo magnético $\boldsymbol{B}_{\mathbf{1}}$, com magnitude igual a $B_{1}$, linearmente polarizado, perpendicular à $\boldsymbol{B}_{\mathbf{0}}$ e com uma freqüência de oscilação $\boldsymbol{\omega}$ (neste caso $\boldsymbol{B}_{\mathbf{1}}$ é um pulso de rádio freqüência),

$$
\boldsymbol{B}_{\mathbf{1}}=\left(B_{1} \cos \omega t\right) \overrightarrow{\boldsymbol{i}}
$$

o movimento de $M$ é descrito pela seguinte equação

$$
\frac{\mathrm{d} \boldsymbol{M}}{\mathrm{d} t}=\gamma \boldsymbol{M} \times\left(\boldsymbol{B}_{\mathbf{0}}+\boldsymbol{B}_{\mathbf{1}}\right)
$$

a solução de A.13 obtém uma melhor interpretação através da seguinte transformações de variáveis

$$
\left[\begin{array}{l}
a_{i^{\prime}} \\
a_{j^{\prime}} \\
a_{k^{\prime}}
\end{array}\right]=\left[\begin{array}{ccc}
\cos \omega t & -\sin \omega t & 0 \\
\sin \omega t & \cos \omega t & 0 \\
0 & 0 & 1
\end{array}\right]\left[\begin{array}{l}
a_{i} \\
a_{j} \\
a_{k}
\end{array}\right]
$$

que basicamente representa um novo sistema de coordenadas que gira em torno do eixo $z$ na mesma freqüência que $\boldsymbol{B}_{\mathbf{1}}$. 
A equação A.13 no novo sistema de coordenadas é

$$
\frac{\mathrm{d} \boldsymbol{M}}{\mathrm{d} t}=\gamma \boldsymbol{M} \times \gamma\left[\frac{B_{1}}{2} \overrightarrow{\boldsymbol{i}^{\prime}}+\left(B_{0}-\frac{\omega}{\gamma}\right) \overrightarrow{\boldsymbol{k}^{\prime}}\right]
$$

De acordo com A.15, $\boldsymbol{M}$ irá precessar em torno de $\frac{B_{1}}{2} \overrightarrow{\boldsymbol{i}^{\prime}}+\left(B_{0}-\frac{\omega}{\gamma}\right) \overrightarrow{\boldsymbol{k}^{\prime}}$ em relação ao novo sistema de coordenadas. Caso a freqüência de oscilação de $\boldsymbol{B}_{\mathbf{1}}$ seja exatamente a freqüência de Larmor $\left(B_{0} \gamma\right)$, $M$ irá precessar em torno do eixo $x$ com freqüência angular igual à $\gamma B_{1} / 2$. Portanto, para um pulso com duração de $t=\pi / 2\left(\gamma B_{1} / 2\right)$, o vetor de magnetização total é colocado $90^{\circ}$ da sua posição original, ou seja, sobre o eixo $x$. Essa excitação é conhecida como pulso de $90^{\circ}$.

\section{A.1.3 As equações de Bloch}

Em 1946 Bloch apresentou suas equações fenomenológicas [16] com o intuito de explicar algumas características do modelo clássico de livre movimento do momento magnético. No modelo de Bloch, após a excitação do sistema, são perturbações térmicas que causam o relaxamento longitudinal de $M_{z}$ (na direção de $\boldsymbol{B}_{\mathbf{0}}$ ) até seu estado de equilíbrio $\left(M_{z}=M_{0}\right)$. No mesmo modelo, Bloch sugere que são interações entre os núcleos excitados que causam o relaxamento transversal de $\boldsymbol{M}_{t r}=\left\{M_{x}, M_{y}\right\}$.

A dinâmica de $M_{z}$ e $\boldsymbol{M}_{t r}$ de acordo com as equações de Bloch é dada por

$$
\begin{array}{r}
\frac{\mathrm{d} M_{z}}{\mathrm{~d} t}=\frac{M_{0}-M_{z}}{T_{1}} \\
\frac{\mathrm{d} M_{x}}{\mathrm{~d} t}=-\frac{M_{x}}{T_{2}}+\gamma M_{y} B_{0} \\
\frac{\mathrm{d} M_{y}}{\mathrm{~d} t}=-\frac{M_{y}}{T_{2}}-\gamma M_{x} B_{0}
\end{array}
$$

As constantes $T_{1}$ e $T_{2}$ são conhecidas respectivamente como tempo de relaxamento spin-lattice e tempo de relaxamento spin-spin, e controlam respectivamente os decaimentos longitudinal e transver- 
sal dados pela resolução de A.16

$$
\begin{array}{r}
M_{z}=M_{0}+\left[M_{z}(0)-M_{0}\right] e^{-t / T_{1}} \\
M_{x}=\left[M_{x}(0) \cos \left(\omega_{0} t\right)+M_{y}(0) \sin \left(\omega_{0} t\right)\right] e^{-t / T_{2}} \\
M_{y}=\left[-M_{x}(0) \sin \left(\omega_{0} t\right)+M_{y}(0) \cos \left(\omega_{0} t\right)\right] e^{-t / T_{2}}
\end{array}
$$

$\omega_{0}=\gamma B_{0}$ e $\left[M_{x}(0), M_{y}(0), M_{z}(0)\right]$ são valores de $\boldsymbol{M}$ logo após o pulso de $90^{\circ}$.

A movimento de $\boldsymbol{M}_{t r}$ pode ser escrita de maneira mais compacta

$$
\begin{array}{r}
\boldsymbol{M}_{t r}=M_{x}+\mathbf{i} M_{y} \\
\boldsymbol{M}_{t r}=\boldsymbol{M}_{t r}(0) e^{-\mathbf{i} \omega_{0} t-t / T_{2}}
\end{array}
$$

Na prática, devido a inomogeneidade do campo magnético, o decaimento transversal é mais rápido que o esperado [48]. O efeito combinado da interação entre os prótons (spin-spin) da inomogeneidade do campo [44] produz o decaimento $T_{2}^{*}$ caracterizado pela constante $T_{2}^{*}$.

$$
\boldsymbol{M}_{t r}=\boldsymbol{M}_{t r}(0) e^{-\mathbf{i} \omega_{0} t-t / T_{2}^{*}}
$$

A equação de Block levando em conta $T_{2}^{*}$ e a presença do campo magnético $\boldsymbol{B}_{\mathbf{1}}$ pode ser aproximada (considerando $\boldsymbol{B}_{\mathbf{1}} \ll \boldsymbol{B}_{\mathbf{0}}$ ) pela seguinte equação

$$
\frac{\mathrm{d} \boldsymbol{M}}{\mathrm{d} t}=\gamma \boldsymbol{M} \times\left(\overrightarrow{\boldsymbol{k}} B_{0}+\boldsymbol{B}_{\mathbf{1}}\right)-\frac{\boldsymbol{M}_{t r}}{T_{2}^{*}}-\overrightarrow{\boldsymbol{k}} \frac{M_{z}-M_{0}}{T_{1}}
$$

\section{A.2 Recepção do Sinal}

De acordo com o princípio da reciprocidade [1], a força eletromotriz induzida na bobina de rádio freqüência para recepção do sinal após a excitação transversal é dada pela seguinte equação

$$
\mathrm{emf}=\mu_{0} N L^{-1} V \omega_{0} M_{0} e^{-t / T_{2}^{*}} \cos \left(\omega_{0} t+\phi\right)
$$


onde $\mu_{0}$ é constante, $L$ e $N$ são respectivamente o tamanho e o número de voltas da bobina de recepção, $V$ o volume analisado, $\omega_{0}$ a freqüência de Larmor do núcleo observado e $\phi$ é uma fase que depende do pulso de excitação [48]. A equação A.20 mostra o sinal observado conhecido como FID (do inglês Free Induction Decay). Assumindo que o tempo de aquisição se inicia em $t=0$, o espectro de RM é

$$
S(\omega)=\int_{0}^{\infty} K e^{-t / T_{2}^{*}+\mathrm{i} \phi} e^{\mathrm{i} \omega t} \mathrm{~d} t
$$

onde $K$ é constante.

A densidade espectral em A.21 mostra que o FID contém informações sobre a quantidade de núcleos em um determinado volume. Este volume inicialmente é capaz de caracterizar um único vóxel. Nas últimas décadas, várias técnicas foram desenvolvidas para a construção de imagens de todo o cérebro, dividindo-o em vários vóxels. Os desafios vão desde a criação de gradientes de freqüência e fase para a codificação espacial (em duas dimensões) até a criação de seqüências de pulso para a aquisição de várias imagens em tempo de repetição curto $(2 \mathrm{~s})$ e com boa relação sinal ruído (seqüencias conhecidas como spin-echo) [44,48]. Essa assunto vai além do escopo deste capítulo que busca apenas discutir a origem do sinal de RMf.

\section{A.3 Bases biológicas da RMf}

A RMf produz imagens cuja variabilidade está indiretamente correlacionada com a atividade cerebral [44]. A principal causa do relaxamento $T_{2}^{*}$ é a inomogeneidade do campo magnético devido as propriedades dos elementos que compõem o tecido. O contraste BOLD mede mudanças nas propriedades magnéticas da molécula de água (principal fonte de ${ }^{1} H$ no corpo humano). Mudanças quânticas nas moléculas de água ocorrem devido a mudanças na concentração de hemoglobina desoxigenada nas proximidades do tecido. A concentração de hemoglobina desoxigenada é um indicador fisiológico de consumo de oxigênio. O oxigênio é um elemento essencial para gerar de energia que será gasta durante o processamento neuronal. Essa cadeia de eventos deve obedecer as restrições neuroanatômicas e neurovasculares. A resposta hemodinâmica é o sinal observado em resposta à estímulos pré estabelecidos (Figura A.1).

O sistema nervoso basicamente é composto de neurônios e células da glia, assume-se que o neurônio seja a unidade básica de processamento da informação mental, principalmente por sua natureza binária. Um neurônio recebe sinais de outros neurônios através de sinapses realizadas nos seus dendritos e como resultado gera um potencial de ação que flui em direção do terminal axonal (Figura 


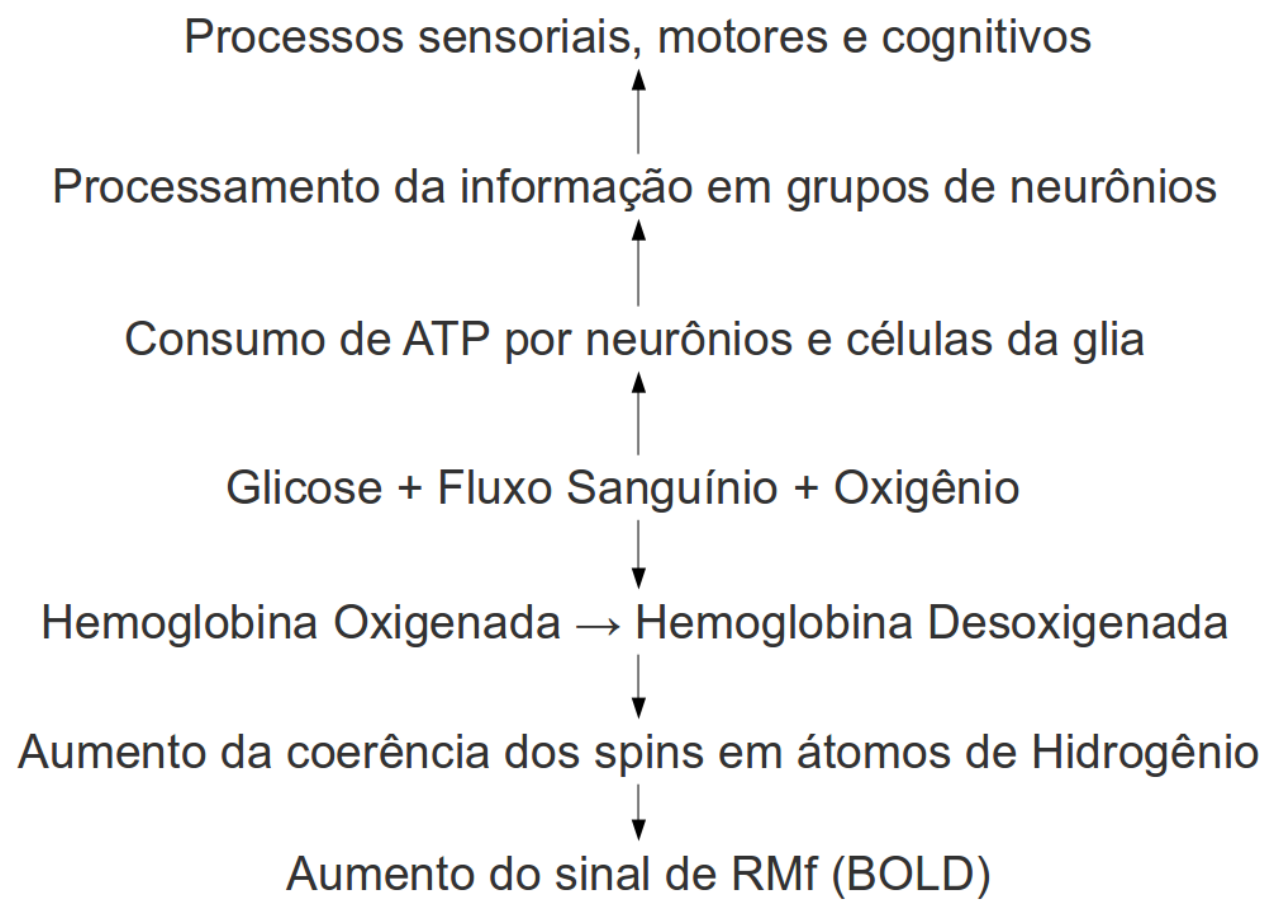

Figura A.1: Representação esquemática da cascata de eventos responsáveis pela geração do sinal BOLD.

A.2). Quando o potencial de ação chega ao terminal axonal, canais dependentes de voltagem se abrem e o influxo de íons especializados $\left(\mathrm{Ca}^{2+}\right)$ causa uma cascata de eventos bioquímicos que resulta na liberação de vesículas cheias de neurotransmissores na fenda sináptica. Os neurotransmissores alteram os canais iônios presentes na membrana pós-sináptica, permitindo que o potencial de equilíbrio da membrana pós-sináptica seja rompido, ou seja, que haja uma variação nas concentrações de íons entre o meio intra celular e extra celular. Caso a variação atinja um limiar característico da membrana neuronal, haverá um novo potencial de ação por parte do neurônio pós-sináptico.

O processo simplificado no parágrafo anterior, é muito mais complexo e possui mais variáveis [39]. O importante é saber que a menbrana neuronal necessita manter um gradiente de concentração para gerar sinal. Como este gradiente não está em equilíbrio osmótico, existe gasto de energia por parte de bombas de sódio e potássio responsáveis por trocar o sódio em excesso no meio intra celular por potássio no meio extra celular. Essa troca é feita contra o gradiente de concentração (existe mais 
sódio fora da célula que dentro da célula), exigindo consumo de ATP (adenosine triphophate).

A ATP pode ser gerada através de duas vias, uma anaeróbia (sem consumo de oxigênio) e outra aeróbica (com consumo de oxigênio). Na via anaeróbia a glicose é convertida em lactato através de um processo chamado de glicólise que produz duas moléculas de ATP. Na via aeróbia existem duas etapas além da glicólise: o ciclo de Krebs e a cadeia de transporte de elétrons. Ambas as etapas exigem a presença do oxigênio e o total de ATP produzido no final é de 34 moléculas. A equação global da oxidação completa da glicose pode ser escrita como [83]

$$
\mathrm{C}_{6} \mathrm{H}_{12} \mathrm{O}_{6}+6 \mathrm{O}_{2}+36 \mathrm{ADP}+2 \mathrm{GDP}+38 \mathrm{P}_{i} \rightarrow 6 \mathrm{CO}_{2}+6 \mathrm{H}_{2} \mathrm{O}+36 \mathrm{ATP}+2 \mathrm{GTP}
$$

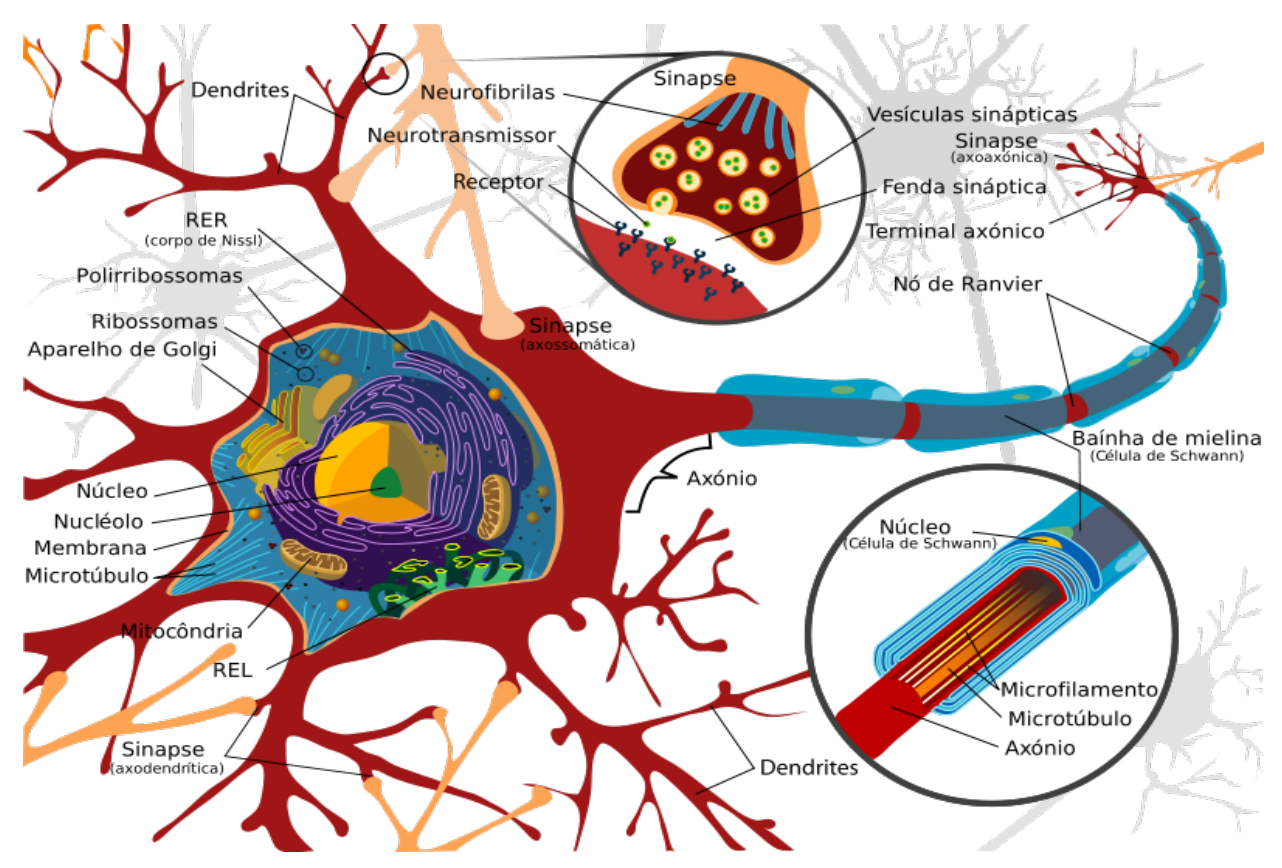

Figura A.2: O neurônio e suas sub componentes. Imagem removida de http://pt.wikipedia.org/wiki/Neurório

Embora a via anaeróbia produza menos moléculas de ATP, esta via é importante devido sua velocidade em converter a glicose em energia. Estima-se que a via anaeróbia seja 100 vezes mais rápida que a via aeróbia [44]. Embora o cérebro represente somente e $2 \%$ da massa corporal total, ele consome cerca de $25 \%$ da energia corporal total [52]. 


\section{A.3.1 A resposta hemodinâmica do efeito BOLD}

A hemoglobina desoxigenada é uma molécula paramagnética, enquanto que a hemoglobina oxigenada é não paramagnética. O campo magnético próximo à hemoglobina desoxigenada é mais intenso que próximo a hemoglobina oxigenada, consequentemente, a freqüência de Larmor dos prótons de hidrogênio é maior próximo à hemoglobina desoxigenada. O efeito BOLD acontece devido às variações locais do campo magnético causadas por paramagnetismo. A presença de hemoglobina desoxigenada causa um decréscimo no tempo de relaxamento $T_{2}^{*}$ e portanto no sinal de RMf.

O sinal BOLD depende da concentração de hemoglobina desoxigenada que depende do volume sanguíneo cerebral (CBV) e fluxo sanguíneo cerebral $(\mathrm{CBF})$ e da taxa metabólica do consumo de oxigênio $\left(\mathrm{CMRO}_{2}\right)$. Como o $\mathrm{CBV}$ depende do $\mathrm{CBF}$, quanto maior a razão $\frac{\mathrm{CBF}}{\mathrm{CMRO}_{2}}$ mais lento o decaimento $T_{2}^{*}$ e mais sinal BOLD é observado. Os métodos para detectar o efeito BOLD se baseiam em modelos para a função de resposta hemodinâmica (HRF) quando há ativação neuronal. Modelos biofísicos, como o modelo de balão [20], procuram caracterizar a HRF através de parâmetros como $\mathrm{CBV}, \mathrm{CBF}, \mathrm{CMRO}_{2}$, largura da resposta, tempo para o pico e resposta máxima. Outros modelos de HRF geralmente são aproximações de respostas observadas após estimulação elétrica [51]. Nesta linha, o mais utilizado é composto da soma de duas funções gammas [38], dado pela seguinte equação:

$$
h(t)=A\left(\frac{t}{a_{1} b_{1}}\right)^{a_{1}} e^{-\frac{t-a_{1} b_{1}}{b_{1}}}-B\left(\frac{t}{a_{2} b_{2}}\right)^{a_{2}} e^{-\frac{t-a_{2} b_{2}}{b_{2}}}
$$

em que $A=1, a_{1}=6, a_{2}=12, b_{1}=b_{2}=0,9$ e $B=0,35$. O gráfico desta função possui algumas características e pode ser observado na Figura A.3.

\section{A.4 Processamento de imagens em RM}

\section{A.4.1 Correção de movimento}

Uma experimento de RMf tipicamente produz milhares de séries temporais que correspondem à volumes em quatro dimensões (espaço e tempo) amostradas em intervalos regulares de 0,5 à 3 segundos. Pequenos movimentos da cabeça $(2 \mathrm{~mm})$ podem deslocar o tecido cerebral levando variações significativas na intensidade do sinal. A correção de movimento busca reduzir os erros devido ao movimento da cabeça durante a tarefa experimental.

Basicamente, a correção de movimento é realizada realinhando todos os volumes em relação a um 


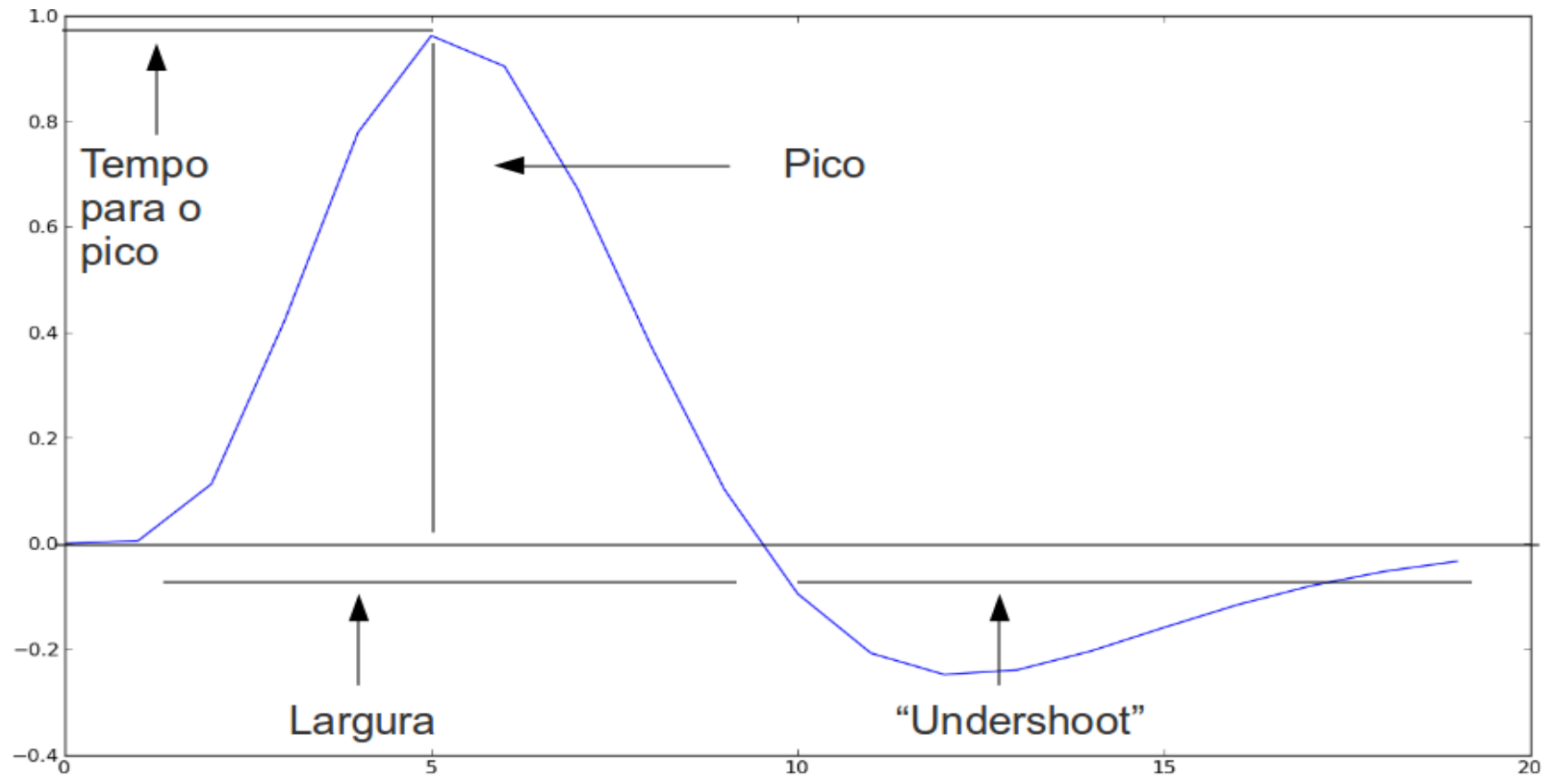

Figura A.3: Resposta hemodinâmica canônica gerada a partir da soma de duas funções gammas.

volume de referência, por exemplo, o primeiro volume. Sejam $\vec{r}=[x, y, z]$ o sistema de coordenadas espaciais do volume de referência e $\overrightarrow{r^{\prime}}=\left[x^{\prime}, y^{\prime}, z^{\prime}\right]$ o sistema de coordenadas espaciais do volume a ser alinhado. A transformação de corpo rígido de $\overrightarrow{r^{\prime}}$ para $\vec{r}$ é definida como:

$$
\overrightarrow{r^{\prime}}=\boldsymbol{R} \vec{r}+\vec{T}
$$

onde

$$
\boldsymbol{R}=\left[\begin{array}{ccc}
1 & 0 & 0 \\
0 & \cos \theta_{y} & \sin \theta_{y} \\
0 & \sin \theta_{y} & -\cos \theta_{y}
\end{array}\right]\left[\begin{array}{ccc}
\cos \theta_{p} & 0 & -\sin \theta_{p} \\
0 & 1 & 0 \\
\sin \theta_{p} & 0 & \cos \theta_{p}
\end{array}\right]\left[\begin{array}{ccc}
\cos \theta_{r} & \sin \theta_{r} & 0 \\
-\sin \theta_{r} & \cos \theta_{r} & 0 \\
0 & 0 & 1
\end{array}\right]
$$

é a matriz de rotação e $\vec{T}=\left[T_{x}, T_{y}, T_{z}\right]^{T}$ é o vetor de translação entre os dois sistemas de coordenadas.

Após a linearização de A.24 os parâmetros de rotação e translação $\theta_{p}, \theta_{r}, \theta_{y}, T_{x}, T_{y}, T_{z}$, solução do problema de movimentação da cabeça, podem ser obtidos através do método de mínimos quadrados [46]. 


\section{A.4.2 Registro}

Quando a análise envolve múltiplos sujeitos, as imagens 4D de cada sujeito devem ser registrados (mapeados) em um espaço comum (mapa estereotático ou template) para fins de comparação. Existem vários tipos de templates sendo os mais utilizados o Talairach and Tournoux [79], Montreal Neurological Institute (MNI) [32] e Human Brain Atlas. A transformação de corpo rígido apresentada em A.4.1 pode ser generalizada para o registro. A equação A.24 deve suportar dilatações e contrações lineares além das translações e rotações. De maneira geral, denomina-se transformação afim de um sistema de coordenadas $[x, y, z]^{T}$ a seguinte equação :

$$
\left[\begin{array}{c}
x^{\prime} \\
y^{\prime} \\
z^{\prime} \\
1
\end{array}\right]=\left[\begin{array}{cccc}
m_{11} & m_{12} & m_{13} & m_{14} \\
m_{21} & m_{22} & m_{23} & m_{24} \\
m_{31} & m_{32} & m_{33} & m_{34} \\
0 & 0 & 0 & 1
\end{array}\right]\left[\begin{array}{l}
x \\
y \\
z \\
1
\end{array}\right]
$$

O problema do registro se resume em determinar os parâmetros $m_{i j}$ tal que a nova imagem adquirida se encaixe dentro do template. Geralmente, utiliza-se métodos não lineares de minimização para determinar os parâmetros de A.25 [45]. Existem outras técnicas de registro que levam em conta outras características cerebrais, por exemplo, a curvatura cortical [23,33]). O problema é o mesmo (registro), porém a abordagem é diferente (utilizam-se transformações em coordenadas esféricas).

\section{A.5 Estado de repouso e RMf}

Um experimento no estado de repouso procura minimizar estímulos sensoriais e evitar que os sujeitos evoquem repostas ou realizem algum tipo de processamento cognitivo voluntário dentro da máquina de RMf [35]. Embora não seja regra, estudos em estado de repouso geralmente exigem que os sujeitos permaneçam de olhos fechados e sem cair no sono.

Recentemente foram observadas correlações de baixa freqüência $([0,01-0,1] \mathrm{Hz})$ no sinal BOLD entre diferentes regiões cerebrais enquanto os sujeitos permaneciam no estado de repouso [13,35,40]. Esta atividade síncrona, conhecida como conectividade funcional no estado de repouso, vem sendo investigada através da correlação ou coerência no sinal BOLD entre diferentes regiões cerebrais. Medidas de fluxo sanguíneo através da técnica FAIR [14] sugerem que a conectividade funcional no estado de repouso tem origem no efeito BOLD e não no CBF. Além disso, a conectividade funcional em estado de repouso está associada a padrões síncronos de disparos neuronais [66] e em 
parte à flutuações gamma $(4 \mathrm{~Hz})$ e na banda delta $(30-100 \mathrm{~Hz})$ em EEG [64]. Utilizando uma decomposição da correlação por componentes de freqüência, [22] mostrou que correlações em RMf no estado de repouso associam-se pouco aos batimentos cardíacos e movimentos respiratórios. Efeito do batimento cardíaco e freqüência respiratória no sinal BOLD podem ser reduzidos através de freqüência de amostragem alta, que significa TR de aproximadamente de 500 milissegundos. Mais importante, [66] sugere que flutuações coerentes de baixa freqüência no espectro do potencial de campo local do córtex visual de macacos estão associadas a flutuações coerentes de baixa freqüência no sinal de RMf. Porém, devido ao artefato de susceptibilidade magnética, regiões próximas ao CSF, do ar ou dos ossos do crânio como o hipocampo e o córtex orbito frontal, podem apresentar oscilações síncronas de baixa freqüência no sinal de RMf [2].

As técnicas comumente empregadas no estudo no estado de repouso são a correlação (veja seção B.2.1) a partir de um voxel semente previamente ativo durante uma tarefa de interesse, análise de componentes independentes (veja seção B.2.5) e decomposições espectrais focando padrões em baixa freqüência $(<0,1 \mathrm{~Hz})$. Independentemente do método de analise costuma-se encontrar regiões cerebrais que embora sejam anatomicamente separadas, são funcionalmente conectadas. [13] foi o primeiro a associar as correlações inter-regionais de baixas freqüências durante o estado de repouso a conectividade cerebral. Biswal utilizou sequências de pulso especializadas para adquirir imagens com TR curto e identificou regiões motoras (área motora primária e área motora suplementar) cujo o sinal de RMf estavam correlacionados mesmo após remover o ruído fisiológico. [11,24,26,61] utilizando diferentes sujeitos, parâmetros de aquisição e técnicas de processamento reportam redes de conectividade funcional com grande sobreposição nos resultados.

As regiões conectadas geralmente compartilham funções cognitivas ou comportamentais [24] e são fazem parte da rede do estado de repouso (RSN). RSN fazem parte de sistemas neurofisiológicos funcionais: visual (visual primária e extra-estriato visual), atencional (parietal superior e frontal superior esquerda e direita), Default Mode Network (DMN) (pré-cúneo, frontal medial, parietal inferior e região temporal) e a Core Network (CN) (cíngulo anterior e bilateralmente córtex insular e lobos temporais).

\section{A.6 Divisões anatômicas do Sistema Nervoso Central}

Esta seção aborda superficialmente questões da anatomia cerebral importantes para o estudo do cérebro. O sistema nervoso central (SNC) é uma estrutura simétrica e anatomicamente está dividido em [39]: 
1. Coluna Vertebral: Recebe e projeta para o córtex informações sensoriais de órgãos e nervos periféricos. Coordena o movimento dos braços e das pernas através das fibras motoras que saem dos nervos espinhais diretamente para os músculos. Existem 31 nervos espinhais contendo fibras sensoriais e motoras. Lesões na coluna vertebral podem cortar a comunicação com o cérebro de partes do corpo inervadas por fibras localizadas abaixo da área lesionada.

2. Tronco Encefálico: No tronco encefálico estão os sítios de origem ou destino das fibras de nove dos doze nervos cranianos. O tronco encefálico é subdividido em três partes que basicamente transmitem informações sensoriais e motoras para o cérebro e demais partes do corpo.

(a) Bulbo: Localiza-se acima da coluna vertebral, controla automaticamente funções vitais tais como respiração, batimento cardíaco e digestão.

(b) Ponte: Situa-se acima do bulbo, transmite informações referentes ao movimento do corpo do cérebro para o cerebelo.

(c) Mesencéfalo: Controla várias funções sensoriais e motoras incluindo o movimento ocular e a coordenação dos reflexos visuais e auditivos.

3. Cerebelo: Está conectado ao troco encefálico por tratos de fibras denominadas de pedúnculos. Está relacionado com funções motoras, como manter o equilíbrio e a postura, controlar o tônus muscular, controlar os movimentos voluntários e aprendizagem motora. Sabe-se que o cerebelo contém mais neurônios que o restante do cérebro.

4. Diencéfalo: Contém duas estruturas, o tálamo e o hipotálamo. O tálamo serve como portão para todo o tipo de informação que chega ao córtex cerebral. O hipotálamo monitora informações que chegam do sistema nervoso vegetativo (autônomo) e as transmitem aos sistemas de regulação interna.

5. Hemisférios Cerebrais: Contém as partes mais desenvolvidas do sistema nervoso central. O córtex cerebral está envolvido nas funções mais complexas do processamento cognitivo, como pensamento, planejamento e capacidade de resolver problemas. Além do córtex cerebral, encontra-se nos hemisférios cerebrais os núcleos da base, o hipocampo e o núcleo amidalóide. Os núcleos da base auxiliam na regulação do desempenho motor. O hipocampo está envolvido no processo de formação e consolidação da memória. O núcleo amidalóide coordena a resposta autônoma e endócrina dos estados emocionais. Os hemisférios cerebrais, embora possuam características estruturais bem semelhantes, o mesmo não ocorre funcionalmente. 
O córtex cerebral pode ser subdividido em regiões de fácil identificação visual denominadas de lóbulos. Durante o desenvolvimento encefálico a superfície cortical é convoluída para dentro do crânio formando gomos chamados de giros. Os espaços criados na intersecção de giros formam fissuras chamadas de sulcos. A convolução para dentro do encéfalo é realizada para maximizar a superfície cortical sujeito a restrição do espaço intracraniano. Assim, normalmente o cérebro possui conjuntos bem conhecidos de giros e sulcos (Figura A.4).

Diferenças regionais também são observadas no estudo da citoarquitetura cortical. Devido às diferenças na composição e arranjo das células neuronais, o córtex cerebral pode ser dividido em regiões conhecidas como áreas de Brodmann [39].

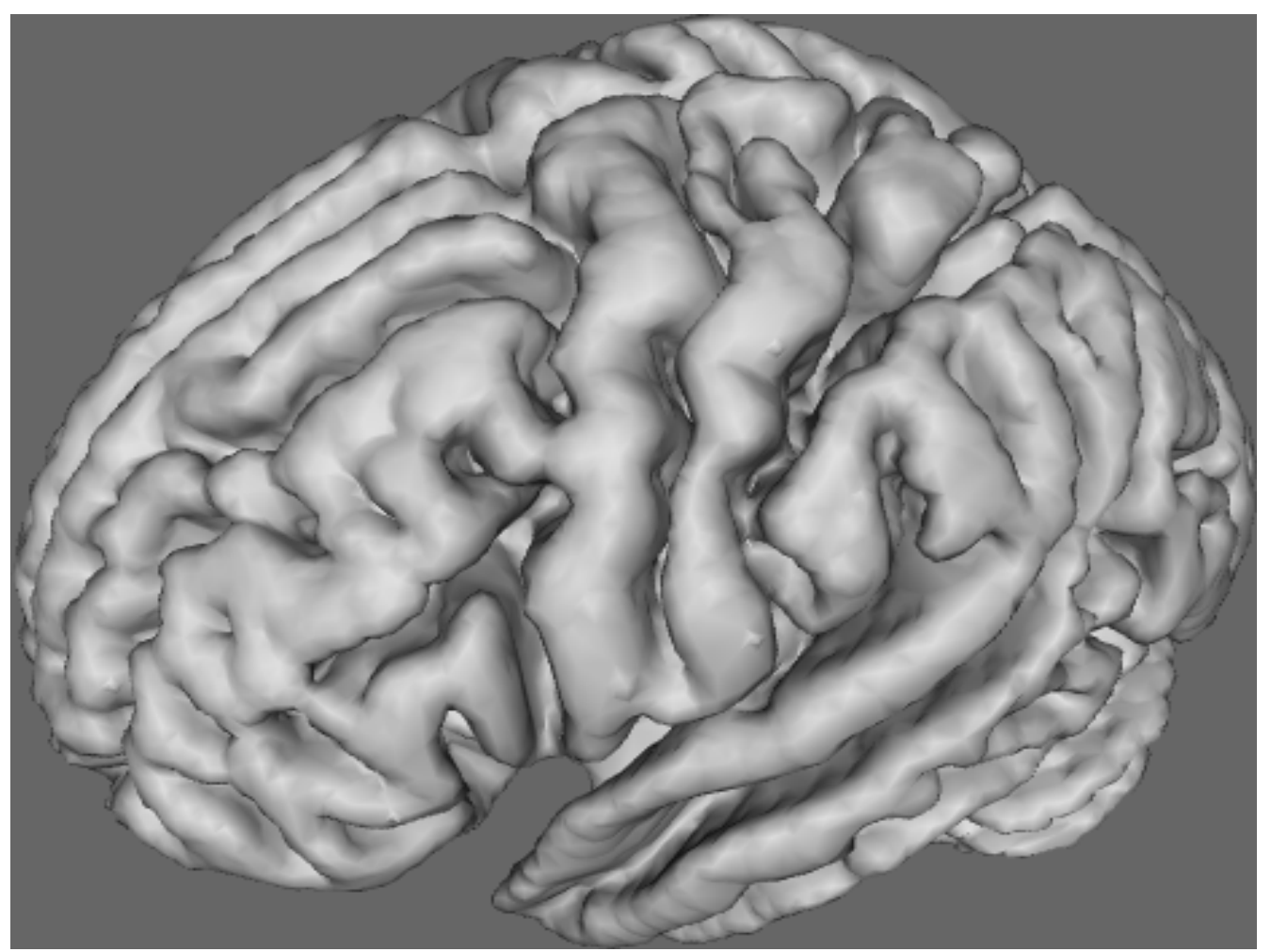

Figura A.4: O cérebro pode ser divido quanto aos padrões de sulcos e giros exibidos pela maioria dos seres humanos 


\section{A.7 Segmentação cerebral}

O parcelamento cerebral é um maiores problemas encontrados no estudo da conectividade cerebral em RMf sendo a principal causa de discrepâncias entre resultados obtidos em diferentes estudos [34]. O parcelamento realizado segundo critérios neuroanatômicos gera alguns problemas. Em neuroanatomia não existem critérios neuroanatômicos bem definidos e independentes do observador que limitem estruturas cerebrais [34]. Não é sabido se limites neuroanatômicos, quando existem, definem ao também limites funcionais, ou seja, quando e onde estrutura e função estão correlacionadas.

A alta dimensionalidade espacial dos dados de RMf também é um agravante no estudo da conectividade funcional. Os atlas de segmentação geralmente possuem centenas de regiões com no mínimo centenas de voxels. Para reduzir a dimensionalidade dentro de uma mesma região anatômica costumase extrair a média ou mediana, tomar a primeira componente na análise de componentes principais ou utilizar análise de correlação canônica.

Analisar a conectividade funcional de centenas de regiões anatômicas simultaneamente é um problema ainda não completamente solucionado. Técnicas que buscam estimar a estrutura de dependência em conjuntos de variáveis onde o número de observações é menor que o número de variáveis geralmente fazem suposições ou restrições na estrutura de dependência. As técnicas de conectividade funcional geralmente:

1. Restringem o número de regiões analisadas simultaneamente. A segmentação é necessária para extrair as séries temporais do conjunto de dados. A partir de um template (Tailarah ou MNI) cria-se uma máscara das regiões de interesse. As imagens são registradas no template e as séries temporais nas regiões de interesse são extraídas.

2. Restringem o número de conexões na matriz de conectividade. O modelo assume que a matriz de conectividade seja esparsa (contém poucas entradas não nulas). Isto reduz o número de parâmetros a serem estimados pelo método de máxima verossimilhança penalizado.

3. Fazem comparações dois a dois. Leva em consideração todo o cérebro, porém possui alto custo computacional e não identifica associações espúrias entre as variáveis.

4. Utilizam voxel semente. Constrói um mapa de conectividade a partir da correlação do voxel semente com os demais voxels da imagem. Esta abordagem é a mais utilizada em estudos do estado de repouso. 


\section{Apêndice B}

\section{Conectividade Funcional Cerebral}

\section{B.1 Introdução}

As questões apresentadas no capítulo A são comuns em protocolos de imagem funcional, porém há uma percepção crescente de que somente listar as áreas ativas é insuficiente para entender o funcionamento cerebral, sendo também necessário estudar como estas áreas interagem, em outras palavras, estudar a conectividade funcional entre regiões cerebrais diferentes. O conceito de conectividade cerebral é visto como central para entender a dinâmica organizacional cerebral [36]. A conectividade cerebral entre duas áreas cerebrais mede a influência que uma região exerce sobre outra durante o processamento cognitivo [37]. As medidas de conectividade geralmente requerem a modelagem dos sinais observados como séries temporais multivariadas onde cada variável representa uma região funcional. Os métodos vão desde a simples correlações envolvendo pares de séries temporais até modelos sofisticados multivariados para estimar a estrutura de dependência parcial entres sinais em determinadas bandas de freqüência.

Diversas metodologias vêm buscando solucionar o problema de estimar a conectividade cerebral [69]. O problema não se resume em escolher a melhor medida de conectividade. Muitos problemas surgem já no começo das análises. O pré-processamento dos dados, correção de movimento, filtros espaciais e temporais e etc., podem viesar os resultados e comprometer a interpretação dos resultados da conectividade cerebral [37].

Neste capítulo será abordado um tema bastante novo na neurociência: a conectividade cerebral. Porém, com o auxílio de teorias matemáticas bastante conhecidas: a teoria dos processos estocásticos estacionários. O termo conectividade funcional refere-se à todos os modelos matemáticos que buscam 
estimar os mecanismos dinâmicos de comunicação e dependência funcional entre estruturas neurais.

\section{B.2 Algumas medidas de conectividade}

Abaixo, segue uma pequena lista das principais medidas de conectividade empregadas na literatura recente e suas principais características.

\section{B.2.1 Correlação e correlação parcial}

A correlação é uma medida instantânea de dependência linear, isto significa que valores significativos de correlação entre pares de séries temporais indicam que duas séries estão variando conjuntamente. O mapa de correlação foi o primeiro a ser empregado no estudo da conectividade cerebral. Basicamente a análise de correlação é feita a partir de um voxel semente previamente selecionado do qual é obtido um mapa de correlação deste voxel com todos os demais voxels da imagem. A correlação parcial é a versão multivariada da correlação e refere-se a correlação entre duas séries após remover a dependência linear do restante da rede sobre estas duas séries. Devido a limitação dos dados de RMf (baixa resolução temporal em relação a resolução espacial), para fazer um mapa de correlação parcial é necessário escolher um número reduzido de regiões de interesse das quais serão extraídas as séries temporais para análise.

\section{B.2.2 Função de auto-correlação e função de auto-correlação parcial}

Semelhante a correlação e correlação parcial. Além de dependências instantâneas, a função de auto-correlação estima dependências entre variáveis em relação a seu passado e em relação o passado de outra variável. A função de autocorrelação é função da distância temporal entre variáveis e o mesmo se aplica a função de autocorrelação parcial. Mais detalhes serão apresentados na seção B.3.

\section{B.2.3 Coerência, coerência parcial e coerência parcial direcionada}

A coerência e coerência parcial são respectivamente a transformação de Fourier da função de autocorrelação e função de autocorrelação parcial. Portanto, é a representação no domínio da freqüência da estrutura de dependência linear entre séries temporais. A coerência parcial direcionada está relacionada com a idéia de fluxo de informação entre processos estocásticos gaussianos. Mais detalhes serão apresentados na seção B.3. 


\section{B.2.4 Informação mútua e informação mútua parcial}

Na prática, a análise de informação mútua ou informação mútua parcial em RMf é semelhante a análise de correlação ou correlação parcial apresentada na seção anterior. A diferença está na maneira de estimar a estrutura de dependência. A informação mútua entre duas variáveis reflete tanto dependências lineares quanto não lineares, pois compara suas distribuições de probabilidade marginais com a distribuição conjunta e mede quanto uma variável prevê características de outra variável. Similar, a informação mútua parcial pode ser obtida através da informação mútua entre duas variáveis após a regressão de todas as outras variáveis da rede contra o par de interesse.

\section{B.2.5 Análise de componentes principais}

Análise de componentes principais identifica padrões de ativação unidos temporalmente conhecidos como componentes. Esta separação em componentes espacialmente correlacionadas e ao mesmo tempo independentes umas das outras faz parte do conjunto de ferramentas conhecidas como identificação cega de canal. A análise de componentes principais é um método amplamente utilizado para analisar a conectividade cerebral no estado de repouso. Neste modelo considera todos os voxels da imagem, portanto é desnecessário escolher regiões de interesse ou voxels semente. Um dos métodos de estimação de componentes principais busca maximizar a correlação intra voxels das componentes enquanto minimiza a informação mútua ou maxiza a não gaussianidade entre as componentes.

\section{B.2.6 Modelo de equações estruturadas}

O modelo de equações estruturadas geralmente é utilizado para confirmar uma hipótese a respeito do grau de conectividade entre estruturas cerebrais. A partir de modelos de conectividade pré-estabelecidos pelo pesquisador, os coeficientes do modelo de equações estruturadas são estimados pelo método de máxima verossimilhança. Diferenças de magnitude entre diferentes condições experimentais são testadas pela razão de verossimilhança. Este tipo de modelagem exige que todas variáveis importantes para a dinâmica do sistema estejam presentes no modelo e que as relações entre as estruturas sejam lineares. Também se assume que os efeitos aleatórios possuam distribuição gaussiana. Além de restritivo, o modelo de equações estruturadas é capaz de estimar somente relações instantâneas presentes na estrutura de correlação dos dados. 


\section{B.2.7 Dynamic Causal Models}

Estima um conjunto de equações de estados de um sistema não linear. A identificação é feita usando argumentos Bayesianos. Como no modelo de equações estruturadas, interações do sistema (relações causais entre estruturas) devem ser previamente determinadas para se estimar os parâmetros.

\section{B.3 O cérebro como o um sistema dinâmico}

O cérebro pode ser entendido como um sistema dinâmico composto de componentes funcionais (subsistemas) interligadas. A conectividade cerebral estuda os diferentes mecanismos de comunicação entre componentes cerebrais. Entender o funcionamento cerebral é um desafio e hoje em dia é cada vez mais natural buscar o entendimento de processos cuja estrutura possua certo tipo de variabilidade através de sistemas dinâmicos. Vários métodos atualmente utilizados na análise de conectividade funcional estão descritos como modelos de sistemas dinâmicos, incluindo a modelagem por equações estruturadas, dynamic causal models e modelagem auto-regressiva.

Um sistema dinâmico determinístico com parâmetros invariantes no tempo é composto de um vetor $K$ variado $\mathbf{X}_{t}$ (chamado de vetor de estados) e um operador de transição de estados $T_{\theta}: \Re^{K} \rightarrow$ $\Re^{K}$, em que $\theta \in \Theta$ define um conjunto de parâmetros. Geralmente, $T_{\theta}$ é dado através de um conjunto de equações diferenciais no caso contínuo ou um conjunto de equações de diferença no caso discreto. É possível atribuir componentes aleatórias a sistemas dinâmicos (erros de medida, por exemplo), que formalmente transforma o sistema dinâmico em processo estocástico.

\section{B.3.1 Processos estocásticos}

Genericamente, um processo estocástico $K$ variado de tempo discreto que assume valores reais é uma família de variáveis aleatórias:

$$
\mathbf{X}: \mathbb{Z} \times \Omega \rightarrow \Re^{K}
$$

definidas sobre um mesmo espaço de probabilidade $(\Omega, \mathcal{A}, P)$.

Portanto, para $t_{0} \in \mathbb{Z}$ fixo e $\mathbf{c} \in \Re^{K}$ o conjunto

$$
A_{c}=\left\{\omega \mid x_{1}\left(t_{0}, \omega\right) \leq c_{1}, \ldots, x_{K}\left(t_{0}, \omega\right) \leq c_{K}\right\}
$$


temos que $A_{c} \in \mathcal{A}$ e a função

$$
F: \Re^{K} \rightarrow[0,1]
$$

tal que

$$
F(c)=P\left(A_{c}\right)
$$

é a função de distribuição acumulada de $\mathbf{X}_{t_{0}}(\omega)$.

Para $\omega_{0}$ fixo, $\mathbf{X}_{t}\left(\omega_{0}\right)$ é uma função $\mathbf{X}: \mathbb{Z} \rightarrow \Re^{K}$ conhecida como realização do processo estocástico ou série temporal. Dado uma série temporal, assume-se que exista um processo estocástico responsável pela realização desta série. Na prática, uma série temporal é um conjunto de observações $\mathbf{X}_{t}$ realizadas em um intervalo de tempo finito $T_{0} \subset \mathbb{Z}$.

Estudar as propriedades de séries temporais envolve a construção de um modelo capaz de explicar os dados que serão observados. Dado uma realização $\mathbf{X}_{t}=\left(\ldots, \mathbf{X}_{T}, \mathbf{X}_{T-1}, \ldots\right)$ de um processo estocástico, um modelo genérico que preserva causalidade é caracterizado através de um mapeamento $f$, tal que

$$
\widehat{\mathbf{X}}_{T+1}=f\left(\mathbf{X}_{T}, \mathbf{X}_{T-1}, \ldots\right)
$$

seja uma "boa" aproximação de $\mathbf{X}_{T+1}$.

Muitas vezes, devido à escassez de conhecimento ou complexidade inerente do que está sendo modelado, assumem-se algumas hipóteses a respeito da natureza dos dados. É importante lembrar que tais hipóteses podem e dever ser testadas através dos dados.

Neste trabalho, $f$ pertence a uma família de funções bem conhecida, a família das funções lineares e com um número finito de parâmetros

$$
\widehat{\mathbf{X}}_{T+1}=\boldsymbol{\mu}+\mathbf{A}_{1} \mathbf{X}_{T}+\mathbf{A}_{2} \mathbf{X}_{T-1}+\ldots+\mathbf{A}_{p} \mathbf{X}_{T-p+1}
$$

$\mathbf{U}_{T+1}=\mathbf{X}_{T+1}-\widehat{\mathbf{X}}_{T+1}$ é o erro de predição do modelo, portanto

$$
\mathbf{X}_{T+1}=\boldsymbol{\mu}+\mathbf{A}_{1} \mathbf{X}_{T}+\mathbf{A}_{2} \mathbf{X}_{T-1}+\ldots+\mathbf{A}_{p} \mathbf{X}_{T-p+1}+\mathbf{U}_{T+1}
$$

é um o processo estocástico e denominado de modelo autoregressivo multivariado de ordem $p$, ou simplesmente $\operatorname{MAR}(p)$. Embora simples, o modelo $\operatorname{MAR}(p)$, com $1 \leq p \leq \infty$, é capaz de representar uma classe bastante abrangente de processos estocásticos, a classe do processos estocásticos estacionários. 


\section{B.3.2 Processos estocásticos estacionários}

Um processo estocástico $\left\{\mathbf{X}_{t}\right\}$ é estacionário ${ }^{1}$ se:

1. $E\left[\left|\mathbf{X}_{t}\right|^{2}\right]<\infty$, para todo $t \in Z$

2. $E\left[\mathbf{X}_{t}\right]=\boldsymbol{\mu}$, para todo $t \in Z$

3. $E\left[\left(\mathbf{X}_{r}-\boldsymbol{\mu}\right)\left(\mathbf{X}_{s}-\boldsymbol{\mu}\right)^{\prime}\right]=E\left[\left(\mathbf{X}_{r+t}-\boldsymbol{\mu}\right)\left(\mathbf{X}_{s+t}-\boldsymbol{\mu}\right)^{\prime}\right]$, para todo $r, s, t \in Z$

Se um processo estocástico é estacionário, sua função de autocovariância

$$
\Gamma_{r, s}=E\left[\left(\mathbf{X}_{r}-E\left[\mathbf{X}_{r}\right]\right)\left(\mathbf{X}_{s}-E\left[\mathbf{X}_{s}\right]\right)^{\prime}\right]
$$

depende somente da diferença $h=r-s$ pois, para $t=-s$ em (iii)

$$
\Gamma_{r, s}=\Gamma_{r+t, s+t}=\Gamma_{r-s, 0}=\Gamma_{h, 0}, \forall r, s \in Z
$$

portanto, para processos estacionários $\Gamma_{r, s} \equiv \Gamma_{h}$.

A generalidade de B.4 deve-se a decomposição de Wold (1983) onde todo processo estocástico estacionário $\mathbf{X}_{t}$ pode ser representado como uma soma de dois processos descorrelacionados, $\mathbf{Z}_{t}$ determinístico (perfeitamente predito pelo seu passado) e $\mathbf{Y}_{t}=\sum_{j=0}^{\infty} \mathbf{\Psi}_{j} \mathbf{W}_{t-j}$ estacionário,

$$
\mathbf{X}_{t}=\mathbf{Z}_{t}+\sum_{j=0}^{\infty} \mathbf{\Psi}_{j} \mathbf{W}_{t-j}
$$

tal que

1. $E\left[\mathbf{W}_{t}\right]=\mathbf{0}$, para todo $t \in Z$ e $E\left[\mathbf{W}_{t} \mathbf{W}_{s}^{\prime}\right]=\left\{\begin{aligned} \boldsymbol{\Sigma} & , \text { se } t=s \\ \mathbf{0} & \text {, caso contrário }\end{aligned}\right.$

2. $\boldsymbol{\Psi}_{0}=\mathbf{I}$ e $\sum_{j=0}^{\infty} \boldsymbol{\Psi}_{j} \boldsymbol{\Psi}_{j}^{\prime}<\infty$

\footnotetext{
${ }^{1}$ Esta definição é conhecida na literatura como estacionaridade no senso amplo. Uma definição no sentido estrito considera que a distribuição conjunta de $n \geq 1$ variáveis consecutivas seja invariante em relação ao tempo. Um processo estocástico estacionário no sentido estrito de ordem $n \geq 1$ necessariamente é estacionário no sentido amplo. Caso as variáveis possuam distribuição normal multivariada, pode ser demonstrado que estacionaridade de ordem $n=1$ garante uma estacionaridade de ordem infinita
} 
$\mathbf{Y}_{t}$ é um processo de médias móveis (MA) de ordem infinita, cujo os termos $\mathbf{W}_{t}$ constituem um ruído branco.

Com base na equação B.5, o processo $\left\{\mathbf{X}_{t}-\mathbf{Z}_{t}\right\}$ é estacionário, pois

1.

$$
E\left[\mathbf{X}_{t}-\mathbf{Z}_{t}\right]=E\left[\mathbf{Y}_{t}\right]=E\left[\sum_{j=0}^{\infty} \mathbf{\Psi}_{j} \mathbf{W}_{t-j}\right]=\sum_{j=0}^{\infty} \mathbf{\Psi}_{j} E\left[\mathbf{W}_{t-j}\right]=\mathbf{0}
$$

2 .

$$
\begin{aligned}
E\left[\left(\mathbf{X}_{t}-\mathbf{Z}_{t}\right)\left(\mathbf{X}_{t+h}-\mathbf{Z}_{t+h}\right)^{\prime}\right] & =E\left[\mathbf{Y}_{t} \mathbf{Y}_{t+h}^{\prime}\right]=E\left[\left(\sum_{j=0}^{\infty} \boldsymbol{\Psi}_{j} \mathbf{W}_{t-j}\right)\left(\sum_{j=0}^{\infty} \boldsymbol{\Psi}_{j} \mathbf{W}_{t+h-j}\right)^{\prime}\right] \\
& =\sum_{j=0}^{\infty} \boldsymbol{\Psi}_{j} \boldsymbol{\Psi}_{j+h}^{\prime} E\left[\mathbf{W}_{t} \mathbf{W}_{t}^{\prime}\right]=\boldsymbol{\Sigma} \sum_{j=0}^{\infty} \boldsymbol{\Psi}_{j} \boldsymbol{\Psi}_{j+h}^{\prime}=\Gamma_{h}
\end{aligned}
$$

a segunda igualdade deve-se ao fato que $E\left[\mathbf{W}_{t} \mathbf{W}_{t-j}^{\prime}\right]=\mathbf{0}$ se $j \neq 0$.

Como $\mathbf{\Psi}_{j}$ é absolutamente somável, temos que a transformada z de $\mathbf{Y}_{t}$

$$
\widetilde{\mathbf{Y}}_{z}=\widetilde{\mathbf{W}}_{z} \sum_{j=0}^{\infty} \boldsymbol{\Psi}_{j} z^{j}
$$

admite a seguinte representação

$$
\widetilde{\mathbf{Y}}_{z} \sum_{j=0}^{\infty} \boldsymbol{\Phi}_{j} z^{j}=\widetilde{\mathbf{W}}_{z}
$$

tal que $\left(\sum_{j=0}^{\infty} \boldsymbol{\Phi}_{j} z^{j}\right)\left(\sum_{j=0}^{\infty} \boldsymbol{\Psi}_{j} z^{j}\right)^{-1}=\mathbf{I}$.

A anti transformada $z$ de B.8 é

$$
\mathbf{Y}_{t}=\sum_{j=0}^{\infty} \boldsymbol{\Phi}_{j} \mathbf{Y}_{t-j}+\mathbf{W}_{t}
$$

tal que é $\mathbf{W}_{t}$ é um ruído branco com $E\left[\mathbf{W}_{t} \mathbf{W}_{t}^{\prime}\right]=\boldsymbol{\Sigma}$. Portanto, quando $\boldsymbol{\Phi}_{j}$ converge rapidamente para zero, B.3 é uma boa aproximação do processo estocástico $\mathbf{X}_{t}$ desde que sua componente determinística $\mathbf{Z}_{t}$ seja aproximadamente constante (igual a média da série temporal) e $E\left[\mathbf{U}_{t} \mathbf{U}_{t+j}^{\prime}\right]=\mathbf{0}$ para $j \neq 0$. 


\section{B.3.3 O estimador de mínimos quadrados}

O modelo definido através do conjunto de parâmetros em B.3 precisa de um estimador dado o número finito de observações. Seja $\mathbf{X}_{t}=\left(\mathbf{X}_{-p+1}, \ldots, \mathbf{X}_{1}, \ldots, \mathbf{X}_{T-1}, \mathbf{X}_{T}\right)$ uma realização finita de um processo estocástico estacionário, o modelo B.4 pode ser reescrito na seguinte forma matricial:

$$
\begin{aligned}
& \mathbf{X}=\left(\mathbf{X}_{1}, \ldots, \mathbf{X}_{T}\right) \quad K \times T \\
& \mathbf{B}=\left(\boldsymbol{\mu}, \mathbf{A}_{1}, \mathbf{A}_{2}, \ldots, \mathbf{A}_{p}\right) \quad K \times(K p+1) \\
& \mathbf{U}=\left(\mathbf{U}_{1}, \ldots, \mathbf{U}_{T}\right) \quad K \times T \\
& \vec{x}=\operatorname{vec}(\mathbf{X}) \quad K T \times 1 \\
& \vec{b}=\operatorname{vec}(\mathbf{B}) \quad\left(K^{2} p+K\right) \times 1 \\
& \vec{u}=\operatorname{vec}(\mathbf{U}) \quad K T \times 1 \\
& \mathbf{Z}=\left[\begin{array}{ccc}
1 & \ldots & 1 \\
\mathbf{X}_{0} & \ldots & \mathbf{X}_{T-1} \\
\vdots & \ldots & \vdots \\
\mathbf{X}_{-p+1} & \ldots & \mathbf{X}_{T-p}
\end{array}\right](K p+1) \times T \\
& \mathbf{X}=\mathbf{B Z}+\mathbf{U} \\
& \operatorname{vec}(\mathbf{X})=\operatorname{vec}(\mathbf{B Z})+\operatorname{vec}(\mathbf{U}) \\
& \vec{x}=\left(\mathbf{Z}^{\prime} \otimes \mathbf{I}_{\mathbf{K}}\right) \vec{b}+\vec{u}
\end{aligned}
$$

O estimador de mínimos quadrados determina $\vec{b}$ tal que a norma ao quadrado do erro de predição $\|\vec{u}\|^{2}$ seja mínima.

$$
\begin{array}{r}
S(\vec{b})=\vec{u}^{\prime} \vec{u}=\left[\vec{x}-\left(\mathbf{Z}^{\prime} \otimes \mathbf{I}_{\mathbf{K}}\right) \vec{b}\right]^{\prime}\left[\vec{x}-\left(\mathbf{Z}^{\prime} \otimes \mathbf{I}_{\mathbf{K}}\right) \vec{b}\right] \\
\frac{\partial S(\vec{b})}{\partial \vec{b}}=2\left(\mathbf{Z} \mathbf{Z}^{\prime} \otimes \mathbf{I}_{\mathbf{K}}\right) \vec{b}-2\left(\mathbf{Z} \otimes I_{K}\right) \vec{x}=0 \\
\left(\mathbf{Z} \mathbf{Z}^{\prime} \otimes \mathbf{I}_{\mathbf{K}}\right) \vec{b}=\left(\mathbf{Z} \otimes \mathbf{I}_{\mathbf{K}}\right) \vec{x} \\
\hat{\vec{b}}=\left(\left(\mathbf{Z} \mathbf{Z}^{\prime}\right)^{-1} \mathbf{Z} \otimes \mathbf{I}_{\mathbf{K}}\right) \vec{x} \\
\widehat{\mathbf{B}}=\mathbf{X} \mathbf{Z}^{\prime}\left(\mathbf{Z} \mathbf{Z}^{\prime}\right)^{-1}
\end{array}
$$


Se $\mathbf{X}_{t}$ é um processo $\operatorname{AR}(p)$, estável e com erro de predição branco $\mathbf{U}_{t} \sim \mathcal{N}\left(\mathbf{0}, \boldsymbol{\Sigma}_{\mathbf{U}}\right)$, pode ser demonstrado [78] que o estimador $\widehat{\mathbf{B}}=\mathbf{X} \mathbf{Z}^{\prime}\left(\mathbf{Z Z} \mathbf{Z}^{\prime}\right)^{-1}$

$$
\widehat{\mathbf{B}} \stackrel{p}{\rightarrow} \mathbf{B}
$$

$\mathrm{e}$

$$
\sqrt{T}(\hat{\vec{b}}-\vec{b}) \stackrel{d}{\rightarrow} \mathcal{N}\left(\mathbf{0}, \boldsymbol{\Gamma}^{-1} \otimes \boldsymbol{\Sigma}_{\mathbf{U}}\right)
$$

tal que

$$
\Gamma \stackrel{p}{\rightarrow} \frac{\mathbf{Z Z}}{T}
$$

Seja $\widehat{\mathbf{B}}$ o estimador de mínimos quadrados de $\mathbf{B}$, também pode ser demonstrado [78] que o estimador

$$
\widehat{\mathbf{\Sigma}}_{U}=\frac{(\mathbf{X}-\widehat{\mathbf{B} Z})(\mathbf{X}-\widehat{\mathbf{B Z}})^{\prime}}{T-K p-1}
$$

é consistente, ou seja,

$$
\widehat{\boldsymbol{\Sigma}}_{U} \stackrel{p}{\rightarrow} \boldsymbol{\Sigma}_{\mathbf{U}}
$$

\section{B.3.4 Causalidade de Granger}

Sejam $\mathbf{Y}_{t}$ um processo estocástico e $\widehat{\mathbf{Y}}_{h}\left(\mathbf{Y}_{\bar{t}}\right)$ o estimador ótimo de $\mathbf{Y}_{\bar{t}+h}$ baseado nos valores de $\mathbf{Y}_{t}$ até o instante $\bar{t}$, ou seja, $\Omega_{\mathbf{Y}_{\bar{t}}}=\left\{\mathbf{Y}_{\bar{t}}, \mathbf{Y}_{\bar{t}-1}, \ldots\right\}$. O estimador $\widehat{\mathbf{Y}}_{h}\left(\mathbf{Y}_{\bar{t}}\right)$ é ótimo no sentido que ele produz o erro quadrático médio mínimo $\Sigma_{\mathbf{Y}_{\bar{t}+h}}\left(\mathbf{Y}_{\bar{t}}\right)$ de previsão de $\mathbf{Y}_{\bar{t}+h}$ dado $\Omega_{\mathbf{Y}_{\bar{t}}}$. Da mesma forma, sejam $\mathbf{W}_{t}$ um processo estocástico e $\widehat{\mathbf{Y}}_{h}\left(\mathbf{Y}_{\bar{t}}, \mathbf{W}_{\bar{t}}\right)$ o estimador ótimo de $\mathbf{Y}_{\bar{t}+h}$ baseado nos valores de $\mathbf{Y}_{t}$ e $\mathbf{W}_{t}$ até o instante $\bar{t}$, ou seja, $\Omega_{\mathbf{Y}_{\bar{t}}, \mathbf{W}_{\bar{t}}}=\left\{\mathbf{Y}_{\bar{t}}, \mathbf{Y}_{\bar{t}-1}, \ldots, \mathbf{W}_{\bar{t}}, \mathbf{W}_{\bar{t}-1}, \ldots\right\}$. Seja $\Sigma_{\mathbf{Y}_{\bar{t}+h}}\left(\mathbf{Y}_{\bar{t}}, \mathbf{W}_{\bar{t}}\right)$ o erro quadrático mínimo de previsão de $\mathbf{Y}_{\bar{t}+h}$ dado $\Omega_{\mathbf{Y}_{\bar{t}}, \mathbf{W}_{\bar{t}}}$.

Na definição de causalidade formulada por Granger (1969), um processo estocástico $\mathbf{W}_{t}$ causa $\mathbf{Y}_{t}$ se

$$
\Sigma_{\mathbf{Y}_{\bar{t}+h}}\left(\mathbf{Y}_{\bar{t}}, \mathbf{W}_{\bar{t}}\right)<\Sigma_{\mathbf{Y}_{\bar{t}+h}}\left(\mathbf{Y}_{\bar{t}}\right)
$$

para algum $h=1,2, \ldots$.

Esta relação será denotada por

$$
\mathbf{W}_{t} \stackrel{\text { Granger }}{\rightarrow} \mathbf{Y}_{t}
$$


Em outras palavras, $\mathbf{W}_{t} \stackrel{\text { Granger }}{\rightarrow} \mathbf{Y}_{t}$ se os valores passados $\mathbf{W}_{t}$ conseguem prever valores de $\mathbf{Y}_{t}$ que somente os valores passados $\mathbf{Y}_{t}$ não conseguem (ref). Esta idéia também pode ser interpretada na sentido de fluxo de informação, $\mathbf{W}_{t} \stackrel{\text { Granger }}{\rightarrow} \mathbf{Y}_{t}$ se existe informação sendo transmitida de $\mathbf{W}_{t}$ para $\mathbf{Y}_{t}$ [78]. Mais detalhes sobre a estimação e interpretação de (B.15) podem ser encontrados em [78].

$\mathrm{Na}$ modelagem $\operatorname{AR}(p)$ para processos estocásticos multivariados e estacionários apresentada na seção B.3.2, a equação B.4 pode ser reescrita da seguinte maneira (assumindo $E\left[\mathbf{X}_{t}\right]=\mathbf{0}$ )

$$
\left[\begin{array}{c}
x_{1, t} \\
\vdots \\
x_{K, t}
\end{array}\right]=\sum_{r=1}^{p}\left[\begin{array}{ccr}
a_{1,1, r} & \ldots & a_{1, K, r} \\
\vdots & \ddots & \vdots \\
a_{K, 1, r} & \ldots & a_{K, K, r}
\end{array}\right]\left[\begin{array}{c}
x_{1, t-r} \\
\vdots \\
x_{K, t-r}
\end{array}\right]+\left[\begin{array}{c}
u_{1, t} \\
\vdots \\
u_{K, t}
\end{array}\right]
$$

Mostrar que $x_{i, t} \stackrel{\text { Granger }}{\rightarrow} x_{j, t}$ é equivalente a mostrar que, estatisticamente, $a_{i, j, r} \neq 0$ para algum $r$ tal que $1 \leq r \leq p$.

\section{B.3.5 Coerência parcial direcionada}

A primeira vista, estimar a causalidade de Granger em dados multivariados de neurofisiologia, como EEG ou RMf, parece ser uma abordagem interessante para o estudo da conectividade funcional. Porém, os sinais neurofisiológicos possuem correlações com outros processos fisiológicos, como freqüência cardíaca, freqüência respiratória, entre outros que fogem do controle do experimentador. Descrições no domínio da freqüência, muitas vezes, representam uma solução que visa filtrar (ou pelo menos restringir a análise à banda de freqüência de interesse) o efeito que estes processos não cognitivos exercem sobre o sinal observado. Em estudos de EEG os estados cerebrais são caracterizados por ritmos $(\alpha, \beta, \ldots)$ que possuem informação clínica e fisiológica de grande importância. Existem evidências de que a conectividade funcional medida em indivíduos no estado de repouso apresenta correlações predominantemente de baixa freqüência $(\leq 1 \mathrm{~Hz})$ entre pares de regiões cerebrais.

Neste contexto define-se a Coerência Parcial Direcionada (CPD) a partir do modelo AR $(p)$ B.16 como

$$
\pi_{i, j, f}=\frac{\frac{1}{\sigma_{i, i}} \tilde{a}_{i, j, f}}{\sqrt{\sum_{l=0}^{K} \frac{1}{\sigma_{l, l}}\left|\tilde{a}_{l, j, f}\right|^{2}}}
$$


onde $\sigma_{i, j}$ e $\tilde{a}_{i, j, f}$ são os respectivamente coeficientes das matrizes $\boldsymbol{\Sigma}=E\left[\mathbf{U U}^{\prime}\right]$ e $\tilde{\mathbf{A}}_{f}$ dada por

$$
\tilde{\mathbf{A}}_{f}=\mathbf{I}_{K}-\sum_{r=1}^{p} \mathbf{A}_{r} e^{-\mathbf{i} 2 \pi f r}
$$

com $\mathbf{i}=\sqrt{-1}$ e $\mathbf{I}_{K}$ sendo a matriz identidade de ordem $K$.

A CPD possui as características desejadas para a análise da conectividade funcional com base na causalidade de Granger, pois, de acordo com [7], a CPD é a representação no domínio da freqüência da causalidade de Granger. Outras definições e propriedades dos estimadores da CPD podem ser encontradas em $[7,78]$. 


\section{Referências Bibliográficas}

[1] A. Abragam, Principles of Nuclear Magnetism, Oxford University Press, 1983. 43

[2] Sophie Achard, Raymond Salvador, Brandon Whitcher, John Suckling, and Ed Bullmore, A resilient, low-frequency, small-world human brain functional network with highly connected association cortical hubs., J Neurosci 26 (2006), no. 1, 63-72. 5, 29, 32, 50

[3] H. Akaike, A new look at the statistical model identification, Automatic Control, IEEE Transactions on 19 (1974), no. 6, 716-723. 21

[4] R. Albert and A.L. Barabási, Statistical mechanics of complex networks, Reviews of modern physics 74 (2002), no. 1, 47-97. 4

[5] Edson Amaro and Gareth J Barker, Study design in fmri: basic principles., Brain Cogn 60 (2006), no. 3, 220-32. 37

[6] S.M. Arcuri, E. Amaro Jr, T.T. Kircher, C. Andrew, M.J. Brammer, S.S.C.R. Williams, V. Giampietro, and P.K. McGuire, Neural correlates of the semantic processing of sentences: effects of Cloze probability in an event-related fMRI study, Neuroimage 11 (2000), no. 5, S333. xv, 2

[7] L.A. Baccala and K. Sameshima, Partial directed coherence: a new concept in neural structure determination, Biological cybernetics 84 (2001), no. 6, 463-474. 21, 65

[8] Luiz A Baccalá, Milkes Y Alvarenga, Koichi Sameshima, Carmen L Jorge, and Luiz H Castro, Graph theoretical characterization and tracking of the effective neural connectivity during episodes of mesial temporal epileptic seizure., J Integr Neurosci 3 (2004), no. 4, 379-95. xv, 4

[9] D.S. Bassett and E. Bullmore, Small-world brain networks, The neuroscientist 12 (2006), no. 6, 512. 4

[10] M.F. Bear, B.W. Connors, and M.A. Paradiso, Neuroscience: Exploring the brain, Lippincott Williams \& Wilkins, 2007. 1

[11] C.F. Beckmann, M. DeLuca, J.T. Devlin, and S.M. Smith, Investigations into resting-state connectivity using independent component analysis., Philos. Trans. R. Soc. Lond. B. Biol. Sci. 360 (2005), no. 1457, 1001-1013. 50 
[12] LuÃs M A Bettencourt, Greg J Stephens, Michael I Ham, and Guenter W Gross, Functional structure of cortical neuronal networks grown in vitro., Phys Rev E Stat Nonlin Soft Matter Phys 75 (2007), no. 2 Pt 1, 021915. 5

[13] B Biswal, F Z Yetkin, V M Haughton, and J S Hyde, Functional connectivity in the motor cortex of resting human brain using echo-planar mri., Magn Reson Med 34 (1995), no. 4, 537-41. 49, 50

[14] B B Biswal, J Van Kylen, and J S Hyde, Simultaneous assessment of flow and bold signals in resting-state functional connectivity maps., NMR Biomed 10 (1997), no. 4-5, 165-70. 49

[15] Bharat B Biswal, Maarten Mennes, Xi-Nian Zuo, Suril Gohel, Clare Kelly, Steve M Smith, Christian F Beckmann, Jonathan S Adelstein, Randy L Buckner, Stan Colcombe, Anne-Marie Dogonowski, Monique Ernst, Damien Fair, Michelle Hampson, Matthew J Hoptman, James S Hyde, Vesa J Kiviniemi, Rolf KÃ $₫$ tter, Shi-Jiang Li, Ching-Po Lin, Mark J Lowe, Clare Mackay, David J Madden, Kristoffer H Madsen, Daniel S Margulies, Helen S Mayberg, Katie McMahon, Christopher S Monk, Stewart H Mostofsky, Bonnie J Nagel, James J Pekar, Scott J Peltier, Steven E Petersen, Valentin Riedl, Serge A R B Rombouts, Bart Rypma, Bradley L Schlaggar, Sein Schmidt, Rachael D Seidler, Greg J Siegle, Christian Sorg, Gao-Jun Teng, Juha Veijola, Arno Villringer, Martin Walter, Lihong Wang, Xu-Chu Weng, Susan Whitfield-Gabrieli, Peter Williamson, Christian Windischberger, Yu-Feng Zang, Hong-Ying Zhang, F Xavier Castellanos, and Michael P Milham, Toward discovery science of human brain function., Proc Natl Acad Sci U S A 107 (2010), no. 10, 4734-9. 30

[16] F. Bloch, WW Hansen, and Packard M., Nuclear Induction, Physical Review 127 (1946). 42

[17] U. Brandes and T. Erlebach, Network Analysis: Methodological Foundations, volume 3418 of Lecture Notes in Computer Science, 2005. 11

[18] E. Bullmore and O. Sporns, Complex brain networks: graph theoretical analysis of structural and functional systems, Nature Reviews Neuroscience 10 (2009), no. 3, 186-198. 2, 35

[19] R.S. Burt, Structural holes and good ideas, American journal of sociology 110 (2004), no. 2, 349-399. 35

[20] R B Buxton, E C Wong, and L R Frank, Dynamics of blood flow and oxygenation changes during brain activation: the balloon model., Magn Reson Med 39 (1998), no. 6, 855-64. 47

[21] Andrea E Cavanna and Michael R Trimble, The precuneus: a review of its functional anatomy and behavioural correlates., Brain 129 (2006), no. Pt 3, 564-83. 33

[22] D Cordes, V M Haughton, K Arfanakis, J D Carew, P A Turski, C H Moritz, M A Quigley, and M E Meyerand, Frequencies contributing to functional connectivity in the cerebral cortex in "resting-state"data., AJNR Am J Neuroradiol 22 (2001), no. 7, 1326-33. 30, 50 
[23] A M Dale, B Fischl, and M I Sereno, Cortical surface-based analysis. i. segmentation and surface reconstruction., Neuroimage 9 (1999), no. 2, 179-94. 20, 49

[24] J.S. Damoiseaux, S.A. Rombouts, P. Scheltens, C.J. Stam, S.M. Smith, and C.F. Beckmann, Consistent resting-state networks across healthy subjects., Proc. Natl. Acad. Sci. U. S. A. 103 (2006), no. 37, 13,848-13,853. 50

[25] WW Daniel, Applied Nonparametric Statistics (PWS, 1990. 22

[26] M. De Luca, C.F. Beckmann, N. De Stefano, Matthews P.M., and S.M. Smith, fmri resting state networks define distinct modes of long-distance interactions in the human brain., Neuro-image 29 (2006), no. 4, 1359-1367. 50

[27] X. Delbeuck, M. Van der Linden, and F. Collette, Alzheimer'Disease as a Disconnection Syndrome?, Neuropsychology review 13 (2003), no. 2, 79-92. 35

[28] Nico U F Dosenbach, Damien A Fair, Francis M Miezin, Alexander L Cohen, Kristin K Wenger, Ronny A T Dosenbach, Michael D Fox, Abraham Z Snyder, Justin L Vincent, Marcus E Raichle, Bradley L Schlaggar, and Steven E Petersen, Distinct brain networks for adaptive and stable task control in humans., Proc Natl Acad Sci U S A 104 (2007), no. 26, 11073-8. 34

[29] Jonas Dyhrfjeld-Johnsen, Vijayalakshmi Santhakumar, Robert J Morgan, Ramon Huerta, Lev Tsimring, and Ivan Soltesz, Topological determinants of epileptogenesis in large-scale structural and functional models of the dentate gyrus derived from experimental data., J Neurophysiol 97 (2007), no. 2, 1566-87. 5

[30] Victor M EguÃluz, Dante R Chialvo, Guillermo A Cecchi, Marwan Baliki, and A Vania Apkarian, Scale-free brain functional networks., Phys Rev Lett 94 (2005), no. 1, 018102. 5, 29

[31] PJ Eslinger and AR Damasio, Age and type of aphasia in patients with stroke., Journal of Neurology, Neurosurgery \& Psychiatry 44 (1981), no. 5, 377. 1

[32] AC Evans, DL Collins, SR Mills, ED Brown, RL Kelly, and TM Peters, 3D statistical neuroanatomical models from 305 MRI volumes, Nuclear Science Symposium and Medical Imaging Conference, 1993., 1993 IEEE Conference Record., IEEE, 2002, pp. 1813-1817. 49

[33] B Fischl, M I Sereno, and A M Dale, Cortical surface-based analysis. ii: Inflation, flattening, and a surface-based coordinate system., Neuroimage 9 (1999), no. 2, 195-207. 20, 49

[34] Alex Fornito, Andrew Zalesky, and Edward T Bullmore, Network scaling effects in graph analytic studies of human resting-state fmri data., Front Syst Neurosci 4 (2010), 22. 4, 29, 53

[35] Michael D Fox and Marcus E Raichle, Spontaneous fluctuations in brain activity observed with functional magnetic resonance imaging., Nat Rev Neurosci 8 (2007), no. 9, 700-11. 19, 34, 49 
[36] K J Friston, L Harrison, and W Penny, Dynamic causal modelling., Neuroimage 19 (2003), no. 4, 1273-302. 30, 55

[37] K.J. Friston, J.T. Ashburner, S.J. Kiebel, T.E. Nichols, W.D. Penny, and Ebooks Corporation, Statistical parametric mapping: the analysis of functional brain images, Elsevier/Academic Press, 2007. 3, 29, 55

[38] G H Glover, Deconvolution of impulse response in event-related bold fmri., Neuroimage 9 (1999), no. $4,416-29.47$

[39] M.E. Goldberg, ER Kandel, JH Schwartz, and TM Jessell, Principles of neural science, 2000. $1,31,32,33,45,50,52$

[40] Michael D Greicius, Ben Krasnow, Allan L Reiss, and Vinod Menon, Functional connectivity in the resting brain: a network analysis of the default mode hypothesis., Proc Natl Acad Sci U S A 100 (2003), no. 1, 253-8. 49

[41] D A Gusnard, M E Raichle, and M E Raichle, Searching for a baseline: functional imaging and the resting human brain., Nat Rev Neurosci 2 (2001), no. 10, 685-94. 34

[42] C C Hilgetag, G A Burns, M A O’Neill, J W Scannell, and M P Young, Anatomical connectivity defines the organization of clusters of cortical areas in the macaque monkey and the cat., Philos Trans R Soc Lond B Biol Sci 355 (2000), no. 1393, 91-110. 1, 5

[43] B. Horwitz and F. Husain, Simulation Frameworks for Large-Scale Brain Systems, Handbook of Brain Connectivity (2007), 275-302. 5

[44] S.A. Huettel, A.W. Song, and G. McCarthy, Functional magnetic resonance imaging, vol. 1, Sinauer Associates Sunderland, MA, 2004. 3, 37, 38, 39, 40, 43, 44, 46

[45] M. Jenkinson, P. Bannister, M. Brady, and S. Smith, Improved optimization for the robust and accurate linear registration and motion correction of brain images, Neuroimage 17 (2002), no. 2, 825-841. 20, 49

[46] M. Jenkinson and S. Smith, A global optimisation method for robust affine registration of brain images, Medical image analysis 5 (2001), no. 2, 143-156. 48

[47] Maciej Kamiński, Multichannel Data Analysis in Biomedical Research, Handbook of Brain Connectivity (2007), 327-357. 5

[48] V. Kuperman, Magnetic resonance imaging: physical principles and applications, Academic Press, 2000. 38, 39, 41, 43, 44

[49] A.N. Langville and C.D. Meyer, A survey of eigenvector methods for web information retrieval, SIAM review 47 (2005), no. 1, 135-161. 16 
[50] Wei Liao, Jurong Ding, Daniele Marinazzo, Qiang Xu, Zhengge Wang, Cuiping Yuan, Zhiqiang Zhang, Guangming Lu, and Huafu Chen, Small-world directed networks in the human brain: Multivariate granger causality analysis of resting-state fmri., Neuroimage (2010). 4, 29, 30, 31

[51] N.K. Logothetis, J. Pauls, M. Augath, T. Trinath, and A. Oeltermann, Neurophysiological investigation of the basis of the fMRI signal, Nature 412 (2001), no. 6843, 150-157. 3, 47

[52] Jacopo Magistretti, David S Ragsdale, and Angel Alonso, Kinetic diversity of single-channel burst openings underlying persistent $n a(+)$ current in entorhinal cortex neurons., Biophys J $\mathbf{8 5}$ (2003), no. 5, 3019-34. 46

[53] Naoki Masuda and Kazuyuki Aihara, Global and local synchrony of coupled neurons in smallworld networks., Biol Cybern 90 (2004), no. 4, 302-9. 5

[54] M.M. Mesulam, Principles of behavioral and cognitive neurology, Oxford University Press, USA, 2000. 31,32

[55] Theoden I Netoff, Robert Clewley, Scott Arno, Tara Keck, and John A White, Epilepsy in small-world networks., J Neurosci 24 (2004), no. 37, 8075-83. 5

[56] J. Ponsford, S. Sloan, and P. Snow, Traumatic brain injury: Rehabilitation for everyday adaptive living, Psychology Press, 1995. 1

[57] F. Radicchi, C. Castellano, F. Cecconi, V. Loreto, and D. Parisi, Defining and identifying communities in networks, Proceedings of the National Academy of Sciences of the United States of America 101 (2004), no. 9, 2658. 35

[58] M E Raichle, A M MacLeod, A Z Snyder, W J Powers, D A Gusnard, and G L Shulman, A default mode of brain function., Proc Natl Acad Sci U S A 98 (2001), no. 2, 676-82. 34

[59] Y. Ramon and S. Cajal, Histologie du Système Nerveux de l'Homme et des Vertébrés, Maloine, Paris (1909), 774-838. 1

[60] R Salvador, S Achard, and ET Bullmore, Frequency-Dependent Functional Connectivity Analysis of fMRI Data in Fourier and Wavelet Domains, Handbook of Brain Connectivity (2007), 379403. 5

[61] Raymond Salvador, John Suckling, Martin R Coleman, John D Pickard, David Menon, and Ed Bullmore, Neurophysiological architecture of functional magnetic resonance images of human brain., Cereb Cortex 15 (2005), no. 9, 1332-42. 5, 29, 50

[62] S. Sanei and J. Chambers, EEG signal processing, Wiley-Interscience, 2007. 3

[63] Gordon E. Sarty, Computing Brain Activity Maps,, vol. 1, Cambridge University Press, UK, 2007. 37 
[64] Marieke L SchÃ $₫$ lvinck, Alexander Maier, Frank Q Ye, Jeff H Duyn, and David A Leopold, Neural basis of global resting-state fmri activity., Proc Natl Acad Sci U S A 107 (2010), no. 22, 10238-43. 50

[65] M.R. Sheldon, M.J. Fillyaw, and W.D. Thompson, The use and interpretation of the Friedman test in the analysis of ordinal-scale data in repeated measures designs, Physiotherapy Research International 1 (1996), no. 4, 221-228. 21

[66] Amir Shmuel and David A Leopold, Neuronal correlates of spontaneous fluctuations in fmri signals in monkey visual cortex: Implications for functional connectivity at rest., Hum Brain Mapp 29 (2008), no. 7, 751-61. 49, 50

[67] S.M. Smith, Fast robust automated brain extraction, Human Brain Mapping 17 (2002), no. 3, 143-155. 20

[68] O. Sporns, D.R. Chialvo, M. Kaiser, and C.C. Hilgetag, Organization, development and function of complex brain networks, Trends in Cognitive Sciences 8 (2004), no. 9, 418-425. 4

[69] O. Sporns and G. Tononi, Structural determinants of functional brain dynamics, Handbook of Brain Connectivity (2007), 117-148. 1, 2, 33, 55

[70] Olaf Sporns and Jonathan D Zwi, The small world of the cerebral cortex., Neuroinformatics 2 (2004), no. 2, 145-62. 32

[71] L.R. Squire, Fundamental neuroscience, Academic Pr, 2003. 31, 32

[72] L.R. Squire and ScienceDirect (Online service) service) service) service), Encyclopedia of neuroscience, Elsevier, 2009. 1

[73] C J Stam, W de Haan, A Daffertshofer, B F Jones, I Manshanden, A M van Cappellen van Walsum, T Montez, J P A Verbunt, J C de Munck, B W van Dijk, H W Berendse, and P Scheltens, Graph theoretical analysis of magnetoencephalographic functional connectivity in alzheimer's disease., Brain 132 (2009), no. Pt 1, 213-24. 4, 35

[74] Cornelis J Stam and Jaap C Reijneveld, Graph theoretical analysis of complex networks in the brain., Nonlinear Biomedical Physics 1 (2007), no. 3. 4

[75] K. Stephan and K. Friston, Models of Effective Connectivity in Neural Systems, Handbook of Brain Connectivity (2007), 303-327. 5

[76] S.H. Strogatz, Exploring complex networks, Nature 410 (2001), no. 6825, 268-276. 4

[77] S.H. Strogatz and D.J. Watts, Collective dynamics of small-world networks, Nature 393 (1998), no. $6684,440-442.5$ 
[78] Daniel Yasumasa Takahashi, Medidas de Fluxo de Informação com Aplicação em Neurociência, Ph.D. thesis, Bioinformática - USP, 2009. 3, 63, 64, 65

[79] J. Talairach and P. Tournoux, Co-planar stereotaxic atlas of the human brain: 3-dimensional proportional system: an approach to cerebral imaging, Thieme, 1988. 49

[80] B. Ulrik, A Faster Algorithm for Betweenness Centrality, Journal of Mathematical Sociology 25 (2001), no. 2, 163-177. 14

[81] Pedro A ValdÃ C)s-Sosa, Jose M SÃßnchez-Bornot, Agustãn Lage-Castellanos, Mayrim VegaHern $\tilde{A}_{j} n d e z$, Jorge Bosch-Bayard, Lester Melie-Garc $\tilde{A} a$, and Erick Canales-RodrÃguez, Estimating brain functional connectivity with sparse multivariate autoregression., Philos Trans $\mathrm{R}$ Soc Lond B Biol Sci 360 (2005), no. 1457, 969-81. 30

[82] S. Wasserman and K. Faust, Social network analysis: Methods and applications, Cambridge Univ Pr, 1994. 11, 12

[83] Anderson Marcelo Winkler, Inferência baseada em voxel para fMRI200, Master's thesis, UTFPR, 2007. 46

[84] Mark W Woolrich, Saad Jbabdi, Brian Patenaude, Michael Chappell, Salima Makni, Timothy Behrens, Christian Beckmann, Mark Jenkinson, and Stephen M Smith, Bayesian analysis of neuroimaging data in fsl., Neuroimage 45 (2009), no. 1 Suppl, S173-86. 20 


\section{Índice Remissivo}

conectividade, 1 anatômica, 1 coerência direcionada, 21

coerência parcial direcionada, 21

funcional, 2

integração, 2

segregação, 2

DSI, 5

DTI, 5

Estado de Repouso, 49

Core Network, 50

Default Mode Network, 50

rede do estado de repouso, 50

estado de repouso, 19

Grafo, 3

índice, 11

arestas, 9

Authority, 15

Betweenness, 13

caminho, 14

Closeness, 12

coeficiente de agrupamento, 4

comprimento do caminho, 4

Degree, 11

eficiência global, 4

função peso, 9

grafo direcionado, 9

grafo exemplo, 10 grau de conectividade, 4

Hub, 15

livre de escala, 5

matriz de adjacências, 9

mundo pequeno, 5

sorvedouros, 13

tamanho do caminho, 14

vértices, 9

vizinhança, 4

Ressonância Magnética Nuclear, 37

presseção, 41

razão giromagnética, 38

Spin, 38

RMf

BOLD, 3

ressonância magnética funcional, 2 voxel, 3 